\title{
Any role for Chlamydia pneumoniae in ischaemic stroke?
}

Citation for published version (APA):

Voorend, J. M. (2005). Any role for Chlamydia pneumoniae in ischaemic stroke? [Doctoral Thesis, Maastricht University]. Universitaire Pers Maastricht. https://doi.org/10.26481/dis.20051213jv

Document status and date:

Published: 01/01/2005

DOI:

10.26481/dis.20051213jv

Document Version:

Publisher's PDF, also known as Version of record

\section{Please check the document version of this publication:}

- A submitted manuscript is the version of the article upon submission and before peer-review. There can be important differences between the submitted version and the official published version of record.

People interested in the research are advised to contact the author for the final version of the publication, or visit the DOI to the publisher's website.

- The final author version and the galley proof are versions of the publication after peer review.

- The final published version features the final layout of the paper including the volume, issue and page numbers.

Link to publication

\footnotetext{
General rights rights.

- You may freely distribute the URL identifying the publication in the public portal. please follow below link for the End User Agreement:

www.umlib.nl/taverne-license

Take down policy

If you believe that this document breaches copyright please contact us at:

repository@maastrichtuniversity.nl

providing details and we will investigate your claim.
}

Copyright and moral rights for the publications made accessible in the public portal are retained by the authors and/or other copyright owners and it is a condition of accessing publications that users recognise and abide by the legal requirements associated with these

- Users may download and print one copy of any publication from the public portal for the purpose of private study or research.

- You may not further distribute the material or use it for any profit-making activity or commercial gain

If the publication is distributed under the terms of Article $25 \mathrm{fa}$ of the Dutch Copyright Act, indicated by the "Taverne" license above, 


\section{Any role for Chlamydia pneumoniae in ischaemic stroke?}

Manuela Voorend 
The research described in this thesis

was supported by a grant from

the Netherlands Heart Foundation.

Grant number: 99.134

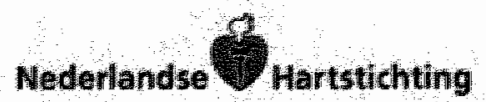

Copyright $\odot 2005 \mathrm{M}$ Voorend, Maastricht ISBN 9052785031

Layout: Tiny Wouters

Production: Datawyse \| Universitaire Pers Maastricht 


\title{
Any role for Chlamydia pneumoniae in ischaemic stroke?
}

\author{
PROEFSCHRIFT \\ ter verkrijging van de graad van doctor \\ aan de Universiteit Maastricht, \\ op gezag van de Rector Magnificus, \\ Prof.mr. G.P.M.F. Mols, \\ volgens het besluit van het College van Decanen, \\ in het openbaar te verdedigen \\ op dinsdag 13 december 2005 om 12.00 uur
}

door

Manuela Voorend

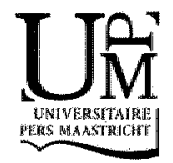


Promotores:

Prof. dr. C. A. Bruggeman

Prof. dr. M. Limburg

Co-promotores:

Dr. A. J. A. M. van der Ven, Radboud Universiteit Nijmegen

Dr. J. Lodder

Beoordelingscommissie:

Prof. dr. W. H. Mess (voorzitter)

Prof. dr. W. A. Buurman

Prof. dr. H. ten Cate

Dr. C. G. Faber

Prof. dr. B. J. Kullberg, Radbould Universiteit Nijmegen 
Voor mijn ouders 


\section{Contents}

Chapter 1 General introduction 9

Chapter 2 Chlamydia pneumoniae is a likely risk factor for 25 ischaemic stroke in young patients

$\begin{array}{lll}\text { Chapter } 3 & \text { Intraperitoneal Chlamydia pneumoniae infection } & 37\end{array}$ enhances microglial activation in the hippocampus of atherosclerotic mice

Chapter 4 Absence of Chlamydia pneumoniae, Cytomegalovirus and Herpes Simplex Virus type 1 in cerebral large vessels, small vessels and brain tissue in clinically unmanifested atherosclerosis of the brain

Chapter 5 Silent ischaemic brain lesions; absence of correlation with Chlamydia pneumoniae antibodies and cytokine responses

Chapter 6 Is the intima-media thickness of the common carotid artery rellated to ipsilaterall silent brain ischaemia, stroke syndrome, and inflammatory parameters?

Chapter $7 \quad$ Azithromycin does not change Chlamydia pneumoniae stimulated cytokine production in mononuclear cells of patients with ischaemic cerebral lesions

Chapter 8 General discussion

Summary

Samenvatting

Dankwoord 


\section{Chapter 1}

General introduction 
40 Chapen 


\section{General introduction}

Despite extensive research, ischaemic stroke remains one of the main causes of death and a significant contributor to disability in the developed countries, especially in the elderly. The underlying pathogenetic condition in the majority of ischaemic strokes is atherosclerosis. Since the early 90 's defined as an inflammatory, immune-mediated disorder, which develops following endothelial injury'. Endothelial injury may have a number of causes such as elevated and modified low-density lipoprotein (LDL), activity of free radicals, hypertension, and elevated homocysteine. One of the factors implicated in the pathogenesis of atherosclerosis is infection. The microorganism Chlamydia pneumoniae ( $C$ pneumoniae) has received the most interest in this respect. Extensive research has been done in the area of infections and cardiovascular disease; cerebrovascular disease has received less attention in this respect. In both areas results and opinions about the role of $C$ pneumoniae in vascular events have been controversial. In this chapter we will summarize the present data on $C$ pneumoniae infection and atherosclerosis, with emphasis on cerebrovascular disease.

\section{Chlamydia pneumoniae}

C pneumoniae is an obligate intracellular respiratory micro-organism. C pneumoniae infection accounts for approximately $10 \%$ of the community acquired pneumonias ${ }^{2}$. Most infections, however, are asymptomatic or cause mild flu-like symptoms. $C$ pneumoniae infection causes an acute phase response with the production of cytokines and acute phase proteins. Interleukin-6 (IL-6) is a central mediator of the acute phase response and one of the most important initiators of hepatic production of $\mathrm{C}$-reactive protein (CRP). Serum immunoglobulin $M(\lg M), \lg G$ and $\lg A$ are also produced in reaction to $C$ pneumoniae infection. Seroprevalence of these antibodies is common and rises with age $^{2}$. By the age of 20 approximately $50 \%$ have detectable antibodies and the prevalence rises to approximately $75 \%$ in the elderly. The first infection only causes a time limited immune response, therefore the high prevalence rates in the elderly are explained by reinfection ${ }^{3}$. 


\section{C pneumoniae and atherosclerosis}

\section{Cardiovascular disease and peripheral arterial occlusive disease}

The first association between $C$ pneumoniae infection and cardiovascular disease was established in 1988 when Saikku et al. found IgG and IgA antibodies against $C$ pneumoniae more often in males under fifty with acute myocardial infarction or chronic ischaemic heart disease than in healthy controls ${ }^{4}$. Numerous studies followed this initial report producing conflicting evidence. In general it can be said that for every study supporting the initial hypothesis given by Saikku et al., there is one reporting no apparent association between $C$ pneumoniae infection and cardiovascular disease. Two meta-analyses were performed on all the available studies, which could not confirm a relationship between the presence of $C$ pneumoniae antibodies and cardiovascular disease ${ }^{5,6}$.

Later studies looked at the association with renal artery stenosis ${ }^{7}$, and stenosis of the arteries of the lower extremities ${ }^{8.9}$. The conflicting results are partly due to differences in study methods. There were cross sectional case control studies and prospective cohort studies. Furthermore, different criteria were used to establish $C$ pneumoniae infection and several authors used evidence of previous and chronic persistent infection interchangeably. Serum antibodies can be detected using a microimmunofluorescence (MIF) test or by using an enzyme linked immunosorbent assay (ELISA). The MIF is the first test and very specific and sensitive, but it is labour intensive and its interpretation is limited to experienced laboratory technicians. The ELISA is an easier test that gives objective (computer generated) results. Regarding the MIF, criteria for past and current $C$ pneumoniae infection have been formally deployed ${ }^{10}$, but these criterla are often not used in the above mentioned studies. In contrast to this, no criteria are known for $C$ pneumoniae infection when the ELISA is used, and the manufacturer of the tests gives cut-off points for seropositivity. In a comparative study between ELISA and MIF, the antibody titres were found to be comparabie between the two tests ${ }^{11}$.

Differences in test methods also account for different results in pathological studies. There are different methods for $C$ pneumoniae detection, among them immunohistochemistry, that is used to detect $C$ pneumoniae antigens in paraffin sections of formalin fixed tissues, or frozen tissue samples, and Polymerase chain reaction (PCR), a technique used to assess the presence of Chlamydial DNA and can be used to detect chlamydial DNA in tissues. The advantage of immunohistochemistry is that it allows localization of the microorganism in specific cells tissues. However, the use of different monoclonal antibodies against $C$ pneumoniae with different specificity, has yielded widely varying results, and interpretation of the results is subjective ${ }^{12}$. PCR is a more 
objective technique to detect very small amounts of Chlamydial DNA, but as well as with immunohistochemistry differences in methodology leads to varying results between laboratories ${ }^{12}$. The presence of $C$ pneumoniae within the atherosclerotic plaque is patchy ${ }^{13}$, so sampling methods strongly influence the risk of false negative results. $C$ pneumoniae within the atherosclerotic plaque of coronary arteries was first determined by electron microscopy ${ }^{14}$. In later studies C pneumoniae was detected within the atherosclerotic plaque of coronary arteries $^{15-118}$, the aorta ${ }^{19,20}$ and peripheral arteries ${ }^{21,22}$. Parallel examination of atherosclerotic and non-atherosclerotic tissue showed that prevalence of $C$ pneumoniae within atherosclerotic tissue is higher than in non-atherosclerotic tissue ${ }^{23,24}$. Prevalence rates of $C$ pneumoniae in the atherosclerotic plaque of coronary arteries differed from $0 \%$ to $79 \%^{14-18,25-30}$, a variation which is at least partly due to the above mentioned differences in test method.

As mentioned above, $C$ pneumoniae infection causes an acute phase response with the production of cytokines and acute phase proteins. IL-6 and CRP levels are higher in patients with atherosclerosis and, both IL-6 levels and CRP levels increase future risk of cardiovascular events in apparently healthy men and women $^{31-33}$

\section{C pneumoniae infection and atherosclerosis of the cerebral vessels}

Ischaemic stroke is defined as an acute focal neurological deficit caused by the occlusion of an intracerebral artery. Occlusion can be due to embolism from either the heart (cardial embolism) or from atherosclerotic plaques in the internal carotid artery or the larger cerebral arteries. Since infection with $C$ pneumoniae has been related to cardiovascular disease, it might also play a role in cerebrovascular disease. However, as with cardiovascular disease, the results of the different studies are conflicting.

Ischaemic stroke risk is related to atherosclerosis in the internal carotid artery. Therefore, $C$ pneumoniae could contribute to stroke risk by influencing carotid atherosclerosis. Several studies have shown an association between past $C$ pneumoniae infection and thickness of the intima media complex (IMT) of the common carotid artery ${ }^{34,35}$. Carotid IMT is a sign of early carotid atherosclerosis. IMT increases with age, and is related to stroke risk and risk of cardiovascular events $^{36}$. The presence of $C$ pneumoniae antibodies is related to a more rapid increase in $I \mathrm{IMT}^{37}$. In contrast to this, other studies have reported no apparent-relationship between past $C$ pneumoniae infection and early or severe carotid atherosclerosis ${ }^{36.39}$. The association between $C$ pneumoniae antibodies and ischaemic stroke was studied in ten reports ${ }^{40-49}$. The proportion of studies implying a role of $C$ pneumoniae in cerebrovascular disease are similar to that in cardiovascular disease. 
Pathological studies show a similar situation, with prevalence rates for C pnoumoniae DNA in the carotid atherosclerotic plaque varying from $0-83 \%{ }^{50-57}$. Pathological examination of the cerebral vessels can only be performed post-mortem and therefore, the number of studies is limited. Four studies found $C$ pneumoniae in the atherosclerotic plaques of the middle cerebral artery, basilar artery and anterior cerebral artery ${ }^{58-61}$. No differences were found between detection of $C$ pneumoniae by $\| H C$ or $P C R^{61}$.

CRP levels and IL-6 levels predict future stroke risk in apparently healthy men and women. Levels of the inflammatory markers high sensitivity CRP (hSCRP) and $\mathrm{LL}-6$ are also related to the IMT of the carotid ${ }^{34,62-64}$ artery. Furthermore, CRP and IL-6 levels are associated with the presence of asymptomatic ischaemic cerebral lesions ${ }^{65}$. The presence of asymptomatic ischaemic cerebral lesions is of importance, since it increases the risk of cognitive decline and dementia ${ }^{66}$, as well as the risk of future stroke ${ }^{67}$.

\section{Mechanisms by which $C$ pneumoniae can induce or accelerate atherosclerosis}

In vitro, $C$ pneumoniae is able to infect endothelial cells, smooth muscle cells and macrophages, and replicate and survive in these cells ${ }^{68-71}$. Reaction to this infection is different for each of these cells. Endothelial infection leads to cell activation in a similar fashion as is seen in the initiation of atherosclerosis ${ }^{72}$. Smooth muscle cells proliferate under the influence of soluble products produced by endothelial cells infected with $C$ pneumoniae ${ }^{68}$. Macrophages turn into foam cells ${ }^{73}$ when infected with $C$ pneumoniae. Infection in all of these cells can be persistent, thereby inducing a continuous state of activation in these cells. Infected endothelial cells and smooth muscle cells can produce IL-6, TNF $\alpha$ and $I L-1 \beta^{74}$ (see also Figure 1.1). These pro-inflammatory cytokines also play an important role in the process of atherosclerosis, and production could induce a chronic persistent inflammatory state within the vascular wall, thereby enhancing the atherosclerotic process.

Detection of the micro-organism in the atherosclerotic plaque cannot answer the question whether $C$ pneumoniae directly influences the atherosclerotic process or is just an innocent bystander. Therefore, animal models were developed to further elucidate the role of $C$ pneumoniae infection in atherosclerosis and to determine the route by which $\mathcal{C}$ pneumoniae infects the vascular wall. Intranasal infection of New Zealand white rabbits showed that $C$ pneumoniae infects alveolar macrophages, which subsequently transmigrate through the mucosal barrier. Infected peripheral blood monocytes then act as the vector system within the bloodstream and transmit the infection to the vascular wall ${ }^{75}$. An often-used animal model used for the study of atherosclerosis is the Apolipoprotein $E$ (ApoE) deficient mouse. ApoE deficient 
mice spontaneously develop atherosclerosis from which the morphollogy and location shows similarity to the human situation ${ }^{76}$. Infection with $C$ pneumoniae accelerates the process of atherosclerosis in these mice ${ }^{76}$. C pneumoniae infection increases T-lymphocyte influx into the vascular wall and induces a shift in type of atherosclerotic plaques to the more severe ones ${ }^{77}$. Furthermore, in the later stages of atherosclerosis, $C$ pneumoniae infection causes more unstable atherosclerotic plaques, thereby increasing the risk of a thromboembolic complication ${ }^{78}$.

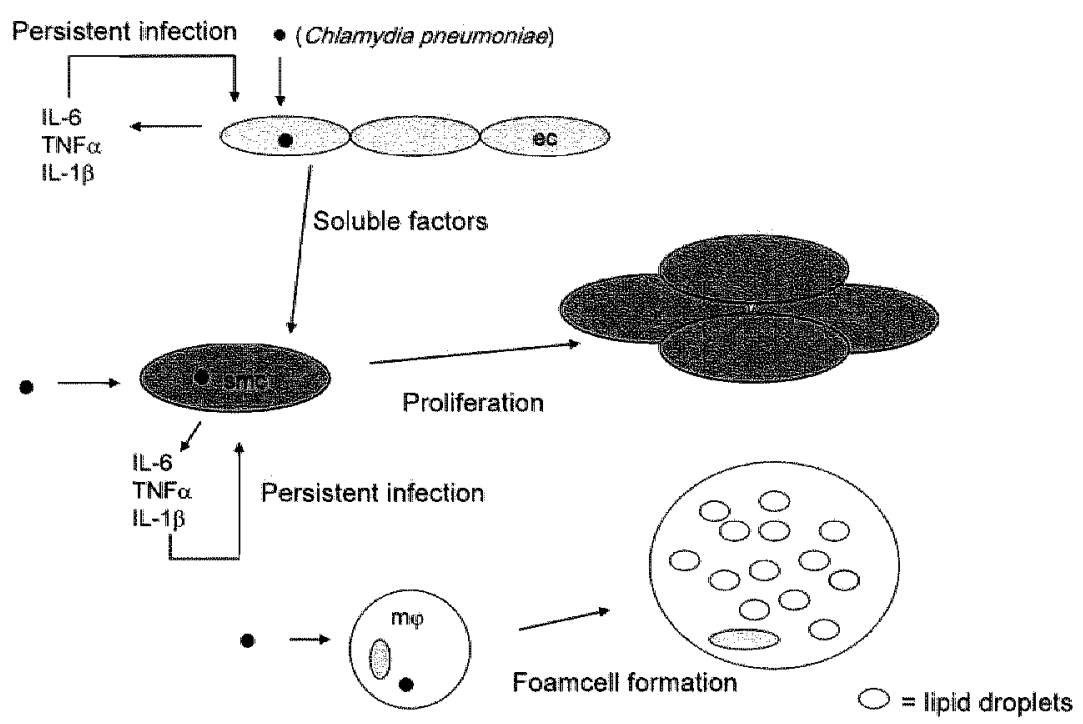

Figure 1.1 Mechanisms by which $C$ pneumoniae can induce or accelerate atherosclerosis.

$\mathrm{ec}=$ endothelial cell; $\mathrm{smc}=$ smooth muscle cell; $\mathrm{m} \varphi=$ macrophage

\section{Treatment options}

A rabbit model of atherosclerosis showed that azithromycin "given before $C$ pneumoniae infection, reduces atherosclerosis ${ }^{79}$. Secondary prevention studies have investigated the effect of antibiotic treatment on future cardiovascular events. Azithromycin reduced the risk of cardiovascular events 5 -fold in a pilot-study of 213 patients ${ }^{80}$, larger studies however, did not show a significant reduction in clinical endpoints, although inflammatory parameters were reduced up to six months after treatment ${ }^{81,82}$. One study investigated the effect of the antibiotic gatifloxacin on reduction of cardiovascular events and found no effect ${ }^{83}$. In two studies, the effect of roxithromycin on the risk of 
cardiovascular events was studied. One study found a significant reduction in cardiovascular events ${ }^{84,35}$, whereas the other study did not. A 28 day course of roxithromycin did reduce the progression of peripheral arterial occlusive disease in $C$ pneumoniae seropositive patients ${ }^{86}$. The effects of antibiotics were also tested in trials using a surrogate endpoint i.e. a non-clinical endpoint. These endpoints however, reflect processes closely related to the atherosclerotic process, and are therefore useful. Markers of endothelial dysfunction were used as a surrogate endpoint in three studies, one study found a significant reduction in E-selectin and in von Willebrand factor ${ }^{87}$, two other studies could not find an effect of antibiotics on endotheliall function ${ }^{88,89}$. In contrast to the cardiovascular trials, onlly two reports have been published on antibiotic treatment and stroke prevention. Both studied the effect of antibiotics on carotid atherosclerosis. Melissano et al. studied the presence of $C$ pneumoniae DNA in atherosclerotic tissue of the carotid arteries after carotid endarterectomy. C pneumoniae DNA was found significantly less frequent in patients who were treated with roxithromycin before surgery. Roxithromycin slows the progression of IMT of the common carotid artery, but does so only temporarily ${ }^{90,91}$. Until now this is the only clinical trial on secondary prevention of cerebrovascular disease, and no intervention trials have been performed investigating the effect of antibiotic treatment on future cerebrovascular events. 


\section{Rationale and outline of the thesis}

Studies on the association between $C$ pneumoniae infection and cerebrovascular disease have been scarce in comparison to cardiovascular disease. The study results do not point in the same direction, and the association between $C$ pneumoniae infection and atherosclerosis remains controversial.

Cerebrovascular disease differs from cardiovascular disease in that it can be divided in two entities: large vessel disease and small vessel disease. Large vessel disease, which is due to atherosclerosis of the larger cerebral vessels, causes mainly larger, usually called territorial infarcts, which often involve the cortex. The risk factors for large vessel disease are rather similar to those of cardiovascular disease in general. Small vessel disease causes small infarcts, less than $15 \mathrm{~mm}$ in diameter on cerebral imaging. which are located in the deep brain structures (basal ganglia and internal capsule) or the pons; these are often referred to as lacunar infarcts. Small vessel disease is also the cause of more diffuse damage to the white matter of the brain: leukoaraiosis. The clinical manifestation of either large vessell disease or small vessel disease is consistent over time ${ }^{92}$. C pneumoniae could have different influences on the different types of cerebral vessel disease, and identifying a subgroup that is related to $\mathrm{C}$ pneumoniae infection could have consequences for secondary prevention.

This thesis aims to answer questions on the association between $C$ pneumoniae infection and cerebral ischaemia and does so by means of an animal experiment, neuropathological examinations of post mortem brain tissue and four clinical studies on the association between $C$ pneumoniae antibody titres, inflammatory parameters, IMT, ischaemic cerebrall lesions, and clinical stroke. The aim of chapter 2 was to explore the association between infection with $C$ pneumoniae, detected by measuring the presence of $C$ pneumoniae antibodies, and ischaemic stroke at young age. In chapter 3 a mouse experiment is described, that aims to explore whether systemic $C$ pneumoniae infection can cause cerebral infection, and whether cerebral infection causes brain damage. The effects of atherosclerosis on cerebral infection and cerebral damage was tested by comparing mice with atherosclerosis, i.e. Apolipoprotein E (ApoE) knockout (KO) and ApoE/Low Density Lipoprotein receptor (ApoE/LDLr) KO mouse, both on a C57BL/6J background, to mice without atherosclerosis, i.e. wild type C57BL/6J mice. The effect of age on cerebral infection and cerebral damage was tested by comparing three months old C57BL/6J mice to 8 months old C57BL/6J mice. The aim of chapter 4 was to assess the prevalence of the presence of $C$ pneumoniae DNA in cerebral large vessels, small vessels, and brain tissue affected by small vessel disease, in patients who died of various causes. The chapters 5,6 and 7 are clinical 
studies, using a patient population derived form the ACSI study (Azithromycin for the prevention of the progression of Cerebral ischaemic lesions in patients Surviving a non-cardioembolic cerebral infarct), which investigates the effect of a three-month treatment schedule of azithromycin on ischaemic cerebral damage progression measured at wo years. Baseline inflammatory parameters and $C$ pneumoniae serology is related to clinical stroke syndrome (large vessel or small vessel disease), the presence of silent brain ischaemia (chapter 5 ) and the IMT of the common carotid artery (chapter 6). Furthermore MT will be related to the presence of ipsilateral silent brain ischaemia (chapter 6). The aim of chapter 7 is to study the effect of a three-month course of azithromycin on levels of inflammatory parameters. In chapter 8 a summary of the findings are presented along with implications and possible future plans. 


\section{References}

1. Ross R. The pathogenesis of atherosclerosis: A perspective for the 1990s. Nature. $1993 ; 362: 801-9$.

2. Grayston JT. Infections caused by Chlamydia pneumoniae strain twar [see comments]. Clin infect Dis. 1992:15:757-61.

3. Patnode D, Wang S-P, Grayston JT. Persistence of Chlamydia pneumoniae, strain twar, micro-immunofluorescent antibody. In: WR Bodie, HD Caldwell, $R P$ Jones, P.A Mardh, $G L$ Ridgeway, I Schachter, W E Stamm, and ME Ward (ed), Chlamydial infections-1990 Cambridge University Press, Cambridge. 1990

4. Saikku $P$, Leinonen $M_{*}$ Mattila $K_{v}$ Ekman MR, Nieminen MS, Makela $\mathrm{PH}_{\text {" }}$ Huttunen $J K_{i}$ Valtonen $V$. Serological evidence of an association of a novel Chlamydia, twar, with chronic coronary heart disease and acute myocardial infarction. Lencet. 1988;2:983-6.

5. Danesh J, Whincup $P$, Walker $M$, Lennon $L$, Thomsan $A$, Appleby $P$, Wong $Y K$, Bernardes Silva $M_{*}$ Ward $M$. Chlamydia pneumoniae igg titres and coronary heart disease: Prospective study and meta-analysis. British Medical Journal. 2000;321:208-12.

6. Bloemenkamp DG, Mali WP, Visseren FL, van der Graaf $Y$. Meta-analysis of seroepidemiologic studies of the relation between Chlamydia pneumoniae and atherosclerosis: Does study design influence results? Am Heart J. 2003;145:409-17.

7. van der Ven AJAM, Hommels MJ, Kroon AA, Kessels A, Flobbe $K_{\mathrm{s}}$ van Engelshoven $J_{\text {, }}$ Bruggeman CA, de Leeuw PW. Chlamydia pneumoniae seropositivity and systemic and renovascular atherosclerotic disease. Arch Intern Med. 2002;162:786-90.

8. Lindholt JS, Vammen S, Lind I, Fasting $H_{1}$, Henneberg EW. The progression of lower limb atherosclerosis is associated with iga antibodies against Chlamydia pneumoniae. Eur $J$ Vaso Endovasc Surg. 1999;18:527-9.

9. Krayenbuehl PA, Wiesli P, Maly FE, Vetter W, Schulthess G. Progressiom of peripheral arterial occlusive disease is associated with Chlamydia pneumoniae seropositivity and can be inhibited by antibiotic treatment. Atherosclerosis. 2005:179:103-10.

10. Dowell SF, Peeling RW, Boman J, Carlone GM, Fields BS, Guarner J, Hammerschlag MR, Jackson LA, Kuo CC, Maass $M_{0}$ Messmer TO, Talkington DF, Tondella ML, Zaki SR. Standardizing Chlamydia pneumoniae assays: Recommendations from the centers for disease control and prevention (USA) and the laboratory centre for disease control (canada). Clin Infect Dis. 2001;33:492-503.

11. Vainas $T$, De Graaf $R$, Stassen FR, Kurvers HA, Grauls GE, Kitslaar PJ, Bruggeman CA. Chlamydia pneumoniae serology: Comparing a commercial enzyme immunoassay and microimmumofluorescence test in patients with cardiovascular disease. Apmis. 2003;111 363-9.

12. Boman J. Hammerschlag MR. Chlamydia pneumoniae and atherosclerosis: Critical assessment of diagnostic methods and relevance to treatment studies. Clin Microbiol Rev. 2002:15:1-20.

13. Cochrane $M$, Pospischil $A$, Walker $P$, Gibbs $H$, Timms $P$. Distribution of Chlamydia pneumoniae DNA in atherosclerotic carotid arteries: Significance for sampling procedures. $J$ Clin Microbiol. 2003;41:1454-7.

14. Shor $A$, Kuo $C C$, Patton DL. Detection of Chlamydia pneumoniae in coromary arterial fatty streaks and atheromatous plaques. S Afr Med $J .1992 ; 82: 158-61$.

15. Kuo CC Grayston JT, Campbell LA, Goo YA, Wissler RW, Benditt EP. Chlamydia pneumoniae (twar) in coronary arteries of young adults (15-34 years old). Proc Natl Acad SCi US A. 1995:92:6911-4.

16. Maass M, Bartels $C$. Engel PM, Mamat U, Sievers $H H$. Endovascular presence of viable Chlamydia pneumoniae is a common phenomenon in coronary artery disease. I Am Coll Cardiol. 1998;31:827-32.

17. Campbell LA, O'Brien ER, Cappuccio AL, Kuo CC, Wang SP, Stewarti D, Patton DL, Cummings PK, Grayston JT. Detection of Chlamydia pneumoniae twar in human coronary atherectomy tissues [see comments]. J Infect Dis. 1995;172:585-8. 


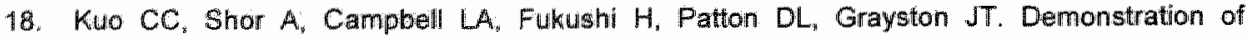
Chlamydia pneumoniae in atheroscterotic lesions of coronary arteries. I Infect Dis. $1993: 167: 841-9$

19. Kuo CC, Gown AM, Benelitt EP, Grayston JT. Detection of Chlamydia pneumoniae in aortic lesilons of atherosclerosis by immunocytochemical stain. Arteriascler Thromb. 1993;13: $1501-4$.

20. Juvonen $J$, Jivonen $T$, Laurila $A$, Alakarppa $H_{4}$ Lounatmaa $K$, Surcel $H M$, Leinonen $M$, Kairaluoma MI, Saikku P. Demonstration of Chlamydia pneumoniae in the walls of abdominal aortic aneurysms. $J$ Vasc Surg. 1997;25:499-505.

21. Gutierrez J, Linares-Patomino J Lopez-Espada $C$, Rodriguez $M$, Ros E, Pledrola $G_{\text {, del }}$ Maroto MC. Chlamydia pneumoniae DNA in the arterial wall of patients with peripheral vascular disease Infection. 2001,29:196-200.

22. Kuo CC, Coulson AS, Campbell LA, Cappuccio AL, Lawrence RD, Wang SP, Grayston لUT. Detection of Chlamydia pneumoniae in atherosclerotic plaques in the walls of arteries of Iower extremities from patients undergoing bypass operation for arterial obstruction. I Vasc Surg. 1997;26:29-31.

23. Ouchi K, Fujil B, Kudo S, Shirai M, Yamashita K, Gondo $T$, Ishihara $T$, Ito $H_{\text {s }}$ Nakazawa $T$. Chlamydia pneumoniae in atherosclerotic and nonatherasclerotic tissue. $J$ Infect Dis. $2000 \div 181$ Suppl $3: 5441-3$

24. Kuo CC, Campbell LA. Detection of Chlamydia pneumoniae in arterial tissues. I Infect Dis. 2000:181 Suppl 3:5432-6

25. Maass M, Gieffers $J$ Krause $E$, Engel PM, Bartels $C$, Solbach W. Poor correlation between microimmunofluorescence serology and polymerase chain reaction for detection of vascular Chlamydia pneumoniae infection in coronary artery disease patients. Med Microbiol Immunol Bert. 1998;187:103-6.

26. Thomas $M$, Wong $Y$, Thomas $D$, Ajaz $M$, Tsang $V$, Gallagher PJ, Ward ME. Relation between direct detection of Chlamydia pneumaniae DNA in human coronary arteries at postmortem examination and histological severity (stary grading) of associated atherosclerotic plaque. Circulation. 1999;99:2733-6.

27. Zamorano J, Garcia-Tejada J, Suarez A, Culebras E, Castanon J, Moreno $R_{y}$ Reguillo $F_{*}$ Gil M. Picazo J, Sanchez-Harguindey L. Chlamydia pneumoniae in the atherosclerotic plaques of patients with unstable angina undergoing coronary artery bypass grafting: Does it have prognostic implications? Int $J$ Cardiol. 2003;90;297-302.

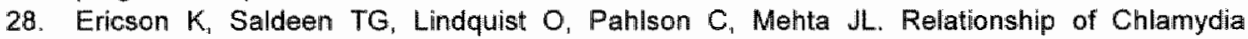
pneumoniae infection to severity of human coronary atherosclerosis. Circulation 2000:101:2568-71.

29. Bartels C, Maass M. Bein G. Brill N, Bechtel JF, Leyh R, Sievers HH. Association of serology with the endovascular presence of Chlamydia pnetumoniae and cytomegalovirus in coronary artery and vein graft disease. Circulation. 2000;101:137-41.

30. Weiss SM, Roblin PM, Gaydos CA, Cummings P. Patton DL, Schulhoff $N$, Shani J, Frankel $R$, Penney K, Quinn TC. Hammerschlag MR, Schachter J. Failure to detect Chlamydia prieumoniae in coronary atheromas of patients undergoing atherectomy, $J$ Infect Dis. $1996,173,957-62$.

31. Ridker $P M$, Buring $J E$, Shih $J$ Matias $M$, Hennekens $\mathrm{CH}$. Prospective study of c-reactive protein and the risk of future cardiovascular events among apparently healthy women. Circulation. 1998;98: 731 .3.

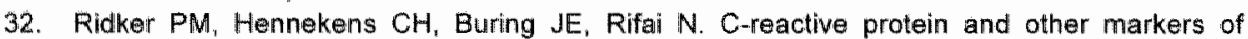
inflammation in the prediction of cardiovascular disease in women. N Engl J Med. 2000:342:836-43.

33. Ridker PM, Rifai N, Stampfer MJ, Hennekens CH. Plasma concentration of interleukin-6 and the risk of future myocardial infarction amongl apparently healthy men. Circulation. $2000: 101: 1767-72$.

34. Hashimoto $H$, Kitagawa $K$, Hougaku $H$, Etani $H$, Hori M. Relationship between c-reactive protein and progressiom of early carotid atherosclerosis in hypertensive subjects. Stroke. $2004 ; 35: 1625-30$. 
35. Melnìck SL, Shahar E, Folsom AR, Grayston JT, Sorlie PD, Wang SP, Szklo M. Past infection by Chlamydia pneumoniae strain twar and asymptomatic carotid atherosclerosis. Atherosclerosis risk in communities (aric) study investigators. Am J Med. 1999;95:499-504.

36. O'Leary DH, Polak JF, Kronmal RA, Manolio TA, Burke GL, Wolfson SK, Jr. Carotid-artery intima and media thickness as a risk factor for myocardial infarction and stroke in older adults. Cardiovascullar health study collaborative research group. $N$ Engl $J$ Med. 1999;340:14-22.

37. Sander $D$, Winbeck $K$, Klingelhofer J, Etgen $T$, Conrad $B$. Enhanced progression of early carotid atherosclerosis is related to Chlamydia pneumoniae (taiwan acute respiratory) seropositivity. Circulation. 2001:103:1390-5.

38. Coles KA, Plant AJ, Rilley TV, Smith DW, McQuillan BM, Thompson PL. Lack of association between seropositivity to Chlamydia pneumoniae and carotid atherosclerosis. Am J Cardiol. $1999 ; 84: 825-8$.

39. Hirashima $Y, K u w a y a m a ~ N$, Kubo $M$, Origasa $H$, Endo $S$. Chlamydia pneumoniae infection is not involved in carotid artery stenosis. Atherosclerosis. 2002;163:165-8.

40. Johnsen SP, Overvad K, Ostergaard L, Tjonneland A, Husted SE, Sorensen HT. Chlamydia pneumoniae seropositivity and risk of ischemic stroke: A nested case-control study. Eur J Epidemiol. 2005;20:59-65.

44. Ngeh J, Gupta S, Goodbourn C, Panayiotou B, McElligott G. Chlamydia pneumoniae in elderly patients with stroke (c-peps): A case-control study on the seroprevalence of Chlamydia pneumoniae in elderly patients with acute cerebrovascular disease. Cerebrovasc Dis. 2003;15:11-6.

42. Madre JG, Garcia JL, Gonzalez RC, Montero JM, Paniagua EB, Escribano JR, Martinez JD, Cenjor RF. Association between seropositivity to Chlamydia pneumoniae and acute ischaemic stroke. Eur J Neurol. 2002;9:303-6.

43. Heuschmann PU, Neureiter D, Gesslein $M$, Craiovan B, Maass $M$, Faller $G$, Beck $G$, Neundoerfer B, Kolominsky-Rabas PL. Association between infection with helicobacter pylori and Chlamydia pneumoniae and risk of ischemic stroke subtypes: Results from a populationbased case-control study. Stroke. 2001;32:2253-8.

44. Cook PJ, Honeybourne D, Lip GYH, Beevers DG, Wise R, Davies AH. Chlamydia pneumoniae antibody titers are significanily associated with acute stroke and transient cerebral ischemia: The west birmingham stroke project. Stroke. 1998;29:404-10.

45. Elkind MS, Lin IF, Grayston JT, Sacco RL. Chlamydia pneumoniae and the risk of first ischemic stroke: The northern manhattan stroke study. Stroke. 2000;31:1521-5.

46. Glader $C_{A}$, Stegmayr $B$, Boman $J$ stenlund $H$, Weinehall $L$, Hallmans $G$, Dahlen GH. Chlamydia pneumoniae antibodies and high lipoprotein(a) levels do not predict ischemic cerebral infarctions. Results from a nested case-control study in northern sweden. Stroke. $1999 ; 30: 2013-8$.

47. Fagerberg B, Gnarpe J, Gnarpe $H_{4}$ Agewall $S$, Wikstrand J. Chlamydia pneumoniae but not cytomegalovirus antibodies are associated with future risk of stroke and cardiovascular disease: A prospective study in middle-aged to elderly men with treated hypertension. Stroke. $1999 ; 30: 299-305$.

48. Wimmer ML, Sandmann Strupp $R_{0}$ Saikku $P$, Haberl RL. Association of Chlamydial infection with cerebrovascular disease. Stroke. 1996;27:2207-10.

49. Voorend $M$, Faber $C$, van der Ven $A$, Kessels $F$, Bruggeman CA, Lodder J. Chlamydia pneumoniae is a likely risk factor for ischemic stroke in young patients. Journal of stroke and cerebrovascular diseases. 2004:13:85-91.

50. Maass $M$, Krause E, Engel PM, Kruger S. Endovascular presence of Chlamydia preumoniae in patients with hemodynamically effective carotid artery stenosis. Angiology. 1997:48: 699-706.

51. Cochrane M, Pospischil $A$, Walker P, Gibbs $H$, Timms P. Discordiant detection of Chlamydia pneumoniae in patients with carotid artery disease using polymerase chain reaction, immunofluorescence microscopy and serological methods. Pathology. 2005;37:69-75. 
52. Sessa $R$, Di Pletro M, Schiavon $\mathrm{O}_{4}$ Santino $\mathrm{I}_{2}$ Benedetti-Valentini $F$, Perna $R$, Romano $S$, del Piano $M$. Chlamydia preumoniae DNA in patients with symptomatic carotid atherosclerotic disease. J Vasc Surg. 2003;37:1027-31.

53. Ong O, Coyle P, AB. A, WG. M, WP. D, ONell H, Wyatt D, KB. B, OLLoughlin B, McCaughey $C$. Non-detection of Chlamydia species in carotid atheroma using generic primers by nested per in a population with a high prevalence of Chlamydia pneumoniae antibody. BMC Infoctious Diseases: 2001;1:12.

54. Prager $M$; Turel $Z$, Speidl WS, Zorn G, Kaun $C$, Niessner A, Heinze $G$, Huk I Maurer $G$, Huber $K$, Wojta J. Chlamydia pneumoniae in carotid artery atherosclerosis:. A comparison of its presence in atherosclerotic plaque, healthy vessels, and circulating leukocytes from the same individuals. Stroke. 2002;33:2756-61.

55. LaBiche $R$, Koziol $D$, Quinn TC, Gaydos $C$, Azhar $S$, Ketron $G$, Sood S, DeGraba TJ. Presence of Chlamydia pneumoniae in human symptomatic and asymptomatic carotid atherosclerotic plaque. Stroke. 2001;32:855-60.

56. Yamashita $K$, Ouchi $K$, Shirai $M$, Gondo $T$, Nakazawa $T$, Ito $H$. Distribution of Chlamydia pneurnoniae infection in the athersclerotic carotid artery. Stroke. 1998;29:773-8.

57. Chiu B. Vira $E$, Tucker W, Fong IW. Chlamydia pneumoniae, cytomegallovirus, and herpes simplex virus in atherosclerosis of the carotid artery. Circulation. 1997;96:2144-8.

58. Viroik $D$, Kis $Z$, Karai $L$, Intzedy $L$, Burian $K_{4}$ Szabo $A$, lvanyi $B$, Gonczol E. Chlamydia pneumoniae in atherosclerotic middle cerebral antery. Stroke. 2001;32:1973-6.

59. Vink $A$, Poppen $M$, Schoneveld AH, Roholl PJ, de Kleijn DP, Borst C, Pasterkamp G. Distribution of Chlamydlia pneumoniae in the human arterial system and its relation to the local amount of atherosclerosis within the individual. Circulation. 2001;103:1613-7.

60. Rassu M, Cazzavillan S, Scagnelli M, Peron A, Bevilacqua PA, Facco M, Bertoloni G, Lauro $F M$, Zambello $R$, Bonoldi $E$. Demonstration of Chlamydia pneumoniae in atherosclerotic arteries from various vascular regions. Atherosclerosis. 2001;158:73-9.

61. Wohlschlaeger J, Wimmer $M L$, Nagler DK, Haberl $R$, Weis $S$. Identification of Chlamydia pneumoniae in intracranial and extracranial arteries in patients with stroke and in controls: Combined immunohistochemical and polymerase chain reaction analyses. Hum Pathal. 2005;36:395-402.

62. Hashimoto $H$, Kitagawa $K$, Hougaku $H$, Shimizu $Y$, Sakaguchi $M$, Nagai $Y$, lyama $S$, Yamanishi $H$, Matsumoto $M$, Hori M. C.-reactive protein is an independent predictor of the rate of increase in early carotid atherosclerosis. Circulation. 2001:104:63-7.

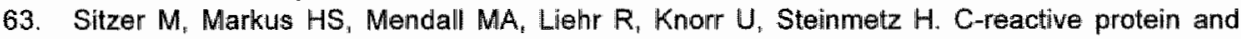
carotjd intimal medial thickness in a community population. I Cardiowasc Risk. 2002;9 9.7.103.

64. Wang TJ, Nam BH, Wilson PW, Wolf PA, Levy D, Polak JF D'Agastino RB, O'Donnell CJ. Association of creactive protein with carotid atherosclerosis in mein and women: The framingham heart study. Arterioscler Thromb Vasc Biol. 2002;22:1662-7.

65. Hoshi $T$, Kitagawa $K$, Yamagami $H$, Furukado $S$, Hougaku $H$, Hori M. Relations of serum high-sensitivity c-reactive protein and interleukin-6 levels with silent brain infarction. Strake. 2005,36:768-72.

66. Vermeer $S E_{i}$ Prins $N_{0}$, den Heijer $T_{\text {"Hofman }} \mathrm{A}_{*}$ Koudstaal PJ, Breteler MM. Silent brain inflarcts and the risk of dementia and cognitive decline. N Engl J Mod. 2003;348:1215-22.

67. de Jong $G$, van Raak $L$, Kessels F, Lodder J. Stroke subtype and mortality. A follow-up study in 998 patients with a first cerebral infarct. $J$ Clin Epidemiol. $2003: 56: 262-8$.

68. Coombes BK, Mahony JB. Chlamydia pneumoniae infection of human endothelial cells induces proliferation of smooth muscle cells via an endothelial cell-derived soluble factor(s). Infoct Immin. 1999;67:2909-15.

69. Fryer RH, Schwobe EP, Woods ML, Rodgers GM. Chlamydia species infect human vascular endothelial cells and induce procoagulant activity. J Investig Med. 1997;45:168-74.

70. Gaydos CA, Summersgill JT, Sahney NN, Ramirez JA, Quinn TC. Replication of Chlamydia pneumoniae in witro in human macrophages, endothelial cells, and aortic artery smooth muscle cells. Infect Immun. 1996;64:1614-20. 
71. Kaukoranta Tolvanen $S S$, Laitinen $K$, Saikku $P$, Leinonen $M$. Chiamydia pnewmoniae multiplies in human endothelial cells in vitro Monob Pathog. 1994:16:313-9.

72. Kaukoranta Tolvanen SS, Ronni $T$, Leinonen M, Saikku $P$, Laitinen K. Expression of adhesion molecules on endothelial cells stimulated by Chlamydia pneumoniae Microb Pathog $1996 ; 21: 407-11$

73. Kalayoglu MV. Byme Gl. Induction of macirophage foam cell formation by Chamydim pneumoniae. J infect Dis: 1998:177:725-9.

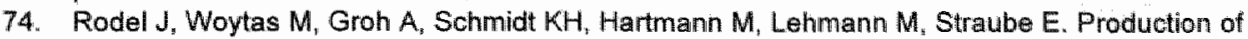
basic fibroblast growth factor and interleukin 6 by human smooth muscle cells following infection with Chlamydia pneumaniae. Infect /mmun. 2000;68:3635-41.

75. Gieffers J, van Zandbergen $G$, Rupp J, Sayk F. Kruger $S$, Ehlers $S$, Solbach W, Maess $M$. Phagacytes transmit Chlamydia pneumoniae from the lungs to the vasculature. Eur Respir $J$. 2004;23:506-10.

76. Moazed TC, Campbell LA, Rosenfeld ME, Grayston JT, Kuo CC. Chlamydia pneumoniae infection accelerates the progression of atherosclerosis in apolipoprotein e-deficient mice. $J '$ Infect Dis. 1999;180:238-41.

77. Ezzahiri R, Nelissen Vranckein HJMG, Kurvers HAJM, Stassen FRM, Vliegen I, Grawls GELM, van PUl MML, Kitslaar PJEHM, Biruggeman CA. Chlamydophila pneumoniae (Chlamydia pneumoniae) accelerates the formation of complex atherasclerotic lesions in apo e3-leiden mice. Cardiovasc Res. 2002;56:269.

78. Ezzahiri $R$, Stassen $F R_{11}$ Kurvers $M A_{\text {, van }}$ Pul MM, Kitslaar PJ, Bruggeman CA. Chlanydia pneumoniae infection induces an unstable atherosiclerotic plaque phenotype in Id-receptor. apoe double knockout mice. Eur J Vasc Endovasc Surg. 2003:26:88-95.

79. Muhlestein JB, Anderson JL, Hammond EH, Zhao L, Trehan S, Schwobe EP, Carlquist JF Infection with Chlamydia pneumoniae accelerates the development of atherosclerosis and treatment with azithromycin prevents it in a rabbit model. Circulation. 1998;97:633-6.

80. Gupta S, Leatham EW, Carrington D, Mendall MA, Kaski JC, Camm AJ. Elevated Chlamydia pneumoniae antibodies, cardiovascular events, and azithromycin in male survivors of myocardial infarction. Circulation. 1997;96:404-7.

81. Muhlestein JB, Anderson JL, Carlquist JF, Salunkhe $\mathrm{K}$, Horne BD, Pearson RR, Bunch TJ, Allen A, Trehan $S$, Nielson $C$. Randomized seconday prevention trial of azithromycin in patients with coronary artery disease: Primary clinical results of the academic study. Circulation. 2000;102:1755-60.

82. O'Connor CM, Dunne MW, Pfeffer MA, Muhlestein JB, Yao L, Gupta S, Benner RJ "Fisher $M R$, Cook TD. Azithromycin for the secondary prevention of coronary heart disease events: The wizard study: A randomized controlled trial. Jama. 2003;290:1459-66.

83. Cannon CP, Braunwald E, McCabe CH, Grayston JT, Muhlestein B, Giugliano RP, Cains R, Skene AM. Antibiotic treatment of Chlamydia pneumoniae after acute coronary syndrome. $N$ Engl J Med. 2005;352:1646-54.

84. Gurfinkel E. Inflammation, infection, or both in atherosclerosis: The roxis trial in perspective. $d$ infect Dis. 2000 181 Suppl 3:\$566-8.

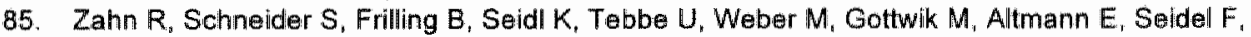
Rox J, Hoffler U, Neuhaus KL, Senges J. Antibiotic therapy after acute myocardial infarction: A prospective randomized study. Circulation. 2003;107:1253-9.

86. Wiesli $P$, Czerwenka W, Meniconi A, Maly FE, Hoffmann U, Vetter W, Schuithess. $G$. Roxithromycin treatment prevents progression of peripheral arterial occlusive disease in Chlamydia pneumoniae seropositive men: A randomized double-blind placebo-controlled trial Criculation. 2002;105:2646-52.

87. Parchure $N$, Zouridakis EG, Kaski JC. Effect of azithromycin treatment on endothellal function in patients with coronary artery disease and evidence of Chlamydia pneumonias infection. Circulation. 2002:105:1298-303.

88. Semaan HB, Gurbel PA, Anderson JL, Muhlestein JB, Carlquist JF, Horne BD, Serebruany VL. The effect of chronic azithromycin therapy on soluble endothelium-derived adhesion molecules in patients with coronary artery disease. J Cardiowasc Pharmacol. 2000,36:533-7. 
89. Kuvin JT, Gokce M, Holbrook M, Hunter LM. Patel AR, Sliney KA, Craven DE, Grayston JT, Keaney JF. Jr., Karas RH, Vita JA. Effect of shortwerm antibiotic treatment on Chlamydia preumonlae and peripheral endothelial function. Am I Cardiol. 2003:91:732-5.

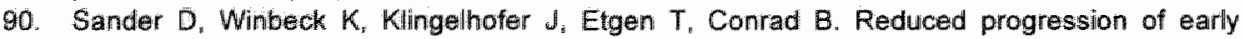
carotid atherosclerosis: after antibiotic treatment and Chlamydia pneumoniae seropositivity. Circulation. 2002, 100,2428-33.

91. Sander D, Wintbeck K, Klingelhofer J. Etgen $T$, Conrad B. Progresision of early carotid atherosclerosis is only temporarily reduced after antibiotic treatment of Chlamydia preumoniae seropositivity. Circulation. 2004:109:1010-5.

92. de Jong $G$, Kessels $F$, Lodder $J$. Two types of lacunar infarcts: Further arguments from a study on prognosis. Stroke. 2002,33:2072-6. 


\section{Chapter 2}

Chlamydia pneumoniae is a likely risk factor for ischaemic stroke in young patients

JM Voorend, CG Faber, A.JAM van der Ven, F Kessels, CA Bruggeman, J Lodder

Journal of Stroke and Cerebrovascular diseases 2004,13:85-91 


\section{Abstract}

Recently. Chlamydia pneumoniae has been identified as a risk factor for atherosclerosis, cardiovascular disease and stroke. In young patients the causes of stroke are more diverse, and remain unknown in about thirty percent of the cases, despite thorough investigations. To find a possible relationship between Chlamydia pneumoniae infection and stroke at young age, we investigated Chlamydia pneumoniae antibody titres in 41 patients with ischaemic stroke under the age of fifty and in 55 healthy controls. A positive IgA antibady titre to Chlamydia pneumoniae was significantly associated with stroke (crude OR: $2.1 ; 90 \% \mathrm{Cl} 1.1-9.5, \mathrm{p}=0.04$ ). After adjusting for hypertension, smoking and hypercholesterolaemia, positive Chlamydia antibodies remained associated with stroke (adjusted OR: $2.8,90 \% \mathrm{Cl} 1.1-7.1, \mathrm{p}=0.04$ ). No significant association between positive $\lg G$ antibodies and stroke was found. Since a positive $\lg A$ antibody titre may reflect a persistent infection, these data indicate that persistent Chlamydia pneumoniae infection may be an independent risk factor for stroke at young age. 


\section{Introduction}

Five to ten percent of ischaemic stroke occurs in patients younger than fifty years. In most cases, atherosclerosis is the cause of the stroke, but in $30 \%$ the cause remains unknown, despite thorough investigations". Recent studies showed that in $20-40 \%$, stroke is preceded by an infection. In many cases this is a respiratory infection ${ }^{2}$. Chlamydia pneumoniae (C pneumoniae) is a recently detected respiratory pathogen. $C$ pneumoniae causes respiratory infection, with symptoms that vary from mild upper respiratory infections to severe pneumonia. In most cases however, infection is asymptomatic ${ }^{3.4}$. Infection with $C$ pneumoniae is common: in epidemiological studies the incidence rate of $C$ pneumoniae was approximately $50 \%$ in middle-aged people ${ }^{5}$. Various studies showed an association between $C$ pneumoniae infection and atherosclerotic cardiovascular disease. In 1988, an association between positive IgG antibody titres to $C$ pneumoniae, ischaemic chronic heart disease and acute myocardial infarction was established ${ }^{6}$. Since then, numerous studies investigated the relation between positive antibody titres to $C$ pneumoniae and ischaemic coronary heart disease. The results of these studies do not always point in the same direction. A recently published prospective study and meta-analysis on the relation between $C$ pneumoniae infection and cardiovascular disease did not establish an association ${ }^{7}$. Apart from seroepidemiological studies, various other investigations have been reported. C pneumoniae was detected within the atheromatous plaques of coronary arteries $^{8,9}$, carotid arteries ${ }^{10-12}$, and the middle cerebral artery ${ }^{13}$. The micro-organism was mainly detected in parts of the artery with severe atherosclerotic changes. One study found no difference between the presence of $C$ pneumoniae and the severity of the atherosclerosis ${ }^{14}$. In vitro studies show that $C$ pneumoniae can infect endothelial cells, smooth muscle cells, monocytes and macrophages, thereby inducing cytokine production, such as tumour necrosis factor alpha (TNF $\alpha$ ), interleukin-1 (IL-1) and interleukin-6 $(\mathrm{IL}-6)^{15,16}$. Several animal studies indicate that infection with $C$ pneumoniae accelerates the process of atherosclerosis ${ }^{17}$, whereas treatment with azithromycin reduced atherosclerotic lesions in a rabbit model ${ }^{18}$. Only few investigated the relationship between $C$ pneumoniae infection and stroke. Wimmer et al. found positive $C$ pneumoniae $\operatorname{lgA}$ and $\lg G$ antibody titres more often in young patients with stroke or TIA, compared to healthy controls ${ }^{19}$. In studies that followed, this association was extended to an elderly population ${ }^{20-}$ 22. C pneumoniae infection is also related to intima-media thickness (IMT) of the carotid artery ${ }^{23}$. A relation between $C$ pneumoniae infection and hemodynamically significant carotid artery stenosis could not be found ${ }^{24,25}$.

The aim of this study was to explore a possible relationship between $C$ pneumoniae infection and ischaemic stroke in patients under the age of fifty, 
in whom no specific cause of the stroke could be detected, thereby leaving atherosclerosis as a possible, or even probable cause of the stroke.

\section{Patients and methods}

\section{Patients}

Forty-one patients under the agle of fifty with ischaemic stroke were included. These patients were included from the ongoing prospective Maastricht Stroke Registry. Fifty-five healthy controlls were recruited among hospital and university personnel, and matched for age and sex. Rare causes of stroke, such as dissection, vasculitis, haematological disorders, and stroke due to cardiac embolism were excluded, leaving patients with atherosclerosis as probable cause of the stroke according to the TOAST criteria $^{26}$. After approval by the medical ethics committee, written informed consent was obtained from patients and controls.

Routine investigations in the patient group included standard blood tests,

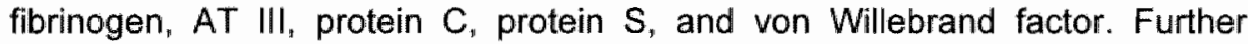
investigations included electrocardiogram, brain $C T$, non-invasive carotid studies, and echocardiography. Cerebral angiography was performed in twenty-one cases for specific individual reasons. Routine laboratory investigations $(\mathrm{Hb}, \mathrm{Ht}, \mathrm{WBC}$, platelet count) were normal. Laboratory investigations in the control group included fibrinogen, AT III and von Willebrand factor.

Since vascular risk factors may be different in patients with small-vessel disease and large-vessel disease, we considered patients with lacunar and territorial infarcts separately.

We also investigated the relation between positive antibody titres to $C$ pneumoniae and the degree of carotid artery stenosis, defined as a diameter reduction more or less than $50 \%$. Carotid IMT was not recorded.

\section{Measurement of $\lg G$ and $\lg A$ antibodies}

Serum $\lg A$ and $\lg G$ antibodies to $C$ pneumoniae were measured using an enzyme linked immunosorbent assay (EL_ISA), (Labsystems, Helsinki, Finland). The presence or absence of $C$ pneumoniae antibodies was determined by comparing the absorbance value of the sample to a cut-off value, as specified by the manufacturer. Specimens with values equal to or greater than the cut-off value were considered positive for anti-Chlamydia antibodies, for $\lg A$ the cut-off value is 8 , for $\lg G 30$. 


\section{Statistical evaluation}

Variables are presented as mean and standard deviations. The association between stroke and positive antibody titres to $C$ pneumoniae was analysed by means of crude odds ratios (OR) with $90 \%$ confidence intervals $(\mathrm{Cl})$. Multivariate logistic regression analysis was subsequently used to determine adjusted odds ratios with $90 \% \mathrm{Cl}$. Adjusted odds ratios for positive IgG and IgA antibody titres were determined separately, with stroke as dependent variable and smoking, hypertension, hypercholesterolaemia and the respective antibody titres as dependent variables. A one-tailed test was used to test for statistic significance because our hypothesis was unidirectional a priori. For the comparison of the characteristics of patients with and without positive $\lg A$ antibodies to $C$ preumoniae, the Student's T-test was used.

\section{Results}

Characteristics of patients and controls are summarised in Table 2.1. We found a positive $\lg$ A antibody titre in 22 controls $(40 \%)$ and in 24 patients $(59 \%)$, $p=0.04$, whereas a positive $\lg G$ antibody titre was present in 38 controls $(69 \%)$ and in 28 patients (68\%) (NS). A positive IgA antibody titre to $C$ pneumoniae was significantly associated with stroke (crude OR $2.1 ; 90 \% \mathrm{Cl}$ 1.4-9.5; $p=0.04$ ). After adjusting for smoking, hypertension and hypercholesterolaemia, IgA remained associated with stroke (adjusted OR 2.8;90\% $\mathrm{Cl}$ 1.1-7.1, $p=0.04)$. In this logistic model the presence of lgG antibodies was not associated with stroke (OR $0.9 ; 90 \% \mathrm{Cl} 0.5-2.0 \mathrm{p}=\mathrm{NS}$ ). The distribution of $\lg \mathrm{A}$ and IgG antibodies in patients and controls is shown in Figures 2.1 and 2.2.

Table 2.1 Characteristics of young stroke patients and controls (percentages between parenthesig)

\begin{tabular}{lcr}
\hline & $\begin{array}{c}\text { Patients } \\
N=41\end{array}$ & $\begin{array}{c}\text { Controls } \\
N=55\end{array}$ \\
\hline Age (mean $\pm S D)$ & $43.9( \pm 6.0)$ & $39.4( \pm 8.6)$ \\
Range & $25-50$ & $23-56$ \\
Sex & 19 malle $(46)$ & 24 male (44) \\
Prior stroke/TIA & $4(9)$ & 0 \\
Myocardial infarction & $3(7)$ & 0 \\
Angina pectoris & $5(12)$ & 0 \\
Hypertension & $19(46)$ & $2(4)$ \\
Hyperchollesterolaemia & $12(29)$ & $1(2)$ \\
Smoking & $28(68)$ & $16(29)$ \\
\hline
\end{tabular}




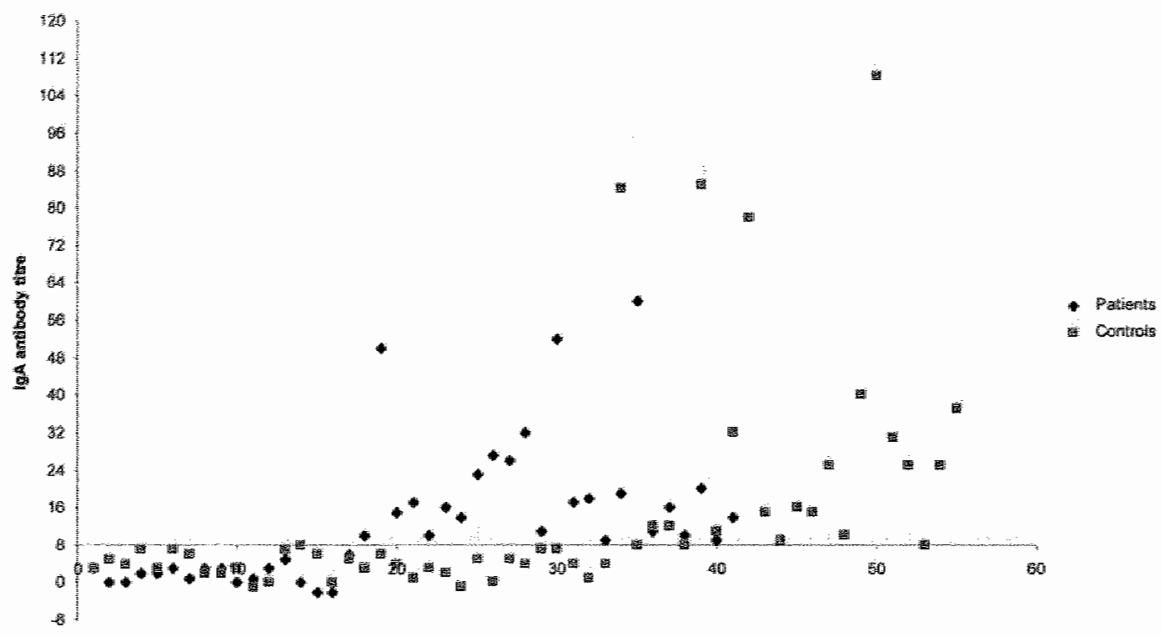

Figure 2.1 Distribution of IgA antibody titres in patients and controls.

Figure showing the distribution of $\lg A$ antibody titres in patients and controls.

The $x$-axis marks the cut-off value for $\lg A$ serropositivity $(=8)$

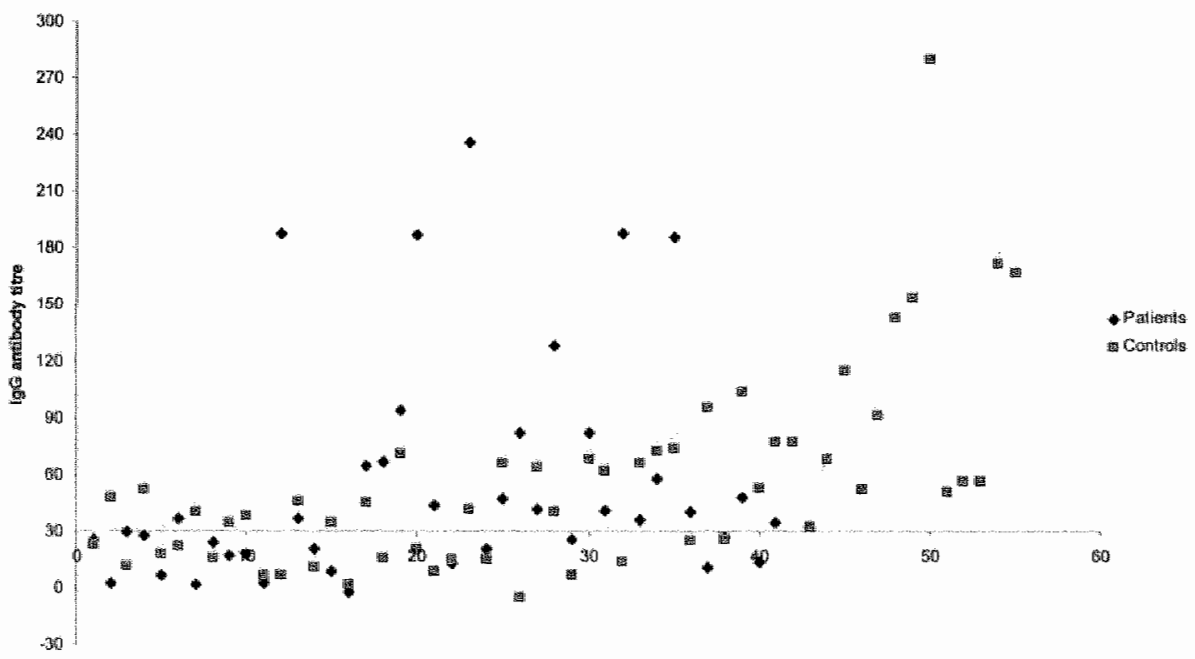

Figure 2.2 Distribution of $\mathrm{lgG}$ antibody titres in patients and controls.

Figure shows the distribution of $\lg G$ antibody titres between patients and controls. The $x$-axis shows the cut-off value for $\lg G$ seropositivity $(=30)$ 
There were no differences in mean values of $\mathrm{lgA}$ and $\mathrm{lgG}$ antibody titres between the patients and controls. (Figure 2.3) Mean IgA antibody titres: (mean \pm SD) $13.0 \pm 14.5$ in patients and $14.8 \pm 23.1$ in controls, mean IgG antibody titres: $55.8 \pm 51.3$ and $55.2 \pm 60.1$ for patients and controls. The patients with positive $\operatorname{lgG}$ and $\operatorname{lgA}$ antibody titres to $C$ pneumoniae did not show statistically significant differences from those patients without a positive antibody titre with respect to age, smoking, hypertension, fibrinogen content and cholesterol (Table 2.2). Patients with a territorial infarct $(n=31)$ more often had a positive IgG antibody titre $(n=23 ; 74 \%)$ than did the 10 patients with a lacunar infarct $(n=5 ; 50 \%)$ (OR $2.88,95 \% \mathrm{Cl} 0.39-21.08$ ), but the difference was not statistically significant. No significant association was found between a positive IgA antibody titre and more than $50 \%$ stenosis of the carotid artery (OR: 1.5; 95\% Cl 0.24-9.3).

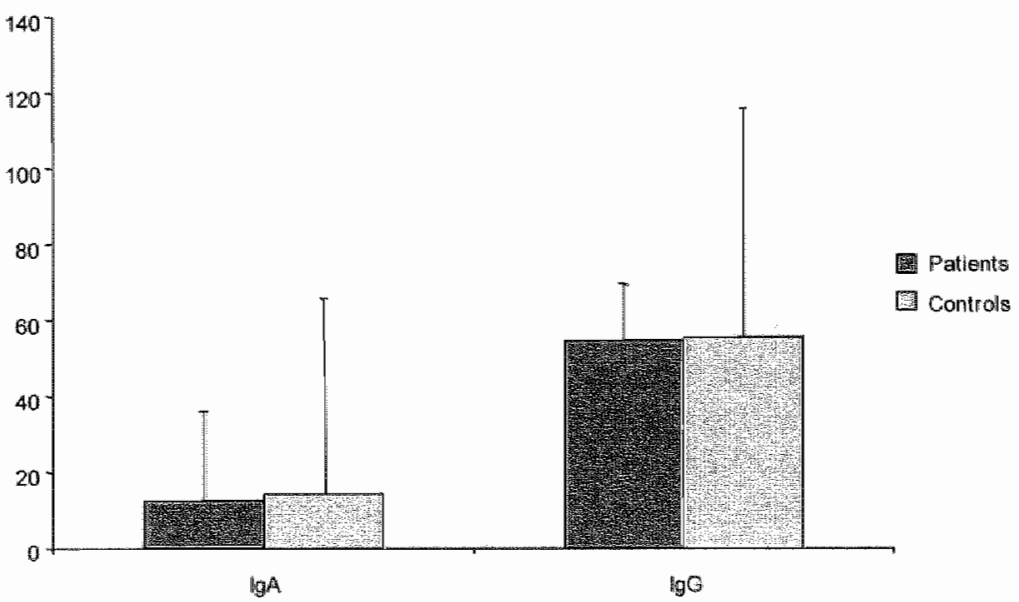

Figure 2.3 Comparison of the mean values for $\lg A$ and $\lg G$ antibody titers to $C$ pneumoniae Values for IgA: (mean \pm SD) $13.0 \pm 14.5$ in patients and $14.8 \pm 23.1$ in controls Values for IgG: (mean \pm SD) $55.8 \pm 51.3$ in patients and $55.2 \pm 60.1$ in controls

Table 2.2 Characteristics of patients with and without positive $\lg A$ antibodies to $C$ pneumoniae.

\begin{tabular}{lccc}
\hline & Positive IgA antibadies & Negative IgA antibodies & P-value \\
\hline Age (mean \pm SD) & $43.2 \pm 6.2$ & $44.8 \pm 5.6$ & 0.392 \\
Smoking, $n(\%)$ & $17(71)$ & $11(65)$ & 0.678 \\
Hypertension, $\mathrm{n}(\%)$ & $10(42)$ & $14(53)$ & 0.477 \\
Serum cholesterol (mmol/l) & $5.9 \pm 1.0$ & $6.1 \pm 1.4$ & 0.709 \\
Fibrinogen $(\mathrm{g} /)$ & $3.4 \pm 0.9$ & $3.5 \pm 1.1$ & 0.821 \\
ESR (mm/hour) & $8.3 \pm 8.9$ & $7.3 \pm 7.2$ & 0.726 \\
WBC $\left({ }^{*} 10^{\circ} /\right)$ & $9.6 \pm 3.0$ & $10.0 \pm 4.1$ & 0.765 \\
\hline
\end{tabular}




\section{Discussion}

In this case-control study of young stroke patients, we found positive serum IgA antibody titres against $C$ pneumoniae more often in patients than in matched controls, although the mean values of the antibody titre did not differ between the groups. The number of patients with a raised IgG titre against $C$ pneumoniae did not differ between the groups. Even though no serological test satisfactory diagnoses chronic persistent $C$ pneumoniae infection ${ }^{27}$, past infection with $C$ pneumoniae is presumed when elevated IgG antibodies are present, whereas an elevated $\lg A$ antibody titre at one time point is believed to be a marker for chronic persistent $C$ pneumoniae infection ${ }^{6,20,28}$. In our study population, the people who had positive $\lg A$ antibody titres also had an elevated IgG antibody titre, indicating that they all had past $C$ pneumoniae infections. Therefore, our data suggest that a chronic $C$ pneumoniae infection is associated with stroke at young age. C pneumoniae has been associated with stroke in earlier reports. At first this relationship was established in a young stroke population. Wimmer et al. found a nearly two-fold increase in the risk of $T \| A$ or ischaemic stroke in patients with $\lg A$ and $\lg G$ antibody titres against $C$ pneumoniae ${ }^{19}$. This study also included patients with cardio-embolic stroke, whereas we included only patients with atherosclerosis as the most likely cause of the stroke. Some did not find a relationship between positive antibody titres to $C$ pneumoniae and stroke, which may have been due to the fact that blood was collected during a $C$ pneumoniae epidemic ${ }^{29}$.

Previous studies found a positive IgA antibody titre associated with fibrinogen level $^{30}$, smoking ${ }^{31}$, hypertension ${ }^{32}$, and an altered lipid metabolism ${ }^{33}$. Our patients with positive $\operatorname{lgG}$ and $\lg A$ antibody titres to $C$ pneumoniae did not differ from those without positive antibody titres with respect to age, smoking, hypertension, fibrinogen content and cholesterol levels. After adjustment for potential contribution to the association by these factors, the presence of $\lg A$ antibody titres remained significantly associated with stroke. These findings suggest that an active $C$ pneumoniae infection is an independent contributor to the risk of stroke. Seven of our patients were without hypertension, had no hypercholesterolaemia, and did not smoke. Five of these seven had a positive $\lg A$ antibody titre, which further underlines the importance of $C$ pneumoniae as an independent risk factor.

Infection with $C$ pneumoniae may contribute to the risk of stroke by enhancing carotid artery atherosclerosis. This issue was addressed in several studies. Some found a relationship between $C$ pneumoniae infection and increased IMT of the carotid artery ${ }^{23}$. Others, however, found no relationship between Cpneumoniae infection and hemodynamically significant carotid artery atherosclerosis ${ }^{24,25}$. This may be related to the fact that internal carotid artery wall ulceration without stenosis, of which IMT increase may be a preceding 
stage, increases stroke risk, although ulceration and degree of stenosis are closely related ${ }^{34}$. Our recent animal experiments established that $C$ pneumoniae infection enhances plaque formation towards the more unstable types $^{35}$. We did not find a significant relationship between a positive $C$ pneumoniae antibody titre and carotid atherosclerosis, possibly due to the small number of patients in the subgroups.

There are several limitations to our study. The relatively small number of patients implied wide confidence intervals, and therefore larger studies including more patients have to be done in the future. Secondly, the association we detected is a serological association. Serological tests detect antibodies to a specific micro-organism, which indicates that infection with this micro-organism took place at some point in time. However, absolute prove of the micro-organism's actual involvement in the process of atherosclerosis could only come from demonstrating its presence in the vascular wall. Positive antibody titres may not be $100 \%$ predictive in that respect, because the presence of $C$ pneumoniae is not always demonstrated in the vascular wall of patients with a positive antibody titre ${ }^{36}$. However, within the limits of these restrictions, our findings suggest that stroke below the age of fifty may be related to a persistent $C$ pneumoniae infection.

The idea that a persistent $C$ pneumoniae infection contributes to the risk of vascular events such as stroke is appealing from a therapeutic perspective. Although $C$ pneumoniae may contribute to the risk of stroke directly, it acts in concordance with the classical risk factors in most cases. Although it is therefore unlikely that antibiotic treatment will reduce the risk of stroke substantially, it is worthwhile investigating, as even a small risk reduction may be clinically significant. In several cardiovascular pilot studies the effect of antibiotic treatment on the risk of cardiovascular events and on inflammatory parameters was studied $^{37-39}$. Two of these studies showed a significant reduction of these events ${ }^{37,39}$, but one did not ${ }^{38}$, despite a significant reduction in inflammatory parameters. Larger studies, that included large numbers of patients did not show a reduction of cardiovascular events ${ }^{40,41}$. A trial on the effect of antibiotic treatment of $C$ pneumoniae in stroke should not exclude patients below the age of fifty in whom no specific cause of stroke was detected "as our data indicate that a chronic $C$ pneumoniae infection may play a role in these patients. Such a study, with magnetic resonance imaging (MRI) detected increase in (sub) clinical ischaemic events is currently being conducted in our institute. 


\section{References}

1. Bogousslavsky $d$ Pierre P. Ischemic stroke in patients under age 45. Neurol Clin. $1992,10: 113-24$

2. Syranen J, Valtonen $M$, Iivanatinen $M$, Kaste $M$, Hutturen JK. Preceding infection as an important isik factor for ischaemic brain infarction in young and middle aged patients. $\mathrm{Br} M e d$ $J$ Chin Fes Ed. 1988;296:1156-60

3. Grayston 17 , Campbell LA, KLo CC, Mordhorst CH, Saikku P, Thom DH, Wang SP. A new respiratony tract pathogen: Chlamydia pneumoniae strain TWAR. I Infect Dis. 1990;161: 618-25

4. Grayston JT. Infections caused by Chlamydia pneumoniae strain TWAR [see comments]. Clin Infect Dis: 1992;15:757-61.

5. Karwonen $M$, Tuomilehto J, Pitkaniemi J, Naukkarinen A, Saikku P. Chlamydia pneumoniae lgG antibody prevalence in south-western and eastern Finland in 1982 and 1987 . Int $J$ Epidemiol. "994:23:176-84.

6. Saikku $P$, Leinonen M, Mattila K, Ekman MR. Nieminen MS, Makela. PH, Huttunen JK, Valtomen $V$. Serological evidence of an association of a novel Chlamydia, TWAR, with chronic coronary heart disease and acute myocardial infarction. Lancet. 1988;2;983-6.

7. Danesh J, Whincup P, Waker M, Lennon L, Thomson A, Appleby P, Wong YK, Bernardes Silva $M$, Ward $M$. Chlamydia pneumoniae lg $G$ titres and coronary heart disease: prospective study and meta-analysis. British Medical Joumal. 2000;321:208-212.

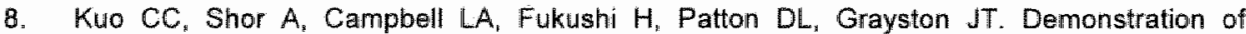
Chlamydia pneumoniae in atherosclerotic lesions of coronary arteries. $J$ infect Dis. $1993 ; 167: 841-9$.

9. Kuo CC. Grayston JT, Campbell LA, Goo YA, Wissler RW. Benditt EP. Chlamydia pneumoniae (TWAR) in coronary arteries af young adults (15-34 years old). Proc Natl Acad Sci U S A. 1995:92:6911-4.

10. Grayston JT, Kuo CC, Coulson AS, Campbell LA, Lawrence RD, Lee Mل, Strandness ED, Wang SP. Chlamydia pneumoniae (TWAR) in atherosclerosis of the carotid artery [see comments]. Circulation. 1995;92:3397-400.

11. Chiu B. Multiple infections in carotid atherosclerotic plaques. Am Heart J. 1999;138:S534 6.

12. Yamashita $K$, Ouchi $K$, Shirai $M$, Gondo $T$, Nakazawa $T$, lio $H$. Distribution of Chlamydia pneumoniae infection in the athersclerotic carotid artery. Stroke. 1998;29:773-8.

13. Virok $D$, Kis $Z$, Karai $L$, Intzedy $L$, Burian $K$ "Szabo $A$, lvanyi $B$, Gonczol $E$ Chlamydia pneumoniae in atherosclerotic middle cerebral artery. Stroke. 2001;32:1973-6.

14. Thomas M, Wong $Y$, Thomas D, Ajaz M, Tsang $V$, Gallaglher PJ. Ward ME. Rellation between direct detection of Chlamydia pneumoniae DNA in human coronairy arterles at postmortem examination and histological severity (Stary grading) of associated atherosclerotic plaque. Circulation. 1999:99:2733-6.

15. Gaydos CA, Summersgill JT, Sahney NN, Ramirez JA, Quinn TC. Replication of Chlamydia pneumoniae in vitro in human macrophages, endothellal cells, and aortic artery smooth muscle colls. Infect Immun. 1996;64:1614-20.

16. Kaukoranta Tolvanen $S S$. Teppo $A M$, Laitinein $K$, Saikku $P$. Linnavuori $K$, Leinonen $M$. Growth of Chlamydia pneumoniae in cultured human peripheral blood mononuclear cells and induction of a cytokine response. Microb Pathog. 1996"21:215-21.

17. Moazed TC, Campbell LA, Rosenfeld ME, Grayston JT: Kuo CC. Chlamydia pneumaniae infection accelerates the progression of atherosclerosis in apolipoprotein E-deficient mice. $J$ Infect Dis. 1999;180:238-41.

18. Muhlestein JB, Anderson JL, Hammond EH, Zhao L, Trehan S, Sichwobe EP, Carlquist JF. Infection with Chlamydia pneumoniae accelerates the development of atherosclerosis and treatment with azithromycin prevents it in a rabbit model. Circulation. 1998;97:633-6.

19. Wimmer ML, Sandmann Strupp R, Saikku P, Haberl RL. Association of chlamydial infection with cerebrovascular disease. Stroke. 1996;27:2207-10 
20. Cook PJ, Honeyboume D, Lip GYH, Beevers DG, Wise $R$, Davies AH. Chlamydia pneumoniae antibody titers are significantly associated with acute stroke and transient cerebral ischemia: the West Birmingham Stroke Project. Stroke. 1998;29:404-10.

21. Elkind MS, Lin IF, Grayston JT, Sacco RL. Chlamydla pneumoniae and the risk of first ischemic stroke: The Northem Manhattan Stroke Study. Stroke. 2000;31:1521-5.

22. Fagerberg B, Gnarpe J. Gnarpe H, Agewall S, Wikstrand J. Chlamydia pneumoniae but not cytomegalovirus antibodies are associated with future risk of stroke and cardiovascular disease: a prospective study in middle-aged to elderly men with treated hypertension. Stroke. 1999,30:299-305.

23. Schmidt C, Hulthe J. Wikstrand J, Gnarpe H, Gnarpe J. Agewall S. Fagerberg B. Chlamydia pneumoniae seropositivity is associated with carotid artery intima-media thickness. Stroke. $2000 ; 31: 15: 26-31$.

24. Markus HS, Sitzer $M_{4}$ Carrington D, Mendall $M A_{n}$ Steimmetz $H$. Chlamydia pneumoniae infection and early asymptomatic carotid atherosclerosis. Circulation. 1999;100:832-7.

25. Melinick SL, Shahar E, Folsom AR, Grayston JT, Sorlie PD, Wang SP, Szklo M. Past infection by Chlamydia pneumoniae strain TWAR and asymptomatic carotid atherosclerosis. Atherosclerosis Risk in Communities (ARIC) Study Inwestigators. Am J Mod. 1999;95: 499-504.

26. Gordon DL, Bendixen BH, Adams HP, Jr., Clarke W, Kappelle LJ, Woolson RF. Interphysician agreement in the diagnosis of subtypes of acute ischemic stroke: implications for clinical trials. The TOAST Investigators. Neurology. 1993;43:1021-7.

27. Dowell SF, Peeling RW, Boman J, Carlone GM, Fields BS, Guarner J, Hammerschlag MR, Jackson LA, Kuo CC. Maass M, Messmer TO, Talkington DF, Tondella ML., Zaki SR. Standardizing Chlamydia pneumoniae Assays: Recommendations from the Centers for Disease Control and Prevention (USA) and the Laboratory Centre for Disease Control (Canada). Clin Infect Dis. 2001;33:492-503.

28. Saikku $P_{*}$ Leinonen $M$, Tenkanen $L$, Linnanmaki $E$ Ekman MR, Manninen $V$, Manttari $M$, Frick MH, Huttunen JK. Chronic Chlamydia pneumoniae infection as a risk factor for coronary heart disease in the Helsinki Heart Study [see comments]. Ann Intem Med. 1992,116:273-8.

29. Glader CA, Stegmayr $B$, Boman J, Stenlund $H$, Weinehall $L$, Hallmans $G$, Dahlen $G H$. Chlamydia pneumoniae antibodies and high lipoprotein(a) levels do not predict ischemic cerebral infarctions. Results from a nested case-control study in Northern Sweden. Stroke. $1999 ; 30: 2013-8$.

30. Toss $H_{*}$ Gnarpe J, Gnarpe $H$, Siegbahn A, Lindahl B, Wallentin L. Increased fibrinogen levels are associated with persistent Chlamydia pneumoniae infection in unstable coronary artery disease. Eur Heant J. 1998:19:570-7.

31. Hahn DL, Gollubjatnikov R. Smoking is a potential confounder of the Chlamydia pneumoniavcoronary artery disealse association. Arterioscler Thromb. 1992;12,945-7.

32. Cook PJ, Lip GY, Davies P, Beevers DG, Wise R, Honeyboume D. Chlamydia pneumoniae antibodies in severe essential hypertension. Mypertension. 1998;31:589-94.

33. Laurila $A L$, Bloigu $A$, Nayha $S$, Hassi J, Leinonen $M$, Saikku P. Chlamydia pneumoniae antibodies associated with altered serum lipid profile. Int J Circumpolar Health. 1998;57 Suppl $1: 329-32$.

34. Beneficial effect of carotid endarterectomy in symptomatic patients with high-grade carotid stenosis. North American Symptomatic Carotid Endarterectomy Trial Collaborators. N Engl al Med. $1991 ; 325: 445-53$.

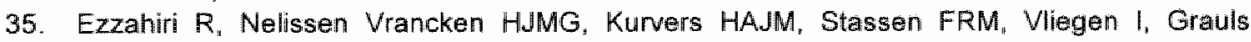
GELM, van PUl MML, Kitslaar PJEHM, Bruggeman CA. Chlamydophila pneumoniae (Chlamydia pneumoniae) accelerates the formation of complex atherosclerotic lesions in Apo E3-Leiden mice. Cardiovasc Res. 2002;56:269.

36. Maass $M$, Bartels $C$. Engel PM, Mamat U. Sievers HH. Endovascular presence of viable Chlamydia pneumoniae is a common phenomenon in coronary artery disease. I Am Coll Cardial. 1998;31:827-32.

37. Gurfinkel E. Inflammation, infection, or both in atherosclerasis: the ROXIS trial in perspective. J Infect Dis. 2000;181 Supp $3: 5566-8$. 
38. Anderson JL, Muhlestein JB, Carlquist J, Allen A, Trehan S, Nielson C, Hall S, Brady J, Egger M. Horne $\mathbb{B}$, Lim T. Randomized secondary prevention trial of azithromycin in patients with coronary artery disease and serological evidence for Chlamydia pneumoniae infection: The Azithromycin in Coronary Artery Disease: Elmination of Myocardial Infection with Chlamydia (ACADEMIC) study. Circulation. 1999:99:1540-7.

39. Gupta S. Chlamydia pneumoniae, monocyte activation, and azithromycin in coronary heart disease. Am Hoan J. 1999:138:\$539-41.

40: Jackson LA. Description and status of the azithromycin and coronary events study (ACES). Journal of Infectious Diseases. 2000;181 Suppl. 3:5579-81.

41. O'Connor CM, Dunne MW. Pfeffer MA, Muhlestein JB, Yao L, Gupta S, Benner RJ, Fisher MR, Cook TD. Azithiromycin for the secondary prevention of coronary heart disease events: the WIZARD study: a randomized controlled trial. Jama. 2003;290:1459-66. 


\section{Chapter 3}

Intraperitoneal Chlamydia pneumoniae infection enhances microglial activation in the hippocampus of atherosclerotic mice

JM Voorend, AJAM van der Ven, M Mulder, J Lodder, HWM Steinbusch, CA Bruggeman

Submitted for publication. 


\section{Abstract}

The presence of Chlamydia pneumoniae in murine brain tissue was studied in atherosclerotic and non-atherosclerotic mice, after peritoneal injection. Furthermore, we investigated whether increased pemeability of the blood brain barrier (BBB) was implicated in cerebral Chamydia pnewmoniae infection and whether intra-cerebral Chamydia pneumoniae infection leads to microglial activation. Using a polymerase chain reaction, Chlamydia preumoniae DNA was found within the brain tissue of $30 \%$ of the mice, three, seven and twenty-one days after infection. Atherosclerosis and age does not influence the extent of the cerebral infection. Semi quantitative analyses showed that intra-cerebral Chlamydia pneumoniae infection was not accompanied by an altered function of the blood brain barrier. Micioglial activation was assessed with immunohistochemistry, quantified in the hippocampus of each infected mouse and compared with mock infected mice. Enhanced microglial activation was found in the atherosclerotic mice. Since microgllal activation is a key factor in a number of neuro-inflammatory diseases, and is seen in chronic cerebral ischaemia, Chlamydia pneumoniae infection might play a rolle in these diseases. 


\section{Introduction}

Chlamydia pneumoniae (C pneumoniae) infection has been implicated in the development and progression of atherosclerosis, cardiovascular and cerebrovascular disease $e^{1-3}, C$ pneumoniae is a respiratory pathogen, causing respiratory infections, which often are asymptomatic ${ }^{4}$. From the respiratory tissue, $C$ pneumoniae disseminates through infection of monocytes ${ }^{4}$, and through this route is able to infect endothelial cells ${ }^{5}$. Endothelial cells infected with $C$ pneumoniae show an increased expression of adhesion molecules, and undergo morphological changes leading to a higher permeability. Infection of cerebral endothelial cells, therefore, can lead to an increased permeability of the blood brain barrier (BBB). In fact, it has been shown that in vitro $C$ pneumoniae infection of human brain endothelial cells promotes transendothelial entry of monocytes, through an up regulation of adhesion molecules ${ }^{7}$. The ability of $C$ pneumoniae to enter the brain after systemic infection in vivo, however, has not been described before.

Intra-cerebral presence of $C$ pneumoniae has been implicated in neuroinflammatory disorders, and it has been stipulated that the presence of this micro-organism causes low-grade inflammation of the brain, subsequently leading to the release of neurotoxic agents, like tumour necrosis factor alpha (TNF $\alpha$ ). Although intra-cerebral presence of $C$ pneumoniae has been described, it is still unknown whether $C$ pneumoniae is just an innocent bystander or plays an active role in neuro-inflammation.

Key factor in the pathogenesis of neuro-inflammatory disorders is activation of microglial cells ${ }^{8}$. Microglia, the primary immune effector cells of the central nervous system, respond to traumatic injury or the presence of pathogens in the brain $^{8}$. Microglial activation is also seen in ischaemic cerebral lesions, caused by cerebrovascular atherosclerosis, or diffuse cerebral hypoperfusion". In this animal experiment we studied if $C$ pneumoniae could be detected in cerebral tissue after an intraperitoneal infection, and whether increased permeability of the $\mathrm{BBB}$ was implicated in cerebral $C$ pneumoniae infection. Subsequently, we studied whether intra-cerebral $C$ pneumoniae infection leads to microglial activation. Furthermore, since cerebral atherosclerosis and age influence BBB function, we studied whether atherosclerosis and/or age influences the development of a cerebral infection and microglial activation. In addition, we studied if intra-cerebral $C$ pneumoniae infection alters BBB function. 


\section{Materials and methods}

\section{Chlamydia pneumoniae}

C pneumoniae strain TWAR 2043 (ATCC) was cultured on HEp-2 cells as previously described ${ }^{10}$.

Bacterial titres were determined by titration in HEp-2 cells and stained with a monoclonal antibody directed against $C$ pneumoniae, RR 402 (DAKO, Glostrup, Denmark), followed by fluorescein isothiocynate (FITC) conjugated rabbit-anti-mouse serum (DAKO, Glostrup, Denmark). Titres were expressed as number of inclusion forming units (IFU) per millilitre.

\section{Animals}

For this study, mice with atherosclerosis, i.e. Apolipoprotein $E(A p o E)$ knockout (KO) and ApoE/Low Density Lipoprotein receptor (ApoE/LDLr) KO mouse, both on a C57BL/6J background were used, and compared to mice without atherosclerosis, i.e. wild type C57BL/6J mice. The ApoE/LDLr KO mice were donated by the department of Internal Medicine (head: Prof. dr. JW van der Meer) of the University Hospital Nijmegen (Nijmegen, the Netherlands), the ApoE KO mice were provided from the own breeding of the Central Animal Facility of the Maastricht University. C57BL/6J mice used as control mice were obtained from Charles Rivers (USA). All the mice were fed standard chow diet. The mice were kept under specific pathogen free (SPF) conditions, at the Centrall Animal Facilities of the Maastricht University, the Netherlands.

Twenty-one mice of each group were infected intraperitoneally with $3^{*} 10^{7} \mathrm{IFU}$ $C$ pneumoniae. ApoE/LDLr KO and ApoE KO mice were infected at eight months of age. To assess the influence of age on $C$ pneumoniae infection and microglial activation, two groups of C57BL/6J were used, aged three and eight months at the time of infection. The same number of mice were mock infected with a sucrose-phosphate-glucose solution (SPG), SPG is the medium in which $C$ pneumoniae is conserved.

The mice were sacrificed, three, seven and twenty-one days after infection $(n=7$ per time point). At the time of sacrifice, the mice were anaesthetized with pentobarbital. After exsanguination through the apex of the heart, and perfusion with Phosphate Buffered Saline (PBS), the brains were removed. A small frontal section was used for $C$ pneumoniae detection by the polymerase chain reaction (PCR). The remaining tissue was fixed in $10 \%$ formol and embedded in paraffin for sectioning and immunohistochemical staining. From the ApoE KO mice only material for PCR was available, and these mice were not used for microglial activation. 


\section{Microglial activation}

As the primary antibody, the F4/80 monoclonal antibody (BMA Biomedicals AG. Augst, Switzerland) was used. The antibody is expressed by most macrophages and macrophage precursors, and is also expressed on activated macrophages and microglial cells ${ }^{11}$. Twelve $\mu \mathrm{m}$ thick paraffin embedded sections were pre-incubated with $2 \%$ BSA in PBS to block aspecific staining, after which the primary antibody was put on the slides, for one hour at $37^{\circ} \mathrm{C}$. After washing in PBS, the slides were incubated with the secondary antibody: biotinylated goat anti-mouse serum (DAKO, Glostrup, Denmark). Immunostaining was performed by the avidin-biotin alkalic phosphatase method (DAKO, Glostrup, Denmark). Fast red was used as a chromogen, after which the sections were counterstained with haematoxylin. The number of activated (F4/80 positive) microglial cells in the hippocampus of each mouse was counted, as described by Long et al. ${ }^{12}$, using the Analysis ${ }^{\otimes}$ system (Soft imaging systems, Munster, Germany). Since the measured surface of the hippocampus could not be standardized, the number of cells was corrected for the surface of hippocampus (number of cells * $1000000 /$ total area of hippoampus measured).

\section{Detection of $\mathrm{C}$ pneumoniae by PCR}

To detect the presence of $C$ pneumoniae in the murine brains, a sensitive PCR was used (detection ability of one copy of DNA). The following sequences were used as primers: sense CPC, 5'-TTA TTA ATT GAT GGT ACA ATA-3'; antisense CPD, 5'-ATC TAC GGC AGT AGT ATA GTT-3' '13. PCR was performed in a total volume of $50: 1$, containing $5 \mu \mathrm{g}$ DNA. DNA was extracted from brain tissue with the Wizard Genomic DNA purification kit (Promega, Germany). Amplification was done by thermal cycling starting at $37^{\circ} \mathrm{C}$ for ten minutes and $95^{\circ} \mathrm{C}$ for fifteen minutes. 20 cycles of "Touchdown PCR" were performed from $60^{\circ} \mathrm{C}$ to $50^{\circ} \mathrm{C}$, followed by 40 cycles of one minute at $94^{\circ} \mathrm{C}$, $50^{\circ} \mathrm{C}$, and $72^{\circ} \mathrm{C}$.

The PCR products were resolved in a $2 \%$ agarose gel, stained with ethidium bromide, and photographed.

\section{Detection of $C$ pneumoniae by immunohistochemistry}

To localize $C$ pneumoniae antigens within the murine brain, immunohistochemistry (IHC) was performed. For this several anti $C$ pneumoniae antibodies were used: mouse anti-C pneumoniae antibody (RR 402, DAKO Glostrup, Denmark), a polyclonal anti-C pneumoniae antibody, and a rat anti- $C$ pneumoniae antibody that was developed in our own laboratory. For each antibody the procedure was as follows: twelve $\mu \mathrm{m}$ thick paraffin embedded 
sections were pre-incubated with PBS containing 2\% BSA to block aspecific staining, after which the primary antibody was put on the slides. After washing in PBS, the slides were incubated with the secondary biotinylated antibody. Immunostaining was performed by the avidin-biotin alkalic phosphatase method (DAKO, Glostrup, Denmark). Fast red was used as a chromogen, after which the sections were counterstained with haematoxylin. As positive controls, $\mathrm{HEp}-2$ cells in vitro infected with $C$ pneumoniae were used.

\section{C pneumoniae antibodies}

To ensure proper infection of the mice, a microimmunofluorescence (MIF) test (Labsystems, Helsinki, Finland) was performed to detect $C$ pneumoniae antibodies in the mice twenty-one days after inoculation, as described previously ${ }^{14}$.

\section{Permeability of the BBB}

Permeability of the BBB was evaluated by measuring the presence of immunoglobulin $G$ in the brain, as described previously ${ }^{15}$, using a specific mouse IgG antibody. The slides were incubated with mouse specific lgG (DAKO) for one hour at room temperature. Staining of the sections was done using horseradish peroxidase (DAKO, Glostrup, Denmark). Where cerebral lgG was present, the colour intensity of the area's coloured by the IgG staining was assessed semiquantitiavely.

\section{Statistics}

A log scale was used because of the non-linear distribution of the values of microglial activation. A linear regression model was used to assess the difference in microglial activation in Chllamydia PCR positive mice versus Chlamydia PCR negative mice, Chlamydia PCR positive mice versus mockinfected mice and Chlamydia PCR negative mice versus mock infected mice. Furthermore, we compared microglial activation in the ApoE/LDLr KO mice versus eight months old C57BL/6J mice and three months old $\mathrm{C} 57 \mathrm{BL} / 6 \mathrm{~J}$ mice, respectively. Results are given in log average values of the number of activated microglial cells and the standard error of mean. 


\section{Results}

\section{Detection of $C$ pneumoniae}

$C$ pneumoniae IgG antibodies were found in all $C$ pneumoniae infected mice twenty-one days after infection.

Five infected ApoE/LDLr KO mice died before scheduled sacrifice, three that were scheduled to be sacrificed seven days after infection and two that were scheduled to be sacrificed twenty-one days after infection. These mice were excluded from the study. The causes of death of these mice were unknown, macroscopic examination of the brains showed no abnormalities. PCR was not performed in these mice, because exact time of death could not be established and DNA might already be degraded in these mice. In total, $C$ pneumoniae DNA was detected in the brain tissue of 24 out of 79 infected mice (30.0\%). As shown in Figure 3.1 and Table 3.1, there is a marked difference in infection pattern in the ApoE/LDLr KO mice, compared the other types of mice. In the ApoE $\mathrm{KO}$ and $\mathrm{C} 57 \mathrm{BL} / 6 \mathrm{~J}$, the infection rate is the highest three days after infection, with a decline afterwards. The ApoE/LDLr KO however, show a low infection rate three days after infection, which rises at the other time points. In total, three days after infection $42.8 \%$ of the brains contained $C$ pneumoniae DNA, this decreased to $24 \%$ and $23.1 \%$ positivity for the time points seven and twenty-one days after infection, respectively. Immunohistochemical staining could not confirm the presence of $C$ pneumoniae in the murine brain tissue.

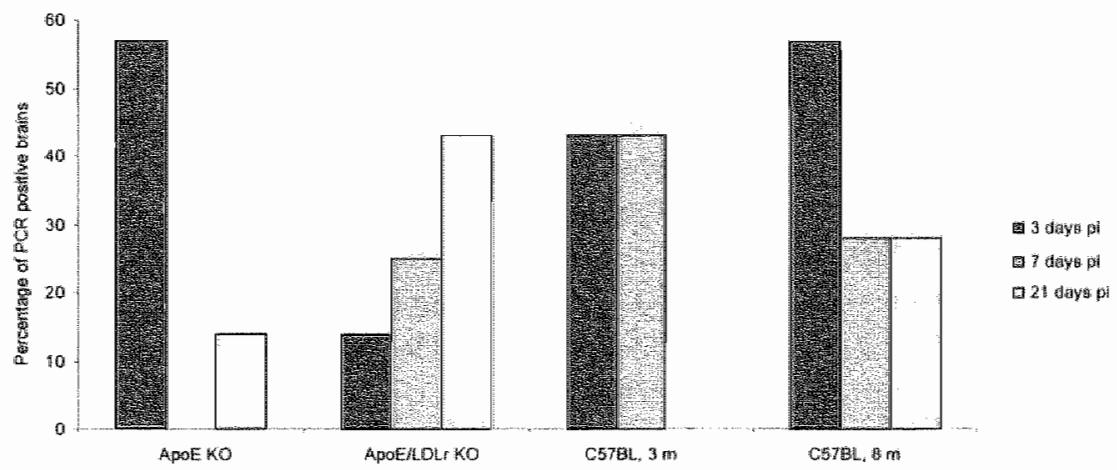

Figure 3.1 Distribution of the proportions of PCR positive brains of ApOE KO, ApoE/LDLr KO, three months ald C57BL/6J (C57BL/6J, 3m), eight months ald C57BL/6J (C57BL/6J, $8 \mathrm{~m})$ mice three, seven and twenty-one days after infection. 
Table 3.1 Distribution of the presence of $C$ pneumoniae DNA in the brain tissue of ApoE KO. ApoELDLr KO, three months old C57BL/6J (C57BL6J, 3m), eight months old C57BL/6.J $(C 57 \mathrm{BL} / 6 \mathrm{~J}, 8 \mathrm{~m})$ mice three, seven and twenty-one days after infection. Results are given as number of positive mice/total mice analysed (percentage positives).

\begin{tabular}{lcccccc}
\hline & ApoE KO & ApoE/LDLr KO & C57BL/6, $3 \mathrm{~m}$ & C57BL/6J, 8m & Total \\
\hline 3 days p.i. & $4 / 7(54)$ & $1 / 7(14)$ & $3 / 7(43)$ & $4 / 7(57)$ & $12 / 28(42.8)$ \\
7 days p.i. & $0 / 7(0)$ & $1 / 4(25)$ & $3 / 7(43)$ & $2 / 7(28)$ & $6 / 25(24)$ \\
21 days p.i. & $1 / 7(14)$ & $3 / 5(60)$ & $0 / 7(0)$ & $2 / 7(28)$ & $6 / 26(23,1)$ \\
\hline
\end{tabular}

\section{Microglial activation}

Microglial activation was assessed in ApoE/LDLr KO mice, three month old C57BL/6J mice and eight months old C57BL/6J mice. In each of these groups, microglial activation was compared in Chlamydia PCR positive mice versus Chlamydia PCR negative mice, Chlamydia PCR positive mice versus mockinfected mice and Chlamydia PCR negative mice versus mock-infected mice. The highest number of activated microglial cells was found in the Chlamydia infected PCR positive ApoE/LDLr KO mice. There were significantly less activated microglial cells in the mock infected ApoE/LDLr KO mice compared with the Chlamydia infected PCR positive mice $(-0.394,95 \% \mathrm{Cl}:-0.716 /-0.073)$ p-value: 0.017 . Chlamydia infected PCR negative mice showed less microglial activation than Chlamydia infected $P C R$ positive mice, but this was not statistically significant, $(-0.252(95 \% \mathrm{Cl}:-0.598 / 0.093)$, p-value 0.150 . No difference in microglial activation was found between the Chlamydia infected PCR negative ApoE/LDLr KO mice and the mock infected ApoE/LDLr KO mice $(-0.142,95 \% \mathrm{Cl}:-0.133 / 0.417)$, p-value: 0.308 . C57BL/6J mice showed significantly less activated microglial cells than the ApoE/LDL" KO mice, in both the three month old $(-0.95395 \% \mathrm{Cl}:-1.252 /-0.655)$ and eight months old mice ( $-0.98995 \% \mathrm{Cl}:-1.276 /-0.702)$, p-value for both 0.000 .

C57BL/6J mice showed no differences in microglial activation between the Chlamydia infected PCR positive, Chlamydia infected PCR negative and mock infected mice, nor was there a difference in microglial activation between the three months old and eight months old mice.

These data are summarized in Figure 3.2.

\section{$\mathrm{BBB}$ permeability}

No cerebral IgG was observed in the infected and mock injected ApoE/LDLr KO mice, nor was there enhanced permeability of the BBB in the C57BL/6J mice. Semi quantitative analyses therefore, was not performed ${ }^{15}$. 


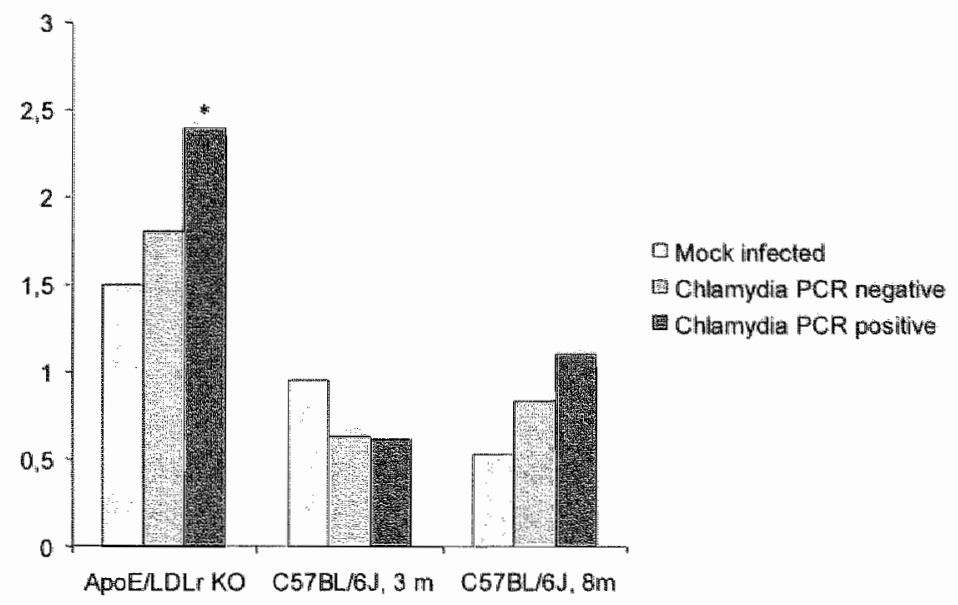

Figure 3.2 Differences in microglial activation in eight months old ApoE/LDLr KO mice (left), three months old C57BL/6J (middle) and eight months old C57BL/6J mice (right), divided into chlamydia PCR positive mice, chlamydia PCR negative mice, and mock infected mice.

${ }^{*} p=0.017$ for the difference in microglial activation in infected $P C R$ positive ApoE/LDLr KO mice compared to mock infected ApoE/LDLr KO mice.

\section{Discussion}

The presence of $C$ pneumoniae DNA in murine brain tissue was established after intraperitoneal injection, proving haematogenic dissemination of $C$ pneumoniae into the brain. Little et al. already showed that intranasal infection with $C$ pneumoniae leads tot the presence of the micro-organism within pulmonary tissue, the heart and the brain ${ }^{16}$. Aged animals are more susceptible to pulmonary infection than younger animals. In our study we focused on the effect of age on intra-cerebral $C$ pneumoniae infection, as well as the effect of atherosclerosis. Infection rate was not influenced by these factors, but the ApoE/LDLr KO mice showed an infection pattern that differed from the ApoE KO and C57BL/6J mice, with the highest amount of positive brains twenty-one days after infection, whereas the ApoE KO and C57BL/6J mice show the highest positivity rate three days after infection. ApoE/LDLr mice show extensive atherosclerosis throughout the vascular tree with advanced lesions already present in 16 week old mice ${ }^{13}$. This extensive atherosclerosis can lead to generalized hypoperfusion, slowing down the haematogenic spread of the infection. Furthermore, hypoperfusion or increased monocyte recruitment into atherosclerotic areas could delay recruitment of monocytes into inflammatory areas, thereby prolonging cerebral presence of $C$ pneumoniae. 
Although all $C$ pneumoniae infected mice seroconverted, indicating that sufficient infection had taken place, not all mice developed cerebral C pneumoniae infection. Only $42.8 \%$ of the murine brains were positive three days after infection, a number that decreased in time. This finding is in agreement with earlier experiments performed in our laboratory, showing the presence of $C$ pneumoniae DNA in $100 \%$ of the spleens and lungs during the first week after infection, compared to only $33 \%$ of the carotid vessels ${ }^{13}$. This suggests variable susceptibility of various organs to $C$ pneumoniae infection, a phenomenón also described by others ${ }^{14}$.

Cerebral $C$ pneumoniae infection enhances microglial activation in the hippocampus of atherosclerotic mice. By measuring the number of activated microglial cells in $C$ pneumoniae infected mice, we found a significant increase in number of activated microglial cells in the brains of $C$ pneumoniae PCR positive ApoE/LDLr KO mice, compared to mock-infected mice. There were no differences in microglial activation between the $C$ pneumoniae infected $C$ pneumoniae PCR negative mice and to the mock-infected mice. Furthermore we observed a higher number of activated microglia in atherosclerotic mice compared to non-atherosiclerotic mice.

The microglial activation is found in the acute phase of the infection, i.e. during the first week after inoculation and remains for at least three weeks after infection. Microglial activation is associated with a number of neurodegenerative diseases, such as Alzheimer's disease (AD). The characterized amyloid depositions in the $A D$ brain are surrounded by clustered activated microglia, in an attempt to phagocytose and degrade amyloid ${ }^{17}$. These activated microglia are responsible for the neuronal injury and neuronal loss seen in $A D$, by means of the production of neurotoxic agents such as inflammatory cytokines, complement factors and acute phase proteins ${ }^{18,19}$. An identical pathogenetic mechanism can be assumed for neuronal damage seen in chronic cerebral ischaemia, as in these circumstances microglial activation is also a prominent feature. The role of $\mathrm{C}$ pneumoniae in this can be double edged, by playing a role in the vascular changes and by cerebral C pneumoniae infection and subsequent microglial activation. The association between cerebral atherosclerosis and microglial activation has never been described before. Microglial activation is seen after focal cerebral ischaemia induced by middle cerebral artery occlusion ${ }^{20}$. In humans activated microglia were demonstrated in autopsied brains from patients with Binswanger's disease ${ }^{21}$, which is characterized by diffuse ischaemic white matter damage due to hypoperfusion

PCR cannot localize the micro-organism within the tissue, so it remains unclear which cells within the sample contain the chlamydial DNA. The detected C pneumoniae DNA can be present in brain tissue, as well as in the endothelial cells of cerebral blood vessels. In an attempt to localize $C$ pneumoniae within 
the brain tissue we used IHC but we were not able to detect positive cells, although the positive controls used in our tests showed presence of intracellular $C$ pneumoniae. Our PCR is very sensitive and can detect up to one copy of DNA, so one explanation for the negative $1 \mathrm{HC}$ might be that only a small amount of $C$ pneumoniae is present within the brain tissue.

Studies performed in our laboratory have proved that intraperitoneal C pneumoniae injection results in dissemination to the vessel wall and various organs, indicating general infection ${ }^{13}$. Since our infection method was the same as in these studies we can assume that this general infection also took place in our mice, even though we only tested the presence of cerebral c pheumoniae. However, significant enhancement of microglial activation only occurs in infected PCR positive mice, indicating that the microglial activation observed is an effect of cerebral $C$ pneumoniae infection, as opposed to a general inflammatory response.

C pneumoniae infection did not alter the integrity of the BBB. Neither the infected nor the mock-infected mice showed a higher permeability of the BBB, in both ApoE/LDLr knockout and C57BL/6J mice. Monocytes can be transported over an intact BBB under physiological conditions ${ }^{22}$. Intracellular micro-organisms, like Streptococcus suis, can cross the BBB and enter the brain via the so-called "Trojan horse mechanism" ${ }^{\text {m23 }}$. C pneumoniae is known to reside in the peripheral blood monocyte ${ }^{24}$, and has recently been detected in leucocytes ${ }^{25}$, and as such could use this Trojan horse mechanism to enter the brain over an intact BBB. Once inside the brain, $C$ pneumoniae is responsible for enhancement of microglial activation, which, through release of neurotoxic agents can lead to neuronal injury and loss.

In conclusion: Intraperitoneal $C$ pneumoniae injection leads to intra-cerebral $C$ pneumoniae infection. This process is not accompanied by or caused by an enhanced permeability of the BBB. Intra-cerebral $C$ pneumoniae infection causes enhanced microglial activation in ApoE/LDLr KO mice. Very small amounts of $C$ pneumoniae DNA might already be responsible for this effect. since microglial activation has been indicated as a key factor in neurodegenerative and neuro-inflammatory disorders such as $A D$ and $M S$, infection with $C$ pneumoniae might contribute to these processes. Whether this is a process unique for $C$ pneumoniae remains to be tested in further experiments. 


\section{References}

1. Saikku $P$, Leinonen M, Mattila $K_{1}$ Ekman MR, Nieminen MS, Makela PH, Huttunen JK, Valtomen $V$. Serological evidence of an association of a nowel Chlamydia, TWAR, with chronic coronary heart disease and acute myocardial infarction. Lancet. 1988;2:983-6.

2. Cook PJ, Honeyboume D, Lip GY. Beevers DG, Wise $R$, Davies $P$. Chlamydia pneumoniae artibody titres are significantly associated with acute stroke and transient cerebral ischaemia: the West Birmingham Stroke Project. Stroke. 1998;29:404-10

3. Elkind MS, Lin $\mathbb{F}_{\text {i }}$ Grayston $\mathrm{JT}$, Sacco RL. Chlamydia pneumoniae and the risk of first ischaemic stroke: The Northern Manhattan Stroke Study. Stroke. 2000;31:1521-5.

4. Grayston JT. Inffections caused by Chlamydia pneumoniae strain TWAR. Clin Infect Dis. $1992 ; 15: 757-64$

5. Rosenfeld ME, Blessing E, Lin TM, Moazed TC, Campbell LA inflammation, and atherogenesis. Infect Dis. 2000;181 Suppl 3:\$492-7.

6. Persidsky $Y$. Model systems for studies of leukocyle migration across the blood - brain barrier. J Neurovirol. 1999;5:579-90.

7. Macintyre A, Abramov R, Hammond C.J, Hudson AP, Arking EJ, Little CS, Appelt DM, Balin BJ. Chlamydia pneumoniae infection promotes the transmigration of monocytes through human brain endothelial cells. INeurosci Res. 2003;71:740-50.

8. Gonzalez-Scarano $F$, Baltuch $\mathcal{G}$. Microglia as mediators of inflammatory and degenerative diseases. Annu Rev Nourosci. 1999;22:219-40.

9. Tomimoto $H_{1}$ Akiguchi I. [The role of immunologic reactions in the pathogenesis in Binswanger's disease; a clue to therapeutitic approach]. Rinsho Shinkeigaku. 1999;39:56-8.

10. Roblin PM, Dumornay W. Hammerschlag MR. Use of HEp-2 cells for improved isolation and passage of Chlamydia pneumoniae. J Clin Microbiol. 1992,30:1968-71.

11. Warschkau $H$, Kiderlen AF. A monoclonal antibody directed against the murine macrophage surface molecule F $4 / 80$ modulates niaturall immune response to Listeria monocytogenes. J Immunol. 1999;163:3409-16.

12. Long JM, Kalehua AN, Muth NJ, Hengemihle JM, Jucker M, Calhoun ME, Ingram DK, Mouton PR. Stereological estimation of total microglia number in mouse hippocampus. I Neurosci Mothods. 1998;84:101-8.

13. Ezzahiri $R$, Stassen $F R$, Kurvers HA, van Pul MM, Kitslaar PJ, Bruggeman CA. Chlamydia pneumoniae infection induces an unstable atheroscleratic plaque phenotype in LDL-receptor, ApoE double knockout mice. Eur IVasc Endovasc Sung. 2003:26:88-95.

14. Ezzahiri $R$, Nelissen Vrancken HJMG, Kurvers HAJM, Stassen FRM, Viegen II, Grauls GELM, vain Pul MML, Kitslaar PJEHM, Bruggeman CA. Chlamydophila pneumoniae (Chlamydia pneumoniae) accelerates the formation of complex atherosclerotic lesions in Apo E3-Leiden mice. Cardiovasc Res. 2002;56;269.

15. Mulder $M$, Blokland $A_{\text {, van den Berg } D} \sharp_{\text {, Schulten }} H_{3}$ Bakker AH, Terwel D, Honig W, de Kloet $E R$, Havekes $L M$. Steinbusch $H W$, de Lange EC. Apolipoprotein $E$ protects aglainst neuropathology induced by a thigh-fat diet and maintains the integrity of the blood-brain barrier during aging. Lab linvest. 2001:81:953-60.

16. Little CS, Hammond $C J$, Macintyre $A, B a l i n$ BJ, Appelt DM. Chlamydia pneumoniae induces Alzheimer-like amyloid plaques in brains of BALB/c mice. Neurobiol Aging. 2004;25:419-29.

17. Rogers J, Strohmeyer R, Kovelowski C.J, Li R. Microglia and inflammatory mechanisms in the cllearance of amyloid beta peptide. Glia. 2002;40:260-9.

18. Akiyama $H$, Barger $S$, Barnum $S$, Bradt B, Bauer J, Cole GM, Cooper NR, Eikelenboom $P$,

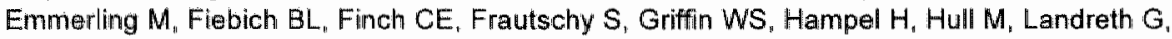
Lue L, Mrak $R_{*}$ Mackenzie IR, McGeer PL, O'Banion MK, Pachter J, Pasinetti G, PlataSalaman C, Rogers J, Rydel R, Shen Y, Streit W, Strohmeyer R, Tooyoma I, Van Muiswinkel FL, Veerhuis $R$, Walker D, Webster S, Wegrzyniak B, Wenk G, Wyss-Coray T. Inflammation and Alzheimer's cisease. Neurobiol Aging. 2000;21:383-421.

19. Eikelenboom P. Bate C, Van Gool WA, Hoozemans JJ, Rozemuller JM, Veerhuis R, Williams A. Neuroinflammation in Alzheimer's disease and prion disease. Glia. 2002;40:232-9. 
20. Buttini $M$, Appel $K$, Sauter A, Gebicke-Haerter PJ Boddeke HW. Expression of tumor necrosis factor alpha after focal cerebral ischaemia in the rat. Newroscience. 1996;71:1-16.

21. Rosenberg GA, Sullivan $N$. Esiri MM. White matter damage is associated with matrix metalloproteinases in vascular dementia. Stroke. 2001;32:1162-8.

22. Qing $Z$, Sewell $D$, Sandor $M$, Fabry $Z$. Artigen-specific $T$ cell trafficking thto the central nerwous system. I Neurommunol. 2000;105:169-78.

23. Willams AE, Blakemore WF. Pathogenesis of meningitis caused by Streptococcus suis type 2. Jinfect Dis. 1990;162:474-81.

24. Kuo CC, Jackson LA, Campbell LA, Grayston JT. Chlamydia pneumoniae (TWAR). Cin Microbiol Rev. 1995;8:451-61.

25. Berger $M$, Schroder $B$, Daeschlein G, Schneider $W$, Busjahn A, Buchwalow I, Luft FC, Haller $H$. Chlamydia pneumoniae DNA in non-coronary atherosclerotic plaques and circulating leukacytes. J Lab Clin Med. 2000;136:194-200. 
${ }_{50} 1$ 


\section{Chapter 4}

Absence of Chlamydia pneumoniae,

Cytomegalovirus and Herpes Simplex Virus

type 1 in cerebral large vessels, small vessels

and brain tissue in clinically unmanifested atherosclerosis of the brain

JM Voorend, AJAM van der Ven, B Kubat, J Lodder, CA Bruggeman

Submitted for publication 


\section{Abstract}

\section{Aim of the study}

To explor whether Chamydia pneumoniae, Cytomegallowirus and Herpes Simplex Virus type 1 could be detected in large and small cerebral arteries, as well as in an area of brain parenchyma where white matter lesions (leukoaraiosis) can be found, in patients with clinically unmanifested cerebrovascular atherosclerosis.

\section{Methods and results}

Arterial specimens from the basilar artery and middle cerebral artery, and brain samples from the basal ganglia and periventricular white matter were obtained. Neuropathological changes were assessed in Haematoxylin/Eosin stained sections. Polymerase chain reaction (PCR) was performed on paraffin embedded sections. Subsequently, we performed immunohistochemical staining on samples, which were found pasitive in PCR. We failed to detect Chlamydia pnewmoniae, CMV, or HSV 1 , in any of the cerebral large vessells. In the brain tissue, we found only one case positive for $\mathrm{CMV}_{\mathrm{i}}$ and one for Chlamydia pneumoniae.

\section{Conclusions}

Our findings suggest a limited role for Chlamydia pneumoniae, CMV and HSV-1 in cerebral large and small vessel atherosclerosis. 


\section{Introduction}

Atherosclerosis is an inflammatory disease. The 'response to injury' hypothesis proposes endothelial dysfunction as the initiating factor, followed by influx of monocyte-derived macrophages and T-lymphocytes". Over the past decade there has been much speculation about the role of micro-organisms in the activation and maintenance of this inflammatory response. The microorganisms most extensively investigated in this context are Chlamydia pneumoniae (C pneumoniae) and Cytomegalovirus (CMV) ${ }^{2-4}$. Some reports have described the role of Herpes Simplex Virus type 1 (HSV-1) as well ${ }^{5,6}$. $\mathrm{C}$ pneumoniae and CMV both reside in the peripheral blood monocyte, from which they can spread into the atherosclerotic plaque ". For both Cpneumoniae and CMV, the relationship between infection and atherosclerosis was first established in the late $80 " \mathrm{~s}^{9,10}$. Two studies showed that patients suffering from cardiovascular disease more often had antibodies against the micro-organisms than a matched control group. After these initial reports various studies followed, using different techniques to document an infection, like serology, immunohistochemistry (IHC) and polymerase chain reaction ( $P C R$ ) (reviewed $\mathrm{in}^{2}$ ). The results of these studies varied, and not all confirmed the association. Pathological studies have shown the presence of C pneumoniae ${ }^{11}, \mathrm{CMV}^{12}$ and $\mathrm{HSV}-1^{13,14}$, in arterial specimens from various sites. One study showed the presence of all three micro-organisms in the same carotid arterectomy sample ${ }^{15}$. Most of the aforementioned studies focused on the role of these micro-organisms in cardiovascular disease and their presence in the atherosclerotic plaques of coronary and carotid arteries. There are only a few reports on the relationship between infection with these micro-organisms and cerebrovascular disease (CVD) ${ }^{16-19}$. Even less attention has been paid to the actual presence of these micro-organisms in the large cerebral vessels. with only a few reports on the presence of $C$ pneumoniae in these vessels ${ }^{20-22}$. In the study by Rassu et al., the presence of CMV was studied as well, the presence of HSV-1 has never been investigated in this context.

Factors involved in CVD may differ from those in cardiovascular disease. CVD may broadly be divided in two entities: large vessel disease (LVD) and small vessel disease (SVD). LVD, which is due to atherosclerosis of the larger cerebral vessels, causes mainly larger, usually called territorial infarcts, which often involve the cortex. The risk factors for large vessel disease are similar to those of cardiovascular disease in general. SVD causes small infarcts, less than $15 \mathrm{~mm}$ in diameter on cerebral imaging. which are located in the deep brain structures (basal ganglia and internal capsule) or the pons; these are often referred to as lacunar infarcts. SVD is also the cause of more diffuse damage to the white matter of the brain: leukoaraiosis. The clinical manifestation of either LVD or SVD is consistent over time ${ }^{23}$. Therefore, it is 
rational to investigate potential causes or factors that sustain these two types of cerebrovascular diseases separately. The role of $C$ pneumoniae, CMV and HSV - 1 in SVD has never been investigated in this respect.

The airn of this study was to investigate whether the presence of C pneumoniae, CMV and HSV -1 could be established in the large and small cerebral arteries, as well as in brain parenchyma where leukoaraiosis can be found, in cases with pathological evidence of cerebrovascular atherosclerosis.

\section{Materials and methods}

\section{Autopsy specimens}

Included in the study were autopsy specimens from ten men and nine women, ranging from 33 to 80 years of age (median 70). Patient characteristics are summarized in Table 4.1. At autopsy the brain was removed, and immersed in $10 \%$ buffered formaldehyde for at least two weeks. The large cerebral vessels were dissected after which the brain was cut in frontal sections. The material was embedded in paraffin and used for routine neuropathological examination. For this study, specimens were obtained from the areas supplied by small vessels, i.e., the basal ganglia and the periventricular white matter. Arterial specimens included the distal $3 \mathrm{~cm}$ of the basilar artery (BA) and the proximal $3 \mathrm{~cm}$ of the middle cerebral artery (MCA), directly after it branches from the internal carotid artery. Arterial sites showing macroscopic signs of atherosclerosis were also included. The large vessels were embedded longitudinally. Paraffin embedded material was used for Haematoxylin/Eosin (HE) staining, immunohistochemical staining and polymerase chain reaction (PCR). Ten $5 \mu \mathrm{m}$ sections were cut, followed by a $50 \mu \mathrm{m}$ section. This was serially continued until all material was used. The first of each $5 \mu \mathrm{m}$ section was used for $\mathrm{HE}$ staining; the following $5 \mu \mathrm{m}$ section was used for $\mathrm{IHC}$. The $50 \mu \mathrm{m}$ sections were used for PCR; three $50 \mu \mathrm{m}$ sections were pooled in one serum tube and stored at $4^{\circ} \mathrm{C}$ until further processing.

\section{Serology}

Post-mortem serum samples were taken from each case. The sera were kept at $-20^{\circ} \mathrm{C}$ until further processing. $C$ pneumoniae serology was performed using a microimmunofluorescence test (Labsystems, Helsinki, Finland). Samples were considered positive when titres were $1 / 32$ or higher.

CMV and HSV-1 antibodies were aimed to detect using commercially available Enzyme Linked Immunoabsorbent Assays used in routine diagnosis of these 
antibodies (Serion, Germany). Samples were considered positive when titres were $>30$.

Table 4.1 Case characteristics.

\begin{tabular}{|c|c|c|c|c|c|}
\hline Case & Sex & Age & LVD & SVD & Cause of death \\
\hline 1 & $\mathrm{~F}$ & 80.0 & + & NA & Hemorragiuc stroke \\
\hline 2 & M & 51.0 & 0 & NA & Hepatic encephalopathy \\
\hline 3 & $M$ & 87.0 & ++ & + & Ischaemic stroke \\
\hline 4 & $M$ & 73.0 & $+t+$ & NA & Cerebellair hematoma \\
\hline 5 & $\mathrm{~F}$ & 57.0 & + & NA & Gastrointestinal bleeding \\
\hline 6 & $M$ & 74.0 & ++ & + & Caridiac arrest \\
\hline 7 & $M$ & 62.0 & + & + & Respiratory arrest \\
\hline 8 & $\mathbb{M}$ & 63.0 & $+4+$ & $++t$ & Hemorragic stroke \\
\hline 9 & $M$ & 47.0 & + & ++ & Cerebral metastasis \\
\hline 10 & $M$ & 39.0 & + & 0 & Sepsis \\
\hline 11 & $M$ & 81.0 & +++ & + & Aschaemic stroke \\
\hline 12 & $\mathrm{~F}$ & 70.0 & ++ & + & Non-hodgkin lymfoma \\
\hline 13 & $\mathrm{~F}$ & 33.0 & + & + & Myocardial infarction \\
\hline 14 & $M$ & 79.0 & $++*$ & ++ & Hemorragic stroke \\
\hline 15 & $\mathrm{~F}$ & 86.0 & +++ & + & Post op bleeding \\
\hline 16 & $M$ & 69.0 & ++ & +4 & Myocardial ischaemia \\
\hline 17 & $F$ & 86.0 & $+t+$ & + & Meningitis \\
\hline 18 & $M$ & 65.0 & + & + & Myociardial ischaemia \\
\hline 19 & $M$ & 79.0 & ++ & 0 & Aortic dissection \\
\hline
\end{tabular}

LVD: + mild atherosclerosis: intimal fibrosis; ++ moderate atherosclerosis: fibro atheromatous plaques; +++ severe atherosclerosis: fibro-atheromatous plaques with calcification.

SVD + Mild: concentric vessel wall thickening in small arteries and arterioles but with mild or minimall luminal narrowing ++ moderate: significant luminal narrowing, but with the lumen spanning more than half the tolal external diameter; +++ severe: the internal vessel diameter was less than half of the external diameter NA: not assessed.

\section{Tissue preparation and PCR analysis}

Prior to DNA isolation, the sections were deparaffinized by adding $700 \mu \mathrm{l}$ of xylol. After this they were vibrated for one minute using the Vortex and centrifuged for ten minutes at $40000 \mathrm{rpm}$ in a Micro $22 \mathrm{R}^{\mathrm{i}}$ rotator. This procedure was repeated. After deparaffination, the sections were rehydrated by adding $70 \%$ ethanol. Again, the samples were vibrated using the Vortex for one minute and centrifuged for ten minutes at $40000 \mathrm{rpm}$ in the Micro $22 \mathrm{R}^{\mathrm{s}}$ rotator. This was also done twice. Following deparaffination, DNA was extracted from brain tissue with the Wizard Genomic DNA purification kit (Promega, Germany). Then, the purified DNA was subjected to PCR aiming to detect either C pneumoniae, CMV or HSV-1 DNA. 
All PCR's were performed in a total volume of $50: 1$, containing $1 \mu \mathrm{g}$ purified DNA, $0.1 \mathrm{mM}$ of each dNTP, $0.5 \mu \mathrm{M}$ of each primer:

- C pneumoniae CPC, 5'-TTA TTA ATT GAT GGT ACA ATA-3; antisense CPD, 5'-ATC TAC GGC AGT AGT ATA GTT-3;

- CMV: sense 5' GCG GGA GAT GTG GAT GGC TTG TAT TAA GGA 3'ant isense 5"GCA GAC TCT CAG AGG ATC GGC CCC C-3";

- HSV-1: sense 5'-GCA TCG TCG AGG TGG AC-3"; antisense 5'-CCT GCC ACT TGG TCA TG-3' DNA

Amplification was carried out in a Perkin Elmer 9600 thermal cycler, using the following cycling conditions:

- C pneumoniae: $37^{\circ} \mathrm{C}$ for ten minutes and $95^{\circ} \mathrm{C}$ for fifteen minutes. 20 cycles of "Touchdown PCR" were performed from $60^{\circ} \mathrm{C}$ to $50^{\circ} \mathrm{C}$, followed by 40 cycles of 1 minute at $94^{\circ} \mathrm{C}, 50^{\circ} \mathrm{C}$, and $72^{\circ} \mathrm{C}$.

- CMV: $37^{\circ} \mathrm{C}$ for ten minutes and $95^{\circ} \mathrm{C}$ for fifteen minutes. PCR was performed in 50 cycles of 30 seconds at $95^{\circ} \mathrm{C}, 70^{\circ} \mathrm{C}$ and $72^{\circ} \mathrm{C}$.

- HSV-1: $37^{\circ} \mathrm{C}$ for ten minutes and $95^{\circ} \mathrm{C}$ for fifteen minutes. PCR was performed in 50 cycles of 30 seconds at $94^{\circ} \mathrm{C}, 69^{\circ} \mathrm{C}$ and $72^{\circ} \mathrm{C}$.

After this the PCR products were kept overnight at $15^{\circ} \mathrm{C}$. The PCR products were resolved in a $2 \%$ agarose gel, stained with ethidium bromide, and photographed.

\section{Histology and immunohistochemistry}

Five $\mu \mathrm{m}$ paraffin sections were used for HE staining, performed using standard procedures. The morphological changes were evaluated on routinely processed $5 \mu \mathrm{m}$ HE sections. The evaluation of the vascular changes was performed by the neuropathologist $(B K)$, who was blinded for case characteristics. Cerebral large vessel atherosclerosis was graded as mild $(+)$ moderate $(++)$, and severe $(+++)$ when intimal fibrosis, fibro-atheromatous plaques, or fibro-atheromatous plaques with calcification were present, respectively. The changes in the small cerebral vessels were recorded as mild $(+)$, moderate $(++)$, or severe $(++)$ in each HE stained block from the basal ganglia or periventricular white matter. Mild SVD was defined as concentric vessel wall thickening in small arteries and arterioles but with mild or minimal luminal narrowing, moderate SVD implied significant luminal narrowing, but with the lumen spanning more than half the total external diameter. In severe SVD the internal vessel diameter was less than half of the external diameter ${ }^{24}$. Apart from this the presence of lacunar infarcts was recorded.

Since the PCR is the most sensitive technique to detect the presence of microorganisms, we first used the PCR to detect CMV $C$ pneumoniae and HSV-1. In cases that were positive by PCR, IHC was performed, to identify the specific cells infected with each micro-organism. For $C$ pneumoniae, the RR402 mouse 
monoclonal antibody (against a major outer membrane protein MOMP of $C$ pneumoniae) (DAKO, Denmark) was used as the primary antibody (dilution 1:50). This antibody is specific for $C$ pneumoniae ${ }^{25}$. Normal mouse ascites was used as a negative control. Five $\mu \mathrm{m}$ thick paraffin embedded sections were pre-incubated with $2 \%$ Bovine Serum Antigen (BSA) in PBS to block aspecific staining, after which the slides were incubated with the primary antibody at $37^{\circ} \mathrm{C}$, for one hour. After washing in Phosphate Buffered Saline (PBS), the sections were incubated with the secondary antibody: biotinylated goat antimouse serum (DAKO, Denmark). Immunostaining was performed by the avidin-biotin alkalic phosphatase method (DAKO, Denmark). Fast red was used as a chromogen, after which the sections were counterstained with haematoxylin. Infected Hep-2 cells were used as a positive control mock infected Hep-2 cells were used as negative control. The same method was used for the immunohistochemical staining of CMV using an antibody against the E13 gene of human CMV as the primary antibody (Argene Biosoft, France) (dilution 1:50).

\section{Results}

\section{Cerebrallarge vessels}

From all cases, either the BA or MCA was avallable for assessment of cerebral large vessel atherosclerosis. Both vessels could be examined in 14/19 cases. In five cases cerebral vessels other than the BA or MCA showed macroscopic signs of atherosclerosis; these were three vertebral artery samples, one anterior cerebral artery, and the intracranial part of one internal carotid artery, respectively. In all but one case microscopic atherosclerotic changes were seen in at least one of the arteries. The case without atherosclerotic changes was a 51-year old male who had died from hepatic encephalopathy. In total, 43 arterial specimens from 19 patients could be investigated. Four of these samples $(9 \%)$ were without atherosclerotic changes. In the remaining $91 \%$ atherosclerotic changes varied from intima fibrosis $(35 \%)$, and fibroatheromatous plaques $(35 \%)$, to fibro-atheromatous plaques with calcification $(21 \%)$. Territorial cerebral infarction as a result of large vessel atherosclerosis was seen in two cases. More severe atherosclerosis was observed in cases that had died from vascular causes, but this difference was not significant. Using the PCR method, we failed to establish the presence of $C$ pneumoniae, CMV, or HSV-1 in any of the cerebral large vessels. No immunohistochemical staining was done on the cerebral large vessel specimens, since we only performed $\mathrm{HC}$ on specimens positive in $\mathrm{PCR}$. 


\section{Cerebral small vessels, basal ganglia, periventricular white matter}

In 15/19 cases cerebral small vessel samples and brain tissue were available for neuropathological examination. SVD was present in either the basal ganglia or periventricular white matter in 13 of these. SVD was mostly observed in the basal ganglia, with some degree of SVD (changes to the cerebral small vessels or lacunar infarction) present in 9/15 cases. Signs of SVD in the periventricular white matter were found in 5/15 cases. When SVD was present, it was graded as mild, with concentric vessel wall thickening in small arteries and arterioles but with mild or minimal luminal narrowing, in 71 percent of the samples. Lacunar infarcts were found in $7 / 15$ basal ganglia, and in 2/15 of periventricular white matter samples. We found only one case positive for CMV, and one for C pneumoniae. In the first case, which had died of basilar artery thrombosis, CMV was found in the basal ganglia. In the second case, which died from a post-operative bleeding after a laparotomy, $C$ pneumoniae was found in the periventricular white matter. $\mathrm{IHC}$ showed the presence of $\mathrm{C}$ pneumoniae in the PCR positive sample. C pneumoniae was present in ganglion cells and underneath the basal membrane, probably in myo-fibrocytes of the medial lamina of the arteriole. $\mathrm{By}$ IHC the presence of CMV in the PCR positive sample could not be confirmed. Since PCR did not show any HSV-1 DNA in any of the samples, IHC for HSV-1 was not performed.

\section{Serology}

$\| \mathrm{gG}$ antibodies against $C$ pneumoniae were found in 15/19 cases, HSV-1 in 16 and, IgG antibodies against CMV in 18.

Both cases that were found positive in PCR had antibodies against CMV and C pneumoniae.

\section{Discussion}

\section{Cerebral large vessel disease}

We failed to establish the presence of $C$ pneumoniae, CMV or HSV-1 DNA in large vessel samples of patients who died from various causes, but who all had signs of atherosclerosis in at least one of the cerebral arteries, varying from intima fibrosis to fully developed atherosclerotic plaques with calcifications.

Considering these findings, our results do not support the hypothesis that these micro-organisms play a conditional role in the generation of cerebrall atherosclerosis, be it large or small vessel disease. However, our data cannot rule out that these micro-organisms do play a role in clinically manifest large vessel 


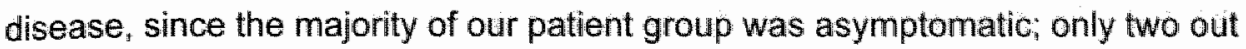
of nineteen patients had had a clinical ischemic stroke.

The presence of micro-organisms in atherosclerotic plaques is patchy. Therefore, detection rates vary between studies ${ }^{26}$. Even if the vessels are embedded and processed longitudinally, and are of considerable length like in our study, not all the material is used in the PCR. Therefore, although the PCR can detect up to one copy of DNA, false negative results may occur as a result of a "sampling error". This patchy presence of micro-organisms is also responsible for the differences in results between $I H C$ and $P C R^{27}$. In one study, that used $\mathrm{IHC}$ to detect $C$ pneumoniae in the cerebral vessels of asymptomatic patients, $C$ pneumoniae was found in only two percent, even though these specimens showed various signs of atherosclerosis ${ }^{20}$. When PCR was used to detect $C$ pneumoniae in fully developed atherosclerotic lesions, the microorganism was found in one third of the vessels ${ }^{21}$.

For PCR, frozen sections as well as formalin fixed sections are used. Deparaffinization of formalin fixed sections, which is needed to allow isolation of DNA from the material, might result in loss of DNA. However, Gass et al. showed that correctly processed material even when embedded in paraffin should provide enough DNA to establish the presence of the micro-organism ${ }^{28}$. The presence of CMV DNA in atherosclerotic tissue was first reported in a study using formalin fixed sections; CMV was found in 94 percent of the samples $^{29}$. Studies on the presence of CMV in atherosclerotic tissue showed a prevalence varying from $0 \%{ }^{30}$ to $94 \%{ }^{29}$. Using frozen sections or paraffin embedded tissue for PCR analysis, does not influence the prevalence of CMV. Therefore, it is unlikely that the absence of micro-organisms in our samples is due to the fact that we used formalin fixed sections.

\section{Cerebral small vessel disease}

We detected $C$ pneumoniae DNA in the brain tissue of one out of 19 cases, and found CMV DNA in one other case. We could not detect HSV-1 DNA in any of the samples. PCR is considered the gold standard for detection of micro-organisms, but it has several disadvantages. Since PCR techniques become more and more sensitive, even very small amounts of DNA can be detected, leaving the question open for the clinical relevance of some findings. Our PCR's are among the most sensitive, with $C$ pneumoniae being detected from up to one copy of DNA and both CMV and HSV-1 from up to 10 copies of DNA. Another disadvantage is that PCR does not localize the micro-organism within the tissue. In an attempt to localize the micro-organisms we used immuno-histochemistry on the samples positive in PCR, C pneumoniae was found in the basal ganglia, more specifically in ganglion cells and underneath 
the basal membrane of a small arteriole. The CMV presence could not be confirmed by IHC.

Studies on the prevalence of $C$ pneumoniae, CMV and HSV-1 in brain tissue, detected these micro-organisms in $95^{31}, 94^{32}$ and $67^{33}$ percent. However, the brain samples tested in these studies came from frontal and temporal cortex, whereas all the patients had clinically manifest dementia. No studies have been reported on the presence of $\mathrm{C}$ pneumoniae, CMV or HSV-1 in the basal ganglia or the periventricular white matter, the areas of the brain supplied by small vessels.

Our results do not point at an important role of the micro-organisms in the generation of SVD, neither as a cause of lacunar infarcts, nor as that of leukoaraiosis. On the other hand, our results cannot deny any role of these micro-organisms in eventual sustenance or acceleration of evident small vessel disease, which can only be accomplished with studying cases with clinically manifest small vessel cerebrovascular disease. However, with the early case fatality rate in small vessel stroke being low, such study would not be easy to perform. Although signs of small vessel disease were found in 13 of our 15 cases, none had clinically manifest disease.

Patients presenting with clinically apparent SVD can be divided in two subtypes with different prognosis. If at first clinical stroke one or more 'silent' lacunar infarcts and/or leukoaraiosis are present, prognosis for recurrent stroke and death are worse ${ }^{23}$. It is hypothesized that there are two entities of SVD with different underlying pathogenesis; micro-atheromatosis in single symptomatic stroke and arteriolosclerosis in the other subtype. There is evidence that in arteriolosclerosis there is a leak in the blood brain barrier, with subsequent leakage of plasma components into the brain, causing neuronal damage ${ }^{34}$. Hypothetically, bload components, but also micro-organisms such as C pneumoniae, CMV or HSV-1 could infiltrate the brain tissue in such patients. It is still unclear whether the presence of these micro-organisms merely reflects a BBB dysfunction, or whether these micro-organisms are a cause of BBB dysfunction. Our series was to small to consider the two lacunar stroke subtypes separately, and therefore cannot deny any differential effect of the micro-organisms in the clinically manifest two types of cerebral small vessel disease.

In contrast to our findings with PCR and $\mathrm{HCC}$, antibodies against $\mathrm{C}$ pneumoniae, CMV and HSV-1 were found in the majority of the cases. This concurs with the prevalence of these antibodies in a general population. Positive antibody titres do not predict the presence of micro-organisms in the vascular wall of cases, whereas the opposite is also true ${ }^{35}$. 


\section{Conclusions}

We were unable to detect $C$ pneumoniae, CMV or HSV-1 in atherosclerotic large cerebral vessels, despite the presence of moderate to severe atherosclerotic changes in these vessels. Except for one case, in which C pneumoniae and CMV were found in a sample of basal ganglia and periventricular white matter, this was also the case with respect to the cerebrall small vessels. Our findings suggest a limited role for $C$ pneumoniae, CMV and HSV-1 in large and small vessel atherosclerosis. Whether these microorganisms play a significant role in symptomatic cerebral LVD and different types of SVD needs to be determined in further studies. 


\section{References}

1. Ross R. Atherosclerosis--an inflammatory disease. N Engl J Med. 1999;340;115-26.

2. de Boer $O J$, van der Wal $A C$. Becker $A E$. Atherosclerosis, inflammation, and infection. I Pathol 2000,180237-43

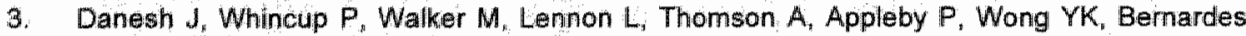
Silva $M_{i}$ Ward $M$. Chlamydia pneumoniae igg titres and coronary theart disease: Prospective study and meta-analysis. British Medical Jourral. 2000;321:208-12.

4. Bruggeman $C$. Does cytomegalovirus play a role in atherosclerosis? Herpes. 2000;7:51-4.

5. Ridker $P M$. Hennekens $\mathrm{CH}$, Stampfer M. Wang $F$. Prospective study of herpes simplex virus, cytomegalovirus, and the risk of future myocardial infarction and stroke. Circulation. $1998 ; 98: 2796-9$

6. Sorlie PD, Adam E, Melnick SL, Folsom A, Skelton T, Chambless LE, Barnes R, Melnick JL. Cytomegalovirus/herpesvirus and carotid atherosclerosis: The aric study. I Med Virol. $1994: 42: 33-7$.

7. May AE, Redecke $V$, Gruner S, Schmidt R, Massberg S, Miethike $T$, Ryba B, Prazeres Da Costa $C$, Schomig $A$, Neumanun FJ. Recruitment of chllamyclia pneumoniae-infected macrophages to the carotid artery wall in noninfected, nonatherasclerotic mice. Arterioscher Thromb Vasc Biol. 2003;23:789-94.

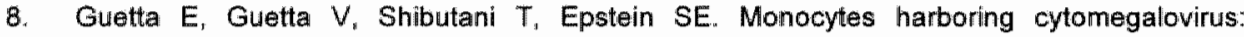
Interactions with endothelial cells, smooth muscle cells, and oxidized low-density lipopirotein. Possible mechanisms for activating virus delivered by monocytes to sites of vascular injury. Circ Res. 1997;81:8-16.

9. Adam E, Melnick U, Probtsfield JL, Petrie BL, Burek d, Bailey KR, McCollum CH, DeBakey ME. High levels of cytomegalovirus antibody in patients requiring vascular surgery for atherosclerosis. Lancet. 1987;2:291-3.

10. Saikku $P$, Leinomen $M$, Mattila $K$, Ekman MR, Nieminen MS, Makela PH, Huttumen JK, Valtonen $V$. Serological evidence of an association of a novel chlamydia, twar, with chronic coronary heart disease and acute myocardial infarction. Lancet. 1988;2:983-6.

11. Taylor Robinson D. Thomas B.J. Chllamydia pneumoniae in atherosclerotic tissue. J infect Dis. 2000;181 Suppl 3:S437 -40 .

12. Radke PW, Merkelbach Bruse $S$, Messmer BJ, vom Dahll J, Darge $H$, Naami A, Vogel $G$, Handt $S$, Hanrath $P$. Infectious agents in coronary lesions obtained by endatherectomy: Pattern of distribution, coinfection, and clinical findings. Coron Artery Dis. 2001;12:1-6.

13. Espinola Klein $C$, Rupprecht HJ. Blankenberg $S$, Bickel $C$, Kopp $H_{0}$ Rippin $G$, Hafner $G_{\text {, }}$ Pifeifer U, Meyer J. Are morphological or functionall changes in the carotid artery wall associated with chlamydia pneumoniae, helicobacter pylori, cytomegalovirus, or herpes simplex virus infection? Stroke. $2000,31: 2127-33$.

14. Yamashiroya $H M$, Ghosh $L$, Yang $R$, Robertson $\mathrm{AL}_{n}$ Jr. Herpesviridae in the coronary arteries and aorta of young trauma victims. Am J Pathol. 1988;130:71-9.

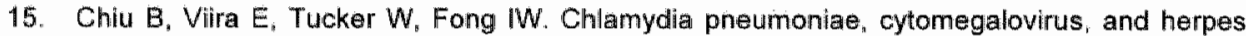
simplex virus in atherosclerosis of the carotid artery. Circulation. 1997;96:2144-8.

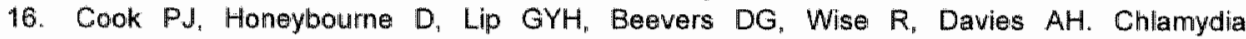
pneumoniae antibody titers are significantly associated with acute stroke and transient cerebral ischemia: The west birmingham stroke project. Stroke. 1998;29:404-10.

17. Elkind MS, Lin IF, Grayston JT. Sacco RL. Chlamydia pneumoniae and the risk of first ischaemic stroke: The northern manhattan stroke study. Stroke. 2000;31:1521-5.

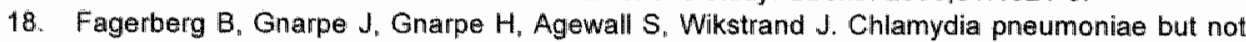
cytomegalovirus antibodies are associated with future risk of stroke and cardiovascular disease: A prospective study in middle-aged to elderly men with treated hypertension. Stroke. $1999 ; 30: 299-305$

19. Wimmer ML, Sandmann Strupp R, Saikku P, Habert RL. Association of chllamydlial infection with cerebrovascular disease. Stroke. 1996;27:2207-10. 
20. Vink $A_{k}$ Poppen M, Schoneveld AH, Roholl PJ, de Kleijn DP, Borst C. Pasterkamp G. Distribution of chlamydia pneumoniae in the human arterial system and its relation to the local amount of atherosclerosis within the individual. Circulation. 2001;103:1613-7.

21. Virok $D_{*}$ Kis $Z$, Karai $L$, Intzedy $L$, Burian $K$, Szabo $A$, Ivanyí $B$, Gonczol $E$. Chlamydia pneumoniae in atherosclerotic middle cerebral artery. Stroke. 2001;32:1973-6.

22. Rassu M, Cazzavillan S, Scagnelli M, Peron A, Bevilacqua PA, Facco M, Bertoloni G, Lauro $F M$, Zambello $R$. Bonoldi $E$. Demonstration of chlamydia pineumoniae in atherosclerotic arteries from various vascullar regions. Atherosclerosis. 2001;158:73-9.

23. de Jong $G$, Kessels $F_{n}$ Lodder $J$. Two types of lacunar infarcts: Further arguments from a study on prognosis. Stroke. 2002;33:2072-6.

24. Lammie GA, Brannan F, Slattery J, Warlow C. Nonhypertensive cerebral small-vessel disease. An autopsy study. Stroke. 1997;28:2222-9.

25. Grayston JT, Campbell LA, Kuo CC, Mordhorst CH, Saikku P. Thom DH, Wang SP. A new respiratory tract pathogen: Chlamydia pneumoniae strain twar. I Infect Dis. 1990; 161:618-25.

26. Cochrane $M_{*}$ Pospischil A, Walker $P$ " Gibbs $H$, Timms $P$. Distribution of chlamydia pneumoniae DNA in atherosclerotic carotid arteries: Significance for sampling procedures. J Clin Microbiol, 2003;41:1454-7.

27. Mygind T, Birkelund $S$, Falk $E$, Christiansen $G$. Evaluation of real-time quantitative pcr for identification and quantification of chlamydia pneumoniae by comparison with immunolhistochemistry. J Microbiol Methods. 2001;46:241-51.

28. Gass $P$, Kiessling M, Schafer P, Mester $C$, Schmitt HP, Kuhn JE. Detection of human cytomegalovirus DNA in paraffin sections of human brain by polymerase chain reaction and the occurrence of false negative results. I Neurol Neurosurg Psychiatry. 1993;56:211-4.

29. Hendrix $\mathbb{M}$, Daemen $M_{4}$ Bruggeman $C$. Cytomegallovirus nucleic acid distribution within the human vascular tree. Am J Pathol. 1991;138:563-7.

30. Watt $S$, Aesch $B$, Lanotte $P$. Tranquart $F$, Quentin $R$. Viral and bacterial DNA in carotid atherasclerotic lesions. Eur J Clin Microbjol Infect Dis. 2003;22;99-105.

31. Balin BJ, Gerard HC, Arking EJ, Appell DM, Branigan PJ, Abrams JT, Whiltum Hudson JA, Hudson AP. Identification and localization of chlamydia pneumoniae in the alzheimer's brain. Med Microbiol Immunol (Berl). „1998;187:23-42.

32. Lin WR, Woznilak MA, Wilcock GK, Itzhaki RF. Cytomegalovirus is present in a very high proportion of brains from vascullar dementia patients. Nourobiol Dis. 2002;9:82-7.

33. Lin WR, Wozniak MA, Cooper RJ, Wilcock GK, Itzhaki RF. Herpesviruses in brain and alzheimer"s disease. J Pathol. 2002;197:395-402.

34. Wardlaw JM, Sandercock PA, Dennis MS, Starr $J$ Is breakdown of the blaod brain barrier responsible for lacunar stroke, leukoaraiosis and dementia? Stroke. 2003;34;806-12.

35. Maass M. Gieffers J "Krause E, Engel PM. Bartels C, Solbach W. Poor correlation between microimmunofluorescence serology and polymerase chain reaction for detection of vascular chlamydia pneumoniae infection in coronary artery disease patients. Med Microbiol Immunol Berl. 1998; 187:103-6. 
6 


\section{Chapter 5}

Silent ischaemic brain lesions; absence of correlation with Chlamydia pneumoniae antibodies and cytokine responses 


\section{Abstract}

\section{Alim of the study}

To investigate whether Chiamydia pneumoniae antibody levels, C-reactive protein and levels of

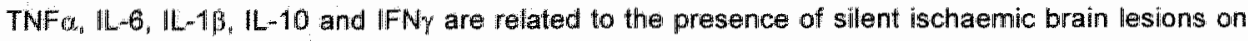
MRi in symptomatic stroke patienits:

\section{Patients and methods}

Patients were derived from a study investigating the effect of a three-month course of azithromycin on progression of sillent ischaemic brain lesions. Levels of high sensitivity CRP (hSCRP) and IL-6 were sisessed on baseline serum samples of 149 patients obtained at randomisation, as was the Chlamydia pneumoniae IgG antibody titre. Cytokine levels were assessed in the supernatant of whole blood stimulated with Chamydia pneumoniae antigen. Baseline brain MRI was scored on the presence of asymptomatic lacunar infarction and leukoarailosis.

\section{Rosuluits}

No differences were found in cytokine levels, hSCRP and Chlamydia pneumoniae serology, between patients with and without silent brain ischaemia, or between patients with a cortical or lacunar infarct.

\section{Canclusions}

Serum inflammatory parameters and Chlamydia prieumoniae serology are not correlated with the presence of silent brain ischaemia on MRI, nor does it distinguish between patients with a cortical or lacunar infarct. 


\section{Introduction}

Inflammation is a key factor in the initiation and progression of atherosclerosis". Inflammatory markers such as high sensitivity C-reactive protein (hsCRP) and Interleukin-6 (IL-6) in serum of apparently healthy men and women predict the risk of future cardiovascular disease or ischaemic cerebrovascular disease ${ }^{2,3}$. Moreover, hsCRP and IL-6 levels are associated with carotid atherosclerosis ${ }^{4,5}$. Infections, specifically infection with Chlamydia pneumoniae (C pneumoniae) have also been implicated in the process of atherosclerosis ${ }^{6}$.

C pneumoniae infection of monocytes, macrophages and endothelial cells induces the production of several inflammatory and anti-inflammatory cytokines that are implicated in the process of atherosclerosis and its clinical sequellae. When $C$ pneumoniae is added to peripheral blood monocytes in vitro, production of tumour necrosis factor alpha (TNF $\alpha$ ) and IL-6 is induced". Serological studies have shown a relationship between the presence of lgG and $\operatorname{IgA}$ antibodies against $C$ pneumoniae and ischaemic stroke ${ }^{8-11}$, and $C$ pneumoniae has been isolated from atherosclerotic plaques of cerebral vessels $^{12-14}$. Neurological symptoms may only be the 'tip of the iceberg' of cerebral atherosclerosis. Even on CT almost 30 percent of ischaemic stroke patients have so-called silent ischaemic lesions, which are (mostly lacunar) infarcts, ischaemic white matter lesions, or both, which progress over time despite secondary prevention measures ${ }^{15,16}$. It is unknown whether $C$ pneumoniae infection contributes to this chronic, progressive process of cerebrovascular atherosclerosis. Therefore, we explored whether the presence of silent ischaemic brain lesions (SBL) on magnetic resonance imaging (MRI) of the brain relates to $C$ pneumoniae infection, possibly mediated by inflammatory markers that are implicated in cerebral atherosclerosis. We studied lacunar and atherothrombotic ischaemic stroke separately in this respect.

\section{Patients and methods}

\section{Patients}

The patients in this study have been randomised in the ACSI study (Azithromycin for the prevention of the progression of Cerebral ischaemic lesions in patients Surviving a non-cardioembolic cerebral Infarct), which investigates the effect of a three-month treatment schedule of azithromycin on ischaemic cerebral damage progression measured at two years. At baseline patients have MRI, whereas blood was drawn for the assessment of hSCRP, IL-6 and C pneumoniae serology. Inclusion ended September 2003, when the 
projected 170 patients had been included. In four of these patients no MRI was performed because of claustrophobia, from another two MRI was of badl quality, so that the presence of asymptomatic ischaemic lesions could not be assessed. In 15 patients serum samples were not available. Therefore, from a total of 149 patients sufficient MRI data and measured baseline serum parameters (hsCRP, $\mathbb{L}-6$ and $\lg G$ antibodies against $C$ pneumoniae) were available for analysis. Baseline whole blood samples were stimulated with $C$ pneumoniae in 75 of these 149 patients. The samples were stimulated for 24 or 48 hours as described by Netea et al. ${ }^{17}$, followed by measurement of TNF $\alpha_{\text {, }}$

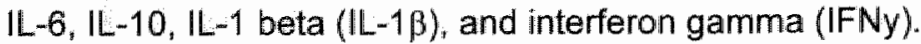

\section{MPI}

The MRI protocol included T2 and FLAIR weighted axial images of the brain. The following parameters were scored: location and type of symptomatic lesion; the presence and number of asymptomatic lacunar infarcts in the basal ganglia, internal capsule or pons; the presence and severity of periventricular hyperintensities and white matter hyperintensities in the centrum semi ovale ${ }^{18}$. The MRI's had been scored without knowledge of clinical information. Silent ischaemic brain lesions (SBL) were analysed as a dichotome variable: presence or absence of one or more silent ischaemic lesions, of white matter lesions (extending peri-ventricular lesions or confluent lesions in the centrum semi ovale), or both ${ }^{18}$.

\section{Definition of lacunar and cortical infarcts}

Lacunar infarct: an acute stroke syndrome with a MRI lesion compatible with the acclusion of a single perforating artery " consisting of a subcortical (basal ganglia, internal capsule, brainstem) small sharply demarcated hypodense lesion with a diameter less than 15 millimetre. If no such lesion was visible we used the established criteria of unilateral motor- and/or sensory signs that involved the whole of at least two of the three body parts (face, arm, leg) without disturbance of consciousness, visual fields, language or other cortical functions. We distinguished four lacunar syndromes: pure motor stroke (PMS), sensorimotor stroke (SMS), pure sensory stroke (PSS) and atactic hemiparesis/dysarthria -clumsy -hand syndrome (AH/DCHS) ${ }^{19}$.

Cortical infarct: an acute stroke syndrome with MRI findings compatible with an infarct involving the cortex. If no such lesion was present we used established clinical criteria consisting of unilateral motor and/or sensory symptoms in combination with signs of disturbance of consciousness, visual fields, language or other cortical functions. Also, patients with an isolated mono-paresis were included as well as patients with incomplete involvement of two body parts, or 
with isolated cortical dysfunction (mostly aphasia) Apart from this, patients had no evidence of an existing source of cardiac embolism.

\section{Cireactive protein}

Venous blood samples drawn on randomisation for the trial were immediately centrifuged for 10 minutes at $1200 \mathrm{rpm}$ and at $4^{\circ} \mathrm{C}$. Serum was stored at $-20^{\circ} \mathrm{C}$ until analysis. HsCRP was determined with the IMMULITE CRP method (Diagnostic Product Corporation, Los Angeles, USA). This assay provides a detection limit of $0.10 \mathrm{mg} / \mathrm{l}$ and has been approved by the Food and Drug Administration for clinical use in the United States.

\section{Serum Interleukin-6}

Levels of IL-6 were determined using an enzyme linked immuno absorbent assay (ELISA, eBiosciences, San Diego, USA). ELISA's were performed as instructed by the manufacturer. Briefly, 96-wells plates were coated with antigen and kept overnight a $4^{\circ} \mathrm{C}$. The following day, the wells were blocked using the tests assay diluent, after which the standards and patient samples were added and incubated for one hour. A biotinylated capture antigen, horseradish peroxide for colouring the samples and $\mathrm{H}_{2} \mathrm{SO}_{4}$ as stop solution, followed this.

\section{Stimulated cytokines}

From 75 consecutive patients, whole blood was stimulated with $C$ pneumoniae antigen as follows: $200 \mu \mathrm{l}$ of whole blood was added to $750 \mu \mathrm{l}$ of RPMI medium and $50 \mu$ of $C$ pneumoniae antigen $\left(3 * 10^{6}\right.$ infection forming units (IFU), dilution 1:20). Mock stimulated samples consisted of $200 \mu \mathrm{l}$ of whole blood added to $800 \mu$ of RPMI medium. The samples were stimulated for 24 hours (TNFa, IL-6 and IL-1 3 ) or 48 hours (IL-10 and IFNy), as described by Netea el al.". Cytokine levels were measured using ELISA (eBiosciences, San Diego, USA), with the method as described above for IL-6.

\section{Measurement of $\operatorname{lgG}$ antibodies against $C$ pneumoniae}

Levels of serum $\lg G$ antibodies against $C$ pneumoniae were measured using an ELISA, (Labsystems, Helsinki, Finland) as described previously ${ }^{20}$. The presence or absence of $C$ pneumoniae antibodies was determined by comparing the absorbance value of the sample to a cut-off value, as specified by the manufacturer. Specimens with values equal to or greater than the cut-off value were considered positive for anti-Chlamydia antibodies. For IgG the cutoff was 30 . 


\section{Statistics}

Since hsCRP, IL-6, and anti $C$ pneumoniae lgG concentrations were skewed, a non-parametric test was used for comparison of the mean values in the groups with and without SBL. Serology values were dichotomised to assess a relationship between the levels of the different serum parameters and the presence of SBL in logistic regression analyses.

\section{Results}

\section{Patient population}

Of the 149 included patients $81(54 \%)$ had silent ischaemic lesions. Table 5.1 shows characteristics of patients with and without silent lesions. Patients with SBL were significantly older than patients without SBL. There were 104 lacunar and 45 territorial infarct patients, of whom $54(52 \%)$ and $27(60 \%)$ had silent ischaemic lesions, respectively.

Table 5.1 Patient characteristics of patients with and without silent brain ischemia (SBL). Numbers indicate percentages, unless otherwise indicated. The numbers in the parenthesis indicate standard deviations.

\begin{tabular}{|c|c|c|c|}
\hline & SBL - & $\mathrm{SBL}+$ & P-value \\
\hline Number of patients & 68 & 81 & \\
\hline Lacumar infarcts & 48 & 52 & 0.36 \\
\hline Cortical infarcts & 40 & 60 & 0.27 \\
\hline Male & 75 & 61 & 0.29 \\
\hline Ago (years) & $61.2(9.4)$ & $65.8(8.8)$ & 0.003 \\
\hline Smoking & 38 & 41 & 0.45 \\
\hline Hypertiemsilon & 40 & 50 & 0.41 \\
\hline Infection & 25 & 24 & 0.98 \\
\hline Seropositive for C pneumoniave & 84 & 83 & 0.79 \\
\hline PAOD & 7 & 4 & 0.98 \\
\hline Hypercholesterolaemia & 21 & 21 & 0.98 \\
\hline DM & 3 & 7 & 0.61 \\
\hline Statin therapy & 62 & 48 & 0.09 \\
\hline Cardiovascular disease & 10 & 12 & 0.98 \\
\hline hsckp (mg/l) & $8.4(18.2)$ & $5.9(8.1)$ & 0.29 \\
\hline $\mathrm{IL}-6(\mathrm{pg} / \mathrm{mi})$ & $6.4(26.3)$ & $2.8(9.7)$ & 0.27 \\
\hline IgG antibody titre (E|A) & $138.5(116.6)$ & $128.9(103.0)$ & 0.59 \\
\hline
\end{tabular}

"History of angina pectoris, myocardial infaretion or coronary by-pass surgeiry 


\section{Baselne serum markers}

There were no differences in mean hsCRP levels, serum IL-6 levels and IgG antibody titres against $C$ pneumoniae between patients with or without SBL, and patients with a cortical or lacunar infarct (data summarized in Table 5.1 and Figures 5.1 and 5.2). Linear regression analysis showed no relationship between the levels of the serum parameters and the presence of SBL. When patients with lacunar infarct were analysed separately, we also found no differences between those with or without silent ischaemic lesions.

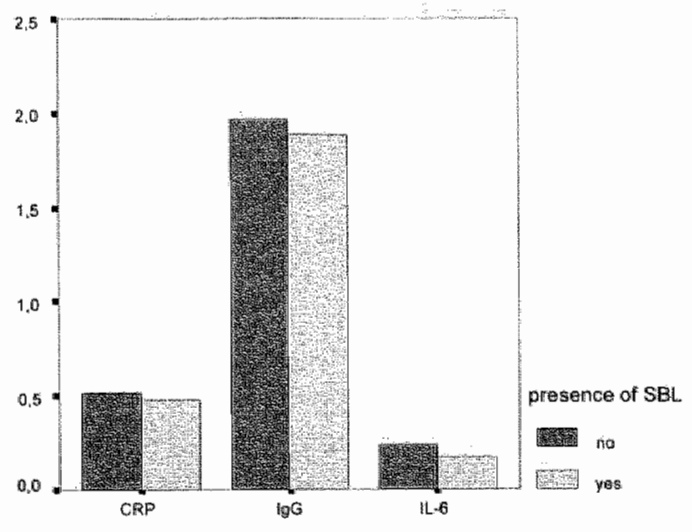

Figure 5.1 Mean $\log$ values of hSCRP, IgG and IL-6 in patients with and without SBL.

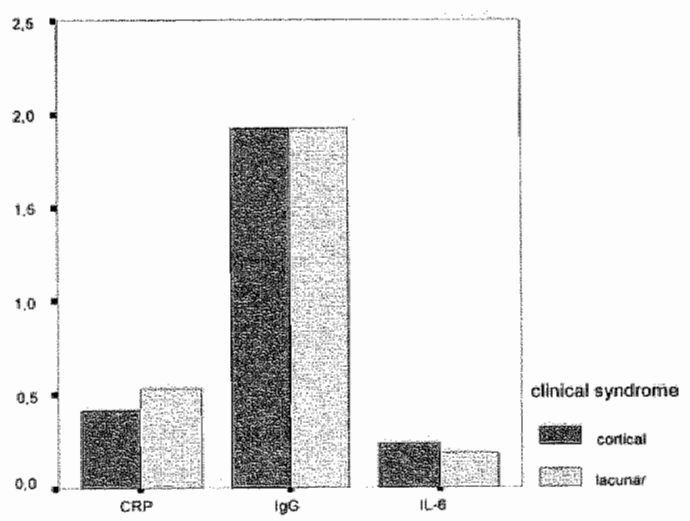

Figure 5.2 Mean log values of hSCRP, IgG and IL-6 in patients with cortical or lacunar infarct.

\section{IgG antibodies against $C$ pneumoniae}

Logistic regression analysis did not show a difference in the presence of positive IgG antibody titres between patients with and without SBL. (Crude OR for the presence of $\mathrm{gG}$ antibodies: $1.30,95 \% \mathrm{Cl}: 0.55-3.16, p=0.54$ ) 
The presence of $\mathrm{gG}$ antibodies against $\mathrm{C}$ pneumoniae did not differ between atherothrombotic and lacunar infarcts (crude OR: $1.10,95 \% \mathrm{Cl}: 0.44-2.95$, $\mathrm{p}=0.79$ )

C pneumoniae antibody titre was not related to hSCRP and IL-6 levels, mean values between seropositive and seronegative patients were similar. (3.9 $9 \pm 3.7$ vs. $5.5 \pm 6.6, p=0.31$ for hsCRP, and $2.1 \pm 3.7$ vs. $6.1 \pm 23.8, p=0.42$ for $\| L-6)$.

\section{Stimulated cytokines}

Mean values of TNFo, IL-6, IL-1 $\beta, I L-10$ and IFN $\gamma$, did not differ between patients with or without SBL, even when analysed separately for lacunar infarct patients (Table 5.2 and figure 5.3). Levels of cytokines did not differ between patients with a cortical infarct and a lacunar infarct (figure 5.4). There were neither correlations between levels of hsCRP and the levels of the stimulated cytokines, nor was there any relationship between $C$ pneumoniae antibody titres and cytokine levels.

Table 5.2 Levels of inflammatory parameters in whole blood stimulated with $C$ pneumoniae antigen in patients with and without silent brain ischemia (SBL).

\begin{tabular}{lccc}
\hline & SBL & SBL + & P-value \\
\hline Number of patients & 36 & 39 & \\
TNF $\alpha(\mathrm{pg} / \mathrm{ml})$ & $9.6(39.8)$ & $36.1(120.5)$ & 0.18 \\
IL-6 $(\mathrm{pg} / \mathrm{ml})$ & $88.7(90.6)$ & $76.7(77.0)$ & 0.93 \\
IL-1 $3(\mathrm{pg} / \mathrm{ml})$ & $64.4(103.5)$ & $96.3(148.2)$ & 0.34 \\
IL-10 $(\mathrm{pg} / \mathrm{ml})$ & $25.7(54.2)$ & $23.0(57.0)$ & 0.99 \\
IFNy $(\mathrm{pg} / \mathrm{ml})$ & $17.6(68.6)$ & $36.5(91.2)$ & 0.65 \\
\hline
\end{tabular}

"Values are given as mean and standard deviation

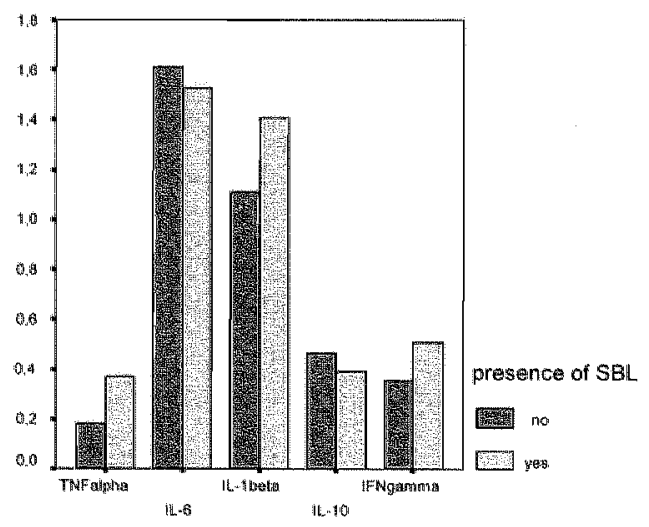

Figure 5.3 Mean log values of TNF $\alpha, 1 \mathrm{~L}-6, \mathrm{LL}-1 \mathrm{~B}, \mathrm{IL}-10$ and IFNy in patients with and without SBL. 


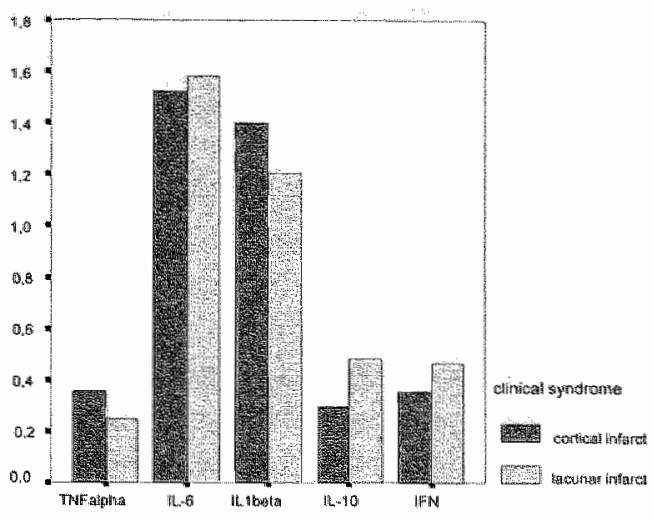

Figure 5.4 Mean $\log$ values of TNFa, $\| L-6, \quad L-1 \beta, \quad L-10$ and IFNy in patients with cortical or lacunar infarct.

\section{Discussion}

In our 149 patients, of whom 81 had silent lesions, we were unable to detect differences between patients with or without "silent" ischaemic lesions for a number of inflammatory markers. Also, when lacunar stroke patients were considered separately, no differences emerged. We also could neither detect a correlation between the presence of serum $C$ pneumoniae antibodies and silent lesions, nor with any of the inflammatory markers. Our findings argue against a prominent role of $C$ pneumoniae infection in the genesis or sustenance of the vascular pathology that underlies silent ischaemic brain lesions. They also do not sustain the idea that infection with this microorganism influences the process of endothelial activation in patients with such lesions.

Our study has some limitations. First, our series was selected because of the in- and exclusion criteria (and willingness) to participate in a clinical trial. Without doubt this resulted in a younger and less severely affected population as is evident from the overrepresentation of lacunar stroke patients and the younger age than expected for stroke in general. Nevertheless, 54 percent of our patients had silent lesions on MRI. Using MRI over CT increases the sensitivity of lesion detection, but the specificity with regard to the severity of the underlying pathology of such lesions may be lower than with CT. Therefore, we cannot exclude the possibility that differences might have emerged in case our population been older and contained more severely affected patients, which means those with a territorial infarct. On the other hand, the most interesting distinction is that between patients with or without silent lesions within a lacunar stroke population because of the issue of phenotyping different types of cerebral small vessel disease ${ }^{21}$. Silent ischaemic brain lesions are 
most strongly associated with lacunar stroke. Secondly, variation in statin therapy may be of influence on the levels of various markers. We were unable to account for duration or intensity of such treatment in our series. A third limitation is the rather small sample size of our study, but in any case it makes any substantial effects of $C$ pneumoniae infection unlikely.

There is some uncertainty in the literature as to the underlying vascular pathology of silent ischaemic lesions, but the available evidence points at socalled lipohyalinosis or also called arteriolosclerosis, as the pathology in most cases $^{22,23}$. Arteriolosclerosis is primarily a hyperplasia of the medial vascular layer, rather than an endothelial affliction. However, this stage may progress to that in which there is ultimately loss of vascular wall integrity, and inflammatory processes may eventually obstruct the vessel lumen ${ }^{23}$. In contrast, small vessel atheromatosis is primarily an inflammatory process from the start with early luminal obstruction, causing symptomatic lacunar infarcts. Consequently, the two types of small vessel disease may differ in terms of endothelial activation and consequently, serum titres of markers participating in this process. However, the extent of silent vascular damage and its stage of progression may be of influence on the degree of endothelial activation in both types of vascular pathology, and the absence of difference in inflammatory markers between our stroke patients with or without silent lesions may be due to the fact that all patients were symptomatic, viz. suffered from atherosclerosis, which might have masked any difference caused by the cerebral vessels alone. Hassan et al, however, were able to detect a lower serum level of the endothelial marker tissue factor pathway inhibitor in 63 lacunar stroke patients with leukoaraiosis compared to 47 without, whereas both groups had elevated levels compared to controls ${ }^{24}$. This suggests that some markers may be more specifically activated, depending on extent and progression of endothelial damage, in which stroke study populations may differ.

To arrive at a genetics-based explanation of cerebral small vessel disease, differences on a molecular level between different subtypes of this disease should be explored. So far $C$ pneumoniae serology nor any of the markers we measured seem to be of value in discriminating between different small vessel phenotypes, nor between cerebral large or small vessel disease. The issue should be further explored in well-defined, large patient series, whereas eventual differences should be valid with regard to differences in prognosis. 


\section{References}

1. Ross R. Atherosclerosis--an inflammatory disease. N Engl J Mod. 1999,340:115-26,

2. Ridker PM. Cushman M, Stampfer MJ, Tracy RP. Hennekens $\mathrm{CH}$. linflammation, aspirin, and the risk of cardiovascular disease in apparently healthy men. N Engl $J$ Med. 1997,336:973-9.

3. Ridker PM, Buring JE, Shih J, Matias $\mathrm{M}_{\mathrm{b}}$ Hennekens $\mathrm{CH}$. Prospective study of C-reactive protein and the risk of future cardiovascular events among apparently healthy women. Circulation. 1998;98:731-3.

4.. Winbeck $K$, Kukla $C$, Poppert $H$, Klingelhofer $\rrbracket$, Conrad $B$, Sander D. Elevated C-reactive protein is associated with an increased intima to media thickness of the common carotid artery. Cerebrovasc Dis. 2002;13:57-63.

5. Yamagami $H$. Kitagawa $K$. Nagai $Y$, Hougaku $H$, Sakaguchi $M$. Kuwabara $K$, Kondo $K$, Masuyama T, Matsumoto M. Hori M. Higher levels of interleukin-6 are associated with lower echogenicity of carotid artery plaques. Stroke. $2004 ; 35: 677-81$.

6. Campbell LA, Kuo CC. Chlamydia pneumoniae-an infectious risk factor for atherosclerosis? Nat Rev Microbiol. 2004:2:23-32.

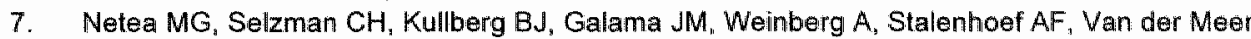
JW. Dinarello CA. Acellular components of Chlamydia pneumoniale stimulate cytokine production in human blood mononuclear cells. Eur J Immunol. 2000;30:541-9

8. Wimmer ML, Sandmann Strupp R, Saikku P. Haberl RL. Association of chlamydial infection with cerebrovascular disease. Stroke. 1996;27;2207-10.

9. Cook PJ, Honeybourne D, Lip GYH, Beevers DG, Wise $R$, Davies AH. Chlamydia pneumoniae antibody titres are significantly associated with acute stroke and transient cerebral ischemia: the West Birmingham Stroke Project. Stroke. 1998;29:404-10.

10. Elkind MS, Lin IF, Grayston JT, Sacco RL. Chlamydia pneumoniae and the risk of first ischemic stroke: The Northern Mainhattan Stroke Study. Stroke. 2000;31:1521-5.

11. Fagerberg B, Gnarpe J, Gnarpe $H$, Agewall $S$, Wikstrand J. Chlamydia pneumoniae but not cytomegalovirus antibodies are associated with future risk of stroke and cardiovascular disease: a prospective study in middle-aged to elderly men with treated hypertension. Stroke. $1999 ; 30: 299-305$

12. Virok D, Kis $Z$, Karai $L$, Intzedy $L$, Burian $K$, Szabo $A$, Wvanyi $B$, Ganczol E. Chlamydia pneumoniae in atherosclerotic middle cerebral artery. Stroke. 2001,32:1973-6.

13. Vink $A$, Poppen $M$, Schoneveld $A_{4}$ Roholl $P$ J, de Kleijn DP, Borst $C$, Pasterkamp $G$ Distribution of Chlamydia pneumoniae in the human arterial system and its relation to the local amount of atherosclerosis within the individual. Circisation. 2001;103:1613-7.

14. Rassu M, Cazzavillan S, Scagnelli M, Peron A, Bevilacqua PA, Facco M, Bertoloni G, Lauro FM, Zambello $R$, Bonolli $E$. Demonstration of Chlamydia pneumoniav in atherosclerotic arteries from various vascular regions. Atherosclerosis. 2001;158:73-9.

15. van Zagten $M_{i}$ Boiten $J$, Kessels $F$, Lodder J. Significant progression of white matter lesions and small deep (lacunar) infarcts in patients with stroke. Arch Nourol. 1996;53:650-55.

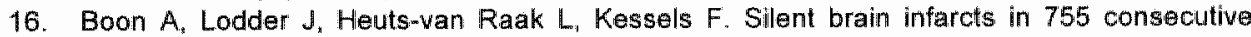
patients with a first-ever supratentorial ischemic stroke. Relationship with index-stroke subtype, vascular risk factors, and mortality. Stroke, 1994;25:2384-90.

17. Netea MG, Selzman CH, Kullberg BJ, Galame JM. Weinberg A, Stalenhoef AF. Van der Meer JW, Dinarello CA. Acellular components of Chlamydia pneumoniae stimulate cytokine production in human blood momonuclear cells. Eur I Immunol. 2000;30:541-9.

18. Schmidt $R$, Scheltens $P$, Erkinjuntti T, Pantoni L, Markus HS, Wallin $A_{1}$ Barkhof $F$, Fazekas $F$ White matter lesion progression: a surrogate endpoint for trials in cerebral small-vessel disease. Neurology. 2004:63:139-44.

19. de Jong $G$, van Raak L, Kessels F, Lodder J. Stroke subtype and mortality. a follow-up study in 998 patients with a first cerebral infarct. $J$ Clin Epidomiol. $2003,56: 262-8$ 


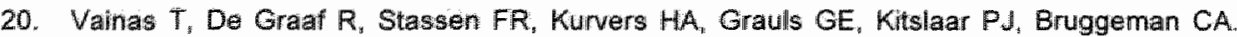
Chlamydia pneumoniae serology: comparing a commercial enzyme immunoassay and microimmunofluorescence test in patients with cardiovascular disease. Apmis. 2003,111: 363-9.

21. Staals J, Lodder J. Hypertension and Lacunar Infarction: Chapter $19 \mathrm{in}$ : Advanced therapy in

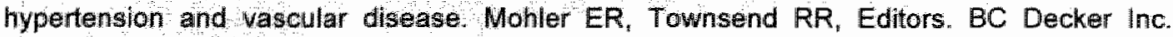
Publisher. 2005.

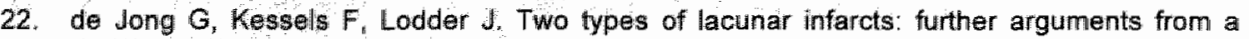
study on prognosis. Stroke. 2002;33,2072-6.

23. Lammie 6 . Pathology of lacunar infarction. in: Subcortical strake Oxford University Press. $2002,37-47$

24. Hassan $A_{*}$ Hunt B. $\mathrm{J}^{\prime}$ Sullivan M, Parmar K, Bamford JM, Brilley D, Brown MM, Thomas DJ, Markus HS. Markers of endothelial dysfunction in lacunar infarction and ischaemic leukoaraiosis. Brain. 2003;126:424-32. 


\section{Chapter 6}

Is the intima-media thickness of the common carotid artery related to ipsilateral silent brain ischaemia, stroke syndrome, and inflammatory parameters? 


\title{
Abstract
}

\begin{abstract}
Aim of the study
To establish whether carotid intima-media thickness is different in cortical versus lacunar infarcts and whether carotid intima-media thickness is related to the presence of silent brain ischaemia, in stroke patients. Furthermore, we investigated the correlation between inflammatary parameters and carotid intima-media thickness.
\end{abstract}

\section{Patients and methods}

Carotid intima-media thickness was measured with B-mode ultrasound, in 74 patients derived from a study investigating the effect of a three-month course of azithromycin on progression of silent ischaemic brain lesions. Levels of high-sensitivity CRP (hsCRP) and IL-6 were assessed on serum samples obtained at randomisation, as was the Chtamydia pneumoniae IgG antibody titre. Cytokine levels were assessed in the supernatant of whole blood stimulated with Chlamydia pneumoniae antigen. Baseline brain MRI was scored on the presence of asymptomatic lacunar infarction and leukoaraiosis.

\section{Results}

No correlations were found between inflammatory levels, Chlamydia pneumoniae serology and caratid intima-media thickness. Mean values of calrotid intima-media thickness did not differ between cortical infarcts and lacunar infarcts, nor were they different between patients with and without silent brain ischaemia.

\section{Conclusions}

In a population of patients with a symptomatic stroke, carotid intima-media thickness values do not differ between patients with and without sillent ischaemic brain lesions on MRI, or between patients with a corticall and lacunar syndrome. Furthermore, carotid intima-media thickness is not related to Chlamydia pneumoniae serology, or inflammatory parameters. 


\section{Introduction}

Common carotid intima-media thickness (CCA-IMT) can be assessed noninvasively by B-mode ultrasonography, and is used as an indicator of early carotid atherosclerosis. CCA-IMT increases with age and is associated with the classical risk factors for cardiovascular disease ${ }^{1-4}$. Increases in CCA-IMT are associated with an increased risk of myocardial infarction and stroke ${ }^{5-7}$. Therefore, CCA-IMT is regarded as a valid indicator of generalized atherosclerosis. Inflammation is a key factor in atherosclerosis development ${ }^{8}$. inflammatory parameters such as C-reactive protein (CRP) are elevated in patients with generalized atherosclerosis ${ }^{9}$, and CRP levels are associated with an increased risk of stroke and myocardial infarction in apparently healthy men and women ${ }^{10,11}$. CRP levels are also associated with higher CCA-IMT ${ }^{12,13}$. AntiChlamydia pneumoniae (C pneumoniae) IgG antibodies are related to CCAIMT levels in patient without clinical evidence of stroke ${ }^{14,15}$, and $C$ pneumoniae seroprevalence is associated with clinical stroke ${ }^{5,7,16-20}$. In approximately 30 percent of stroke patients so-called silent brain lesions (SBL) are seen on CT, consisting of lacunar infarcts, ischaemic white matter lesions or both. These lesions progress over time, despite sufficient secondary prevention ${ }^{21,22}$. SBL increase the risk of cognitive decline ${ }^{23}$, and the presence of SBL is associated with a higher risk of future stroke ${ }^{24}$. The relation between CCA-IMT and the risk of stroke has only been investigated in population based studies ${ }^{5,7}$, and data on the relation between CCA-IMT and stroke subtypes are scarce ${ }^{25,26}$. We therefore sought to find out whether CCA-IMT is related to stroke subtype, the presence of ipsilateral SBL on MRI, and to serum inflammatory parameters and C pneumoniae serology.

\section{Patients and methods}

The patients in this study were randomised in the ACSI study (Azithromycin for the prevention of the progression of Cerebral ischaemic lesions in patients Surviving a non-cardioembolic cerebral Infarct), which investigates the effect of a three-month treatment schedule of azithromycin on ischaemic cerebral damage progression on magnetic resonance imaging (MRI) of the brain measured at two years, in patients with a symptomatic stroke. Patients with a symptomatic stroke were recruited in two hospitals, the University Hospital Maastricht, and one affiliated clinic. Three months after the stroke, the patients were randomised to receive either azithromycin $500 \mathrm{mg}$ or a matching placebo once daily for 3 days, then once weekly for twelve weeks. At baseline patients have MRI, whereas bload was drawn for the assessment of high-sensitivity CRP (hsCRP), $\|$ L-6 and $C$ pneumoniae serology. CCA-IMT could only be 
assessed in the University Hospital Maastricht, therefore, baseline CCA-IMT was assessed in eighty-six patients from the ACSI study. Twelve of these patients were left out from the analysis, because they had an atherosclerotic plaque in the common carotid artery. So CCA-IMT data were available of seventy-four patients.

\section{CCA-IMT measurements}

With high resolution B-mode ultrasonography (SONOS 5500; Philips, Eindhoven, the Netherlands) a longitudinal image of the common carotid artery in the late diastolic phase is obtained. The thickness of the double line pattern of the far wall is estimated manually, and expressed as the mean of 4 separate measurements. The settings of the ultrasound system are identical for all measurements. Special attention is paid to only acquire images that do not exceed the dynamic range of the system.

\section{MRI}

The MRI protocoll included T2 and FLAIR weighted axial images of the brain. The following parameters were scored: location and type of symptomatic lesion; the presence and number of asymptomatic lacunar infarcts in the basal ganglia, internal capsule or pons; the presence and severity of periventricular hyperintensities and white matter hyperintensities in the centrum semi ovale ${ }^{27}$. The MRl's had been scored without knowledge of clinical information. Silent ischaemic brain lesions (SBL) were analysed as a dichotome variable: presence or absence of one or more sillent ischaemic lesions, of white matter lesions (extending peri-ventricular lesions or confluent lesions in the centrum semi ovale), or both. Separate variables were made for right-sided SBL, left sided SBL, and overall presence of SBL.

\section{C-reactive protein}

Venous blood samples drawn on randomisation for the trial were immediately centrifuged for 10 minutes at $1200 \mathrm{rpm}$ and at $4^{\circ} \mathrm{C}$. Serum was stored at $-20^{\circ} \mathrm{C}$ until analysis. CRP was determined highly sensitive (hsCRP) with the IMMULITE CRP method (Diagnostic Product Corporation, Los Angeles, USA). This assay provides a detection limit of $0.10 \mathrm{mg} / \mathrm{l}$ and has been approved by the Food and Drug Administration for clinical use in the United States.

\section{Stimulated cylokines}

Stimulation of mononuclear cells with $C$ pneumoniae induces the production of the inflammatory cytokines TNF $\alpha, I L-6, \quad \mathrm{~L}-1 \beta, \mathrm{IL}-10$ and IFN $\gamma^{28}$. For this 
purpose, whole blood was stimulated with $C$ pneumoniae antigen as follows: $200 \mu l$ of whole blood was added to $750 \mu \mathrm{l}$ of RPMll medium and $50 \mu$ of $C$ pneumoniae antigen ( $3 * 10^{6}$ infection forming units (IFU), ditution 1:20). Control samples consisted of $200 \mu$ of whole blood where $800 \mu$ of RPMI medium was added to. The samples were incubated at $37^{\circ} \mathrm{C}$ for 24 hours (TNF $\alpha, 1 L-6$ and IL-1 $\beta$ ) or 48 hours ( $L-10$ and IFN $\gamma$ ), as described by Netea et al. ${ }^{28}$. After this, the samples were centrifuged and the supernatant was collected and stored for further analysis. Cytokine levels were determined using an enzyme linked immune absorbent assay (ELISA) (eBiosciences, San Diego, USA). ELISA's were performed as instructed by the manufacturer. Briefly, 96wells plates were coated with antigen and kept overnight a $4^{\circ} \mathrm{C}$. The following day, the wells were blocked using the tests assay diluent, after which the standards and patient samples were added and incubated for one hour. A biotinylated capture antigen, HRP for colouring the samples and $\mathrm{H}_{2} \mathrm{SO}_{4}$ as stop solution, followed this.

\section{Measurement of IgG antibodies against $C$ pneumoniae}

Levels of serum $\lg G$ antibodies against $C$ pneumoniae were measured using an ELISA, as described before ${ }^{29}$ (Labsystems, Helsinki, Finland). The presence or absence of $C$ pneumoniae antibodies was determined by comparing the absorbance value of the sample to a cut-off value, as specified by the manufacturer. Specimens with values equal to or greater than 30 were considered positive for anti-Chlamydia antibodies. We also recorded the absolute levels of the $\lg G$ antibody titre.

\section{Statistics}

Non-parametric tests were used to assess mean CCA-IMT values in patients with and without silent brain lesions. Mean levels of right CCA-IMT were assessed in patients with and without right-sided SBL, left sided CCA-IMT in patients with and without left sided SBL. Furthermore, a variable was made with the highest CCA-IMT found in the left or right CCA, and mean values of the highest CCA-IMT were assessed in patients with and without asymptomatic lacunar infarction, leukoaraiosis or both. Spearman correlations tests were used to assess correlations between CCA-IMT and levels of hsCRP. TNF IL-6, IL-1B, IL-10, IFN $\gamma$ and levels of $\| \mathrm{gG}$ antibodies. 


\section{Results}

The patients in this study did not differ from the remainder of the ACSI population, with respect to age, risk factors or seroprevalence for $\lg \mathrm{G}$ antibodies. There were no differences in mean CCA-IMT with regard to the presence of psilateral SBL on the right side $(0.76 \pm 0.18 \mathrm{vs} .0 .76 \pm 0.19)$ or the left side $(0.82 \pm 0.25$ vs. $0.77 \pm 0.17)$. Furthermore, when we compared the highest mean CCA-IMT values of both sides in patients with and without SBL, no differences were found $(0.85 \pm 0.19$ vs. $0.86 \pm 0.21)$. These results are summarized in Table 6.1.

Table 6.1 Mean CCA.IMT values in millimetre (SD in parenthesis) related to asymptomatic ischaemic brain lesions, $\mathrm{SBL}+=$ lesions present, $\mathrm{SBL}$ - = no lesions

\begin{tabular}{lccc}
\hline & SBL + & SBL & P-value \\
\hline Right CCA-IMT $(\mathrm{mm})$ & $0.76(0.18)$ & $0.76(0.19)$ & 0.71 \\
Left CCA-IMT (mm) & $0.82(0.25)$ & $0.77(0.17)$ & 0.62 \\
Highest CCA-IMT values of both left and right CCA (mm) & $0.85(0.19)$ & $0.86(0.21)$ & 0.87 \\
\hline
\end{tabular}

CCA-IMT was associated with age ( $p$-value $<0.05)$. There were no correlations between CCA-IMT levels and levels of TNF $\alpha, I L-6, I L-1 \beta, I L-10$, IFN $\gamma$, hsCRP and IgG antibody titre (table 6.2). There were no differences in CCA-IMT levels between patients with $C$ pneumoniae antibody titre $>30$ (cut-off for seropositivity) and those with titres $<30(0.083 \pm 0.016$ vs. $0.093 \pm 0.030$, $p=0.194)$.

Table 6.2 Top: Spearman correlation coefficients of the correlation between baseline serum levels of IL-6, haCRP, and IgG antibody titre and common carotid intima-media thickness (CCA-MMT)

Bottom: Spearman correlation coefficients of the correlation between cytokine levels in the supernatant of mononuclear cells stimulated with $C$ pneumoniae antigen and CCAIMT.

\begin{tabular}{lcc} 
Baseline serum & CCA-IMT & P-value \\
\hline HsCRP & -0.007 & 0.954 \\
Sertum IL-6 & 0.072 & 0.547 \\
IgG antibody titre & -0.064 & 0.589 \\
Mononuclear cells stimulated with C pneumoniae antigen & & \\
TNFa & & \\
IL-6 & -0.074 & 0.530 \\
IL-19 & 0.229 & 0.056 \\
IL-10 & 0.002 & 0.988 \\
IFNy & -0.060 & 0.613 \\
\hline
\end{tabular}




\section{Discussion}

\section{CCA-IMT, inflammation and SBL.}

In this series of patients with a symptomatic stroke, the CCA-IMT was not related to inflammatory parameters (hSCRP, IL-6, IL-10, $L-1 \beta, I F N \gamma$, and TNF $\alpha$ ). Furthermore the CCA-IMT could not distinguish between a cortical or lacunar syndrome, and no relation was found between CCA-IMT levels and the presence of ischaemic SBL on MRI.

When the relation between CRP levels and CCA-IMT was studied in community based cohort studies, results were conflicting. In two community based studies of over a 1000 individuals without clinical signs of atherosclerosis, CRP was related to CCA-IMT in univariate analysis ${ }^{13.30}$. After correcting for cardiovascular risk factors, the association either weakened ${ }^{13}$, or was no longer present ${ }^{30}$. In a smaller study, including 186 patients, the association was found to be weak, and confined to smokers ${ }^{31}$. Leinonen et al. studied the relation between CCA-IMT and CRP in 239 patients with diabetes type 2 , and 78 healthy controls ${ }^{32}$. CCA-IMT was found to be higher in diabetes patients, than in controls, as were CRP levels. In the diabetes group however, CRP levels and CCA-IMT did not correlate. The association between CCA-IMT and CRP does not seem to be very strong, since it has only been proven in large cohort studies, and is closely related to cardiovascular risk factors. Furthermore, in a small selected group of 239 patients with known cardiovascular risk factors ${ }^{32}$, or with stroke as in our series, the two parameters do not correlate. In the acute phase of stroke, inflammatory parameters rise, thereby obscuring any relationship between CCA-IMT and inflammatory markers. Our patients, however, did not enter the study within three months after stroke, thereby eliminating this confounding factor. The results of our study therefore indicate that within a selected group of patients with a symptomatic stroke, CCA-IMT levels and levels of inflammatory parameters do not correlate. We can of course not exclude a weak association between the two because of the rather small sample size, but at least CCA-IMT does not seem to be a significant marker of endothelial activation in symptomatic cerebrovascular disease patients.

A few studies report on the association between CCA-IMT and stroke $e^{5,7}$, but in these studies no distinction was made between ischaemic and hemorrhagic stroke, or between cortical and lacunar strokes. CCA-IMT is considered as a valid sign for early carotid atherosclerosis, and as such should be more related to ischaemic stroke than to hemorrhagic stroke. This issue was addressed in two studies, which found that CCA-IMT is higher in patients with ischaemic stroke compared to patients with hemorrhagic stroke ${ }^{33,34}$. Different ischaemic stroke subtypes, i.e. cortical and lacunar stroke might be differently associated 
with CCA-IMT, due to differences in vascular pathology. When cardial embolism and rare causes such as dissection are ruled out as the cause of a cortical stroke, carotid atherosclerosis remains one of the main causes. Lacunar infarcts are less frequently associated with carotid atherosclerosis. Therefore, CCA-IMT might be closer related to cortical stroke. In two case control studies CCA-IMT was measured in ischaemic stroke patients, compared to controls, and to subtypes of stroke ${ }^{25,26}$. One study, including approximately 300 patients $^{25}$, found that CCA-IMT values were higher in patients with a cortical stroke, compared to a lacunar stroke; cardial risk factors were identical between the groups. Another study identified stroke type, according to the cause (atherothrombotic, cardioembolic, lacunar, dissection, other rare causes of stroke), and found no differences between these subtypes, in a population of approximately 1000 patients. In our series we did not find any differences in mean CCA-IMT between patients with a cortical and lacunar stroke. CCA-IMT values between cortical and lacunar patients were almost identical, thereby making a clinical relevant association unlikely, even though it was tested in a small population.

Future risk of stroke increases when SBL are present on MRI at first clinical presentation. SBL are closely related to lacunar infarcts, and their underlying pathology is arteriolosclerosis rather than atherosclerosis. Arteriolosclerosis is primarily a hyperplasia of the medial vascular layer, rather than an endothelial mediated vascular lesion. One would expect CCA-IMT not to be related with conditions due to arteriolosclerosis. However, vascular risk factors are identical in patients with and without $\mathrm{SBL}^{24}$, and the severity of SBL might merely reflect more severe generalized vascular pathology. In our patient population, vascular risk factors were not different between patients with and without SBL, and accordingly, we could not find any differences in CCA-IMT values in patients with and without SBL.

\section{Chlamydia pneumoniae serology and CCA-IMT}

We did not find an association between the presence of anti- $C$ pneumoniae antibodies and CCA-IMT. Mean CCA-IMT values were identical in seropositive and seronegative patients, whereas also, the levels of the anti $C$ pneumoniae IgG antibody titres did not correlate with CCA-IMT values. The association between $C$ pneumoniae antibodies and CCA-IMT was mainly investigated in patients without clinical evidence of stroke. A positive association was found in patients with cardiovascular risk factors ${ }^{14}$, but without any clinical signs of cardiovascular disease, and in patients with cardiovascular and peripheral arterial occlusive disease, without stroke ${ }^{15}$. Seroprevalence of antiC pneumoniae lgG antibodies is higher in stroke patients, than in healthy controls, and seroprevalence in our population was $81 \%$, compared to $58 \%{ }^{14}$ 
and $34 \%^{15}$ respectively, in the above mentioned studies. One study investigated CCA-IMT progression over time in stroke patients with and without $C$ pneumoniae antibodies, and found CCA-IMT progression to be related to $C$ pneumoniae seropositivity ${ }^{35}$. Increases in CCA-IMT increase the risk of future cardiovascular disease and stroke ${ }^{5,36-40}$. An increase in CCA-IMT between 0.15 and $0.2 \mathrm{~mm}$ increases the relative risk of stroke $\mathrm{e}^{5.6}$. At this moment, follow up data are lacking in our study, but will be obtained in a later phase. So our data do not exclude an association between baseline levels of inflammation and enhanced CCA-IMT progression.

To conclude, CCA-IMT values are not different in patients with a cortical or lacunar stroke, nor do they differ between patients with and without SBL on $\mathrm{MRI}$, in a population of patients with a symptomatic stroke. Furthermore, CCAIMT is not related to $C$ pneumoniae serology, or inflammatory parameters. 


\section{References}

1. Heiss $G$, Sharrett AR, Barnes R, Chambless LE, Szklo M, Alzola C. Ciarotid atherosclenosis measured by B-mode ultrasound in populations: associations with cardiovascular risk factors in the $A R C$ S study. Am I Epidemiol. 1991;134:250-6.

2. Burke GL, Ewans GW, Riley WA Sharrett AR, Howard G, Barnes RW, Rosamond W, Crow RS, Rautaharju PM, Heiss G. Arterial wall thickness is associated with prevalent cardiovascular disease in middle-aged adults. The Atherasclerosis Risk in Communities (ARIC) Study. Stroke. 1995:26:386-91.

3. Allan PL, Mowbray PI, Lee AJ, Fowkes FG. Relationship between carotid intima-media thickness and symptomatic and asymptomatic peripheral arterial disease. The Edinburgh Artery Study. Stroke. 1997:28:348-53.

4. Salonen $R$, Salonen JT. Progression of carotid atherosclerosis and its determinants: a population-based ultrasonography study. Atherosclerosis. $1990 ; 81: 33-40$.

5. O'Leary DH, Polak JF, Kronma RA, Manolio TA, Burke GL. Wolfson SK, Jr. Carotidl-artery intima and media thickness as a risk factor for myocardial infarction and stroke in older adults. Cardiovascular Health Study Collaborative Research Group. $N$ Engl J Med. 1999:340:14-22.

6. Salonen JT, Salonen R. Ultrasonographically assessed carotid morphology and the risk of coronary heart disease. Arteriascler Thromb. 1991;11:1245-9.

7. Bots ML, Hoes AW, Koudstaal PJ, Hofman A, Grobbee DE. Common carotid intima-media thickness and risk of stroke and myocardial intalction: the Rotterdam Study. Circulation. $1997,96: 1432-7$.

6. Ross R. Atherosclerosis is an inflammatory disease. Am Heart J. 1999;138:S419-20.

9. Van Der Meer M, De Maat MP, Hak AE Killiaan AJ, Del Sol Al, Van Der Kuip DA, Nijhuis RL. Hofman $A$, Witteman $J C$. C-reactive protein predicts progression of atherosclerosis measured at various sites in the arterial tree: the Rotterdam Situdy. Stroke. 2002;33:2750-5.

10. Ridker $P M_{8}$ Cushman $M$, Stampfer MJ, Tracy RP. Hennekens $C H$. Inflammation, aspirin and the risk of cardiovascular disease in apparently healthy men. N Engl J Med. 1997;336:973-9.

11. Ridker PM; Buring JE, Shih J, Matias M, Hennekens $\mathrm{CH}$. Prospective study of C-reactive protein and the risk of future cardiovascular events among apparently healthy women. Cinculation. 1998,98:731-3.

12. Hashimoto $H_{1}$ Kitagawa $K$, Hougaku $H_{\text {, Etani }} H_{4}$ Hori $M$. Relationship between $C$-reactive protein and progression of early carotid atherosclerosis in hypertensive subjects. Stroke. 2004:35:1625-30.

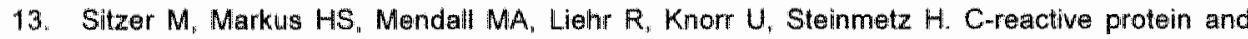
carotid intimal medial thickness in a community population. J Cardiovaso Risk. 2002;9: $97-103$

14. Schmidl $C_{n}$ Hulthe J, Wikstrand J Gnarpe $H_{n}$ Gnarpe J, Agewall S, Fagerberg B. Chiamydia pneumoniae seropositivity is associated with carotid artery intima-media thickness. Stroke. $2000,31: 1526-34$

15. Espinola Klein $C$. Rupprecht $H J$, Blankenberg $S$, Bickel $G$, Kopp $H$, Rippin $G_{3}$ Hafner $G$, Pfeifer $U$, Meyer J. Are morphological or functional changes in the carotid artery wall associated with Chlamydia pneumoniae. Helicobacter pylori, cytomegalovirus, or herpes simplex virus intection? Stroke. 2000;31:2127-33.

16. Cook PJ, Honeyboume D, Lip GYH, Beevers DG, Wise R, Davies AH. Chlamydia pneumoniae antibody titers are significanlly associated with acute stroke and transient cerebral ischemia: the West Birmingham Strolke Project. Stroke. 1998;29:404-10.

17. Elkind MS, Lin IF, Grayston JT, Sacco RL. Chlamydia pneumoniae and the risk of first ischemic stroke: The Northern Manhattan Stroke Study. Stroke. 2000;31:1521.5.

18. Fagerberg $B$, Gnarpe J, Gnarpe H, Agewall $S$, Wikstrand J. Chlamydia pneumoniae but not cytomegalovirus antibodies are associated with future risk of stroke and cardiovascular disease: a prospective study in middle-aged to elderly men with treated hypertension. Stroke. 1999;30:299-305. 
19. Voorend $M$. Faber $C$, van der Ven $A$, Kessels F, Bruggeman $C A$, Lodder $J$. Chlamydia pneumoniae is a likely risk factor for ischemic stroke in young paitients. Joumal of stroke and cerebrovascular diseases. 2004,13:85-91.

20. Wimmer ML, Sandmann Strupp R, Sa . . Wu $P$, Haberl RL. Association of chlamydial infection with cerebrovascular disease. Stroke. 1996;27:2207-10.

21. van Zagten M, Boiten J, Kessels F, Lodder J. Significant progression of white matter lesions and small deep (lacunar) infarcts in patients with stroke. Arch Neurol. 1996;53:650-55.

22. Boon $A_{s}$ Lodder J, Heuts-van Raak L, Kessels F. Silent brain infarcts in 755 consecutive patients with a first-ever supratentorial ischemic stroke. Rellationship with index-stroke subtype, vascular risk factors, and mortality. Stroke. 1994;25:2384-90.

23. Vermeer SE, Prins ND, dien Heijer T. Hofman A, Koudstaal PJ. Breteler MM. Silent brain infarcts and the risk of dementia and cognitive clecline. N Engl 1 Med. 2003;348:1215-22.

24. de Jong $G$, Kessels $F$, Loddeir $J$. Two types of lacunar infarcts: further arguments from a study on prognosis. Stroke. 2002;33:2072-6.

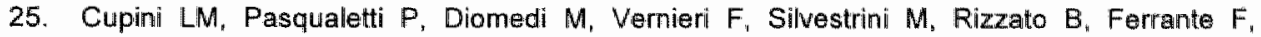
Bernardi $G$. Carotid artery intima-media thickmess and lacunar versus nonlacunar infarcts Stroke. 2002;33:689-94.

26. Touboul PJ, Elbaz A, Koller C, Lucars C, Adrai $V$, Chedru F. Amarenco P. Common carotid artery intima-media thickness and brain infarction: the Etude du Profil Genetique de I'Infarctus Cerebral (GENIC) case-control study. The GENIC Investigators. Circulation. 2000:102:313-8.

27. Schmidt R, Scheltens $P$, Erkinjuntti T, Pantoni L, Markus HS, Wallin A, Barkhof F, Fazekas F. White matter lesion progression: a surrogate endpoint for trials in cerebral small-vessel disease. Neuralogy. 2004:63:139-44.

28. Netea MG, Selzman CH, Kullberg BJ, Galama JM, Weinberg A, Stalenhoef AF, Van der Meer JW, Dinarello CA. Acellular components of Chlamydia pneumoniae stimulate cytokine production in human blood mononuclear cells. Eur J Immunol. 2000;30:541-9.

29. Vainas T, De Graaf R, Stassen FR, Kurvers HA, Grauls GE Kitslaar PJ, Bruggeman CA. Chlamydia pneumoniae serology: comparing a commercial enzyme immunoassay and microimmunofluorescence test in patients with cardiovascular disease. Apmis. 2003;111: 363-9.

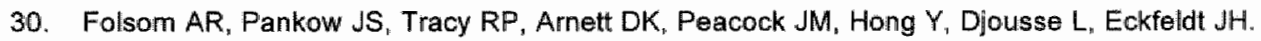
Association of C-reactive protein with markers of prevalent atherosclerotic disease. Am $d$ Cardiol. 2001;88:112-7.

31. Hak AE, Stehouwer CD, Bots ML. Polderman KH, Schalkwijk CG, Westendorp IC, Hofman A, Witteman JC. Associations of C-reactive protein with measures of obesity; insulin resistance, and subclinical atherasclerosis in heaithy, middle-aged women. Arterioscler Thromb Vasc Biol. 1999; 19:1986-91.

32. Leinonen ES, Hiukika A, HurtwCamejo E, Wiklund O, Sarna SS, Mattson Hulten L, Westerbacka $ل$, Salonen RM. Salonem JT, Taskinen MR. Low:grade infiammation, endothelial activation and carotid intima-media thickness in type 2 diabetes. J lotem Mod. 2004;256: 119-27.

33. Vemmos $K N$, Tsivgoulis $G$, Spengas $K$, Papamichenel $C M$, Zakopoulas $N$, Daffertshofer $M$, Lekakis JP. Mavrikakis M. Common carotid artery intima-media thickness in patients with brain infarction and intracerebral haemorrhage. Cerebrovasc Dis. 2004;17:280-6

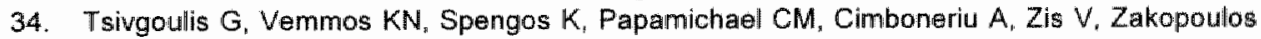
$N$, Mavrikakis $M$. Common carrotid artery intima-media thickness for the risk assessment of lacunar infarction versus intracerebral haemorrhage. Neurol 2005.

35. Sander D, Wimbeck $K$, Klingelhofer J, Etgen $T$, Conrad B. Enhanced progression of early carotid atherosclerosis is related to Chlamydia pneumoniae (Taiwan acute respiratory) seropositivity. Circulation. 2001:103:1390-1395.

36. Chambless LE, Heiss G, Folsom AR, Rosamond W, Szklo My Sharreft AR, Clegg LX. Association of coronary heart disease incidence with carotid arterial wall thickness and major risk factors: the Atherosclerosis Risk in Communities (ARIC) Study, 1987-1993. Am J Epidemiol. 1997;146:483-94: 


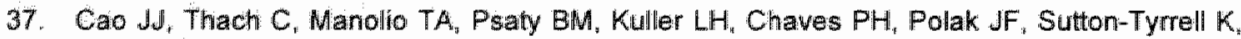
Herringtom DM, Price TR, Cushman M. C-reactive protein, carotid intima-media thickness, and incidence of ischemic stroke in the elderly: the Candiovascular Health Study. Circulation. $2003 ; 108: 166-70$

38. Hollander M, Hak AE, Koudstaal PJ, Bots $\| L_{t}$ Grobbee DE, Hofman A, Witteman JC, Breteler MML Comparison between measures of atherosclerosis and risk of stroke: the Rotterdam Study. Stroke 2003,34,2367-72.

39. Rosvall $M$, Janzon $L$, Berglund $G$, Engstrom $G$, Hedblad $B$. Incidence of stroke is related to carotid IMT even in the absence of plaque. Atherosclerosis. 2005;179:325-31.

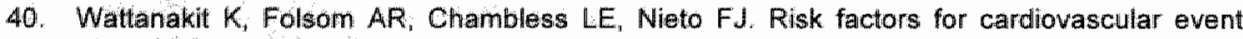
recurrence in the Atherosclerosis Risk in Communities (ARIIC) study. Am Heart $J$ $2005: 149: 606-12$ 


\section{Chapter}

Azithromycin does not change Chlamydia pneumoniae stimulated cytokine production in mononuclear cells of patients with ischaemic cerebral lesions 


\section{Abstract}

\section{Aim of the study}

To investigate the effect of azithromycin on cytokine production of mononuclear blood cells stimulated with Chlamydia pneumoniae.

\section{Patients and methods}

Patients were derived from a study investigating the effect of a three-month course of azithromycin on progression of silent ischaemic brain lesions. The patients were randomised to receive either azithromycin $500 \mathrm{mg}$ or a matching placebo once daily for 3 days, then once weekly for twelve weeks. Whole blood samples of 75 consecutive patients were stimulated with Chlamydia pneumoniae and levels of TNF $\alpha, \mathrm{IL}-6, \mathrm{IL}-1 \beta, \mathrm{IL}-10$, and IFNy were assessed in the supernatant, using an enzyme linked immuno absorbent assay. To assess the ratio between the proinflammatory $T$ helper 1 cells and the anti-inflammatory $T$ helper 2 cells, the IFN $\gamma / L$ - 10 ratio was calculated.

\section{Results}

Stimulation of mononuclear cells with Chlamydia pneumoniae induces cytokine production in these cells. Cytakine levels and IFNy/L-10 ratio at three months post-treatment did not differ between the patients treated with azithromycin or placebo, nor did the changes in cytokine levels.

\section{Conclusions}

A three-month course of azithromycin does not influence cytokine production in mononuclear cells of ischaemic stroke patients, stimulated with Chlamydia pneumoniae. 


\section{Introduction}

Since the early 90's, atherosclerosis is defined as an inflammatory. immunological disorder, developing after endothelial injury". The inflammatory cytokines Interferon gamma (IFN $\gamma$ ), Interleukin-6 (IL-6), Tumour necrosis factor alpha (TNF $\alpha$ ), and IL-1 $\beta$ play a role in the inflammatory response related with atherosclerosis. T-lymphocytes are present in all stages of the atherosclerotic plaque. T-lymphocytes can be divided in the pro-inflammatory $T$ helper (Th) cells 1 and Th2 cells. The Th1 cell induces macrophage activation, leading to the production of IFN $\gamma$, a potent inflammatory cytokine. IL-10 induces Th2 activation, thereby exerting an anti-inflammatory effect by blocking production of $\mathbb{I L}-1 \beta$ and TNF $\alpha^{2}$. In atherogenic mouse models, atherosclerotic lesion development can be stopped by pharmacological blocking of Th1 cells, or through $I L-10$ stimulation ${ }^{3}$. In humans with unstable angina pectoris, lymphocyte activation is towards production of IFN $\gamma$, more than in patients with stable angina pectoris ${ }^{4}$, which indicates that inflammation plays a role in the thrombo-embolic events leading to myocardial infarction.

One of the factors implicated in the pathogenesis of atherosclerosis is infection with intracellular micro-organisms such as the gram-negative bacteria Chlamydia pneumoniae (C pneumoniae). Sero-epidemiological studies reported an association between the presence of anti-Chlamydia antibodies and cardiovascular or cerebrovascular events ${ }^{5-10}$. C pneumoniae is able to infect, replicate and survive in the cells of the vascular wall ${ }^{11-14}$. Low-grade infection of human endothelial results in endothelial dysfunction and the expression of adhesion molecules ${ }^{15}$. Persistent infection of endothelial cells and monocytes in vitro, leads to production of all the above mentioned cytokines $^{16-18}$. Incubation of human mononuclear cells with $C$ pneumoniae induces the production of the pro-inflammatory cytokines $\mathbb{L}-6$, TNF $\alpha$ and $L-1 \beta^{19}$, and $\| L-10^{20}$. Azithromycin has anti-microbial and anti-inflammatory effects $^{21}$, therefore, we expect that treatment with azithromycin results in a diminished inflammatory state.

Our group is performing a double blind, placebo controlled trial investigating the effect of a three-month course of azithromycin on the progression of cerebrovascular lesions in patients surviving a non-cardioembolic ischaemic stroke. The aim of the present study was to investigate whether a three-month course of azithromycin changes cytokine production by mononuclear cells stimulated with $C$ pneumoniae antigen, in an ex-vivo experiment. 


\section{Patients and methods}

\section{Patients}

The patients in this study had been randomised in the ACSI study (Azithromycin for the prevention of the progression of Cerebral ischaemic lesions in patients Surviving a non-cardioembolic cerebral Infarct), which investigates the effect of a three-month treatment schedule of azithromycin on ischaemic cerebral damage progression on magnetic resonance imaging (MRI) measured at two years. The patients were randomised to receive either azithromycin $500 \mathrm{mg}$ or a matching placebo once daily for 3 days, then once weekly for twelve weeks. Blood was drawn at randomisation and at three months, after finishing the course of study medication. Because the final followup of the ACSI trial is not yet completed, deblinding of the patients was not preferred. Therefore, the patients were assigned to two groups ( $A$ and $B$ ), without deblinding the allocated treatment. At the time of data analysis for this study, it was not known which group was verum or placebo.

\section{Stimulation of cytokine production}

From 75 consecutive patients, whole blood was stimulated with $C$ pneumoniae antigen as follows: $200 \mu \mathrm{l}$ of whole blood was added to $750 \mu$ l of RPMI medium and $50 \mu \mathrm{ll}$ of $\mathrm{C}$ pneumoniae antigen $\left(3 * 10^{6}\right.$ infection forming units (IFU), dilution 1:20). Mock stimulated samples consisted of $200 \mu \mathrm{l}$ of whole blood added to $800 \mu$ of RPMI medium. The samples were stimulated for 24 hours (TNF $\alpha$, IL-6 and IL-1 $\beta$ ) or 48 hours (IL-10 and IFN $\gamma$ ), as described by Netea et al. ${ }^{19}$. After this, the samples were centrifuged and supernatant was collected and stored at $-80^{\circ} \mathrm{C}$ for further analysis.

\section{Measurement of cytokines}

Levels of cytokines were determined using an enzyme linked immuno absorbent assay (ELISA) (eBiosciences, San Diego, USA). ELISA's were performed as instructed by the manufacturer. Briefly, 96-wells plates were coated with coating antigen and kept overnight a $4^{\circ} \mathrm{C}$. The following day, the wells were blocked using the tests assay diluent, after which the standards and patient samples were added and stimulated for one hour. A biotinylated capture antigen, horseradish peroxidase for colouring the samples and $\mathrm{H}_{2} \mathrm{SO}_{4}$ as stop solution, followed this. 


\section{C-reactive protein}

Venous blood samples drawn on randomisation for the trial were immediately centrifuged for 10 minutes at $1200 \mathrm{rpm}$ and at $4^{\circ} \mathrm{C}$. Serum was stored at $-20^{\circ} \mathrm{C}$ until analysis. CRP was determined highly sensitive (hSCRP) with the IMMULITE CRP method (Diagnostic Product Corporation, Los Angeles, USA). This assay provides a detection limit of $0.10 \mathrm{mg} / \mathrm{L}$ and has been approved by the Food and Drug Administration for clinical use in the United States.

\section{Measurement of $\lg G$ antibodies against $C$ pneumoniae}

Levels of serum lgG antibodies against $C$ pneumoniae were measured using an ELISA, as described before ${ }^{22}$. (Labsystems, Helsinki, Finland). The presence or absence of $C$ pneumoniae antibodies was determined by comparing the absorbance value of the sample to a cut-off value, as specified by the manufacturer. Specimens with values equal to or greater than 30 were considered positive for anti-Chlamydia antibodies.

\section{Statistics}

Since the levels of the cytokines were skewed, non-parametric tests were used. Mean levels of cytokines produced in $C$ pneumoniae stimulated cells were compared to mean levels of cytokines produced by mock stimulated cells, at baseline, as well as after three months. We assessed differences in cytokines at three months between patients treated with azithromycin or placebo. A variable was made to assess the differences in cytokine levels after three months compared with baseline values (levels at three months - levels at baseline). We used a non-parametric test to assess the mean differences these changes, in the azithromycin group and the placebo group. In a linear regression model associations were tested between changes in cytokine levels after three months, with sex, current smoking, hypertension, age, cardiovascular disease, hypercholesterolaemia, peripheral arterial occlusive disease, the presence of $C$ pneumoniae antibodies and baseline hsCRP levels. A p-value of $<0.05$ was considered significant. Results were given as mean values and the standard deviation.

\section{Results}

The patient groups were designated group $A$ and $B$, without knowledge which one of these groups is verum or placebo. The patients in this study did not differ from the remainder of the ACSI population, with respect to age and cardiovascular risk factors; only seroprevalence for lgG antibodies was higher 
in the study group ( $89 \%$ vs. $81 \%$ ), but this was not statistically significant. Patient characteristics are listed in Table 7.1. At baseline, as well as at three months cytokine levels of the $C$ pneumoniae stimulated cells were significantly higher than in the mock stimulated cells (Table 7.2). There were no significant differences in levels of TNF $\alpha, I L-6, I L-1 \beta, / L-10$, IFN $\gamma$ and IFN $\gamma / I L-10$ ratio in the supernatant of $\mathrm{C}$ preumoniae stimulated cells, between the two patient groups (Table 7.3). Furthermore, we found no significant differences in changes in the levels of TNF $\alpha, \| L-6, I L-1 \beta, I L-10$ IFN $\gamma$ and IFN $\gamma / L-10$ ratio, in the supernatant of $C$ pneumoniae stimulated celis, between the two patient groups, after three months of treatment. (Table 7.4). No differences were found in cytokine levels, and differences in cytokine levels, in the supernatant of mock stimulated cells, between the two patient groups (data not shown).

In a multiple linear regression model using the cytokines as the dependent variable and sex, current smoking, hypertension, age, cardiovascular disease, hypercholesterolaemia, peripheral arterial occlusive disease, allocated treatment, $C$ pneumoniae serology and baseline hsCRP as independent variables, we only found an association between differences in TNF $\alpha$ levels at three months and baseline $C$ pneumoniae serology.

Table 7.1 Baseline characteristics befween the two treatment groups.

\begin{tabular}{lcc}
\hline Characteristics $^{3}$ & $\mathrm{~A}(\mathrm{~N}=39)$ & $\mathrm{B}(\mathrm{N}=36)$ \\
\hline Age (years) & $62.41 \pm 8.74$ & $62.35 \pm 9.87$ \\
Sex (male) & $25(64)$ & $26(72)$ \\
Smoking & $16(41)$ & $9(25)$ \\
Hypertension & $19(51)$ & $14(40)$ \\
Diabetes & $1(2.6)$ & $1(2.8)$ \\
Hypercholesterolaemia & $10(26)$ & $7(19)$ \\
Cardiovascular disease & $5(13)$ & $2(6)$ \\
Peripheral arterial disease & $4(10.3)$ & $0(0)$ \\
C pheumoniae antibodies & $39(100)$ & $28(78)$ \\
HsCRP (mg/i) & $3.45 \pm 3.57$ & $3.84 \pm 5.21$ \\
\hline
\end{tabular}

${ }^{a}$ walues are expressed as number (percentage); ${ }^{b}$ values are expressed as mean \pm standard deviation 
Table 7.2 Cytokine levels in supernatant of mononuclear cells stimulated with $C$ pneumonia antigen or mock stimulated (all patients combined).

\begin{tabular}{|c|c|c|c|}
\hline Cytokines: $^{a}$ & C pheumoniae stimulated & RPNII stimulated & P-value \\
\hline \multicolumn{4}{|c|}{ TNF } \\
\hline Baseline & $22.66 \pm 89.22$ & $0.36 \pm 1.71$ & $<0.05$ \\
\hline 3 months & $62.45 \pm 150.20$ & $0.28 \div 1.63$ & $<0.01$ \\
\hline \multicolumn{4}{|l|}{$\| L-6(\mathrm{pg} / \mathrm{ml})$} \\
\hline Baselline & $105.28 \pm 74.33$ & $4.94 \pm 25.89$ & $<0.011$ \\
\hline 3 months & $82.53 \pm 75.40$ & $11.38 \pm 39.11$ & $<0.01$ \\
\hline \multicolumn{4}{|l|}{$1 \mathrm{~L}-1 \beta(\mathrm{pg} / \mathrm{ml})$} \\
\hline Baselline & $91.36 \pm 131.71$ & $3.86 \pm 26.92$ & $<0,011$ \\
\hline 3 months & $115.26 \pm 163.44$ & $4.09 \div 12.17$ & $<0.01$ \\
\hline \multicolumn{4}{|l|}{$\| \mathrm{L}-10(\mathrm{pg} / \mathrm{ml})$} \\
\hline Baseline & $23,11 \pm 53.98$ & $0.40 \pm 1.77$ & $<0.01$ \\
\hline 3 months & $29.62 \pm 61.17$ & $0.35 \pm 2.84$ & $<0.01$ \\
\hline \multicolumn{4}{|l|}{$\mathbb{I F N}(\mathrm{pg} / \mathrm{mll})$} \\
\hline Baseline & $48.66 \pm 109.47$ & $0.65 \pm 3.81$ & $<0.01$ \\
\hline 3 months & $86.07 \pm 167.04$ & $1.05 \pm 4.98$ & $<0.01$ \\
\hline
\end{tabular}

* values are expressed as mean \pm standard deviation; p-values for the comparison of $C$ pneumoniae stimulated and mock stimulated cells.

Table 7.3 Cytokine levels of the $C$ pneumoniae stimulated cells of patient in groups $A$ and $B$, three months after treatment with either azithromycin or placebo.

\begin{tabular}{|c|c|c|c|}
\hline Cyltokines $^{a}$ & $\begin{array}{c}\text { Treatment groups } \\
\text { A }\end{array}$ & $\mathrm{B}$ & P-value \\
\hline TNFo $(\mathrm{pg} / \mathrm{m} /)$ & $57.02 \pm 147.66$ & $68.33 \pm 154.78$ & 0.64 \\
\hline $\mid L-6(p g / m /)$ & $78.08 \pm 79.79$ & $87.85 \pm 71.01$ & 0.68 \\
\hline $\mid \mathrm{L}-1 \beta(\mathrm{pg} / \mathrm{ml})$ & $122.75 \pm 174.50$ & $107.57 \pm 153.70$ & 0.99 \\
\hline$\| l=10(\mathrm{pg} / \mathrm{ml})$ & $26.93 \pm 60.98$ & 32.55 t 62.15 & 0.54 \\
\hline $\mathbb{I F N y}(\mathrm{pg} / \mathrm{ml})$ & $48.50 \pm 82.29$ & $126.16 \pm 221.82$ & 0.87 \\
\hline$\| F N y / L-10$ ratio & $0.07 \pm 0.24$ & $0.36 \pm 1.12$ & 0.73 \\
\hline
\end{tabular}

${ }^{8}$ values are expressed as mean \pm standard deviation; $p$-value for the comparison of the treatment groups

Table 7.4 Differences in changes of levels ${ }^{b}$ af cytokines levels of the $C$ proumoniae stimulated in both treatment groups.

\begin{tabular}{|c|c|c|c|}
\hline Cytokines $^{a}$ & A & B & P-value \\
\hline TNF $\alpha(\mathrm{pg} / \mathrm{ml})$ & $42.65 \pm 25.49$ & $36.69 \pm 34.17$ & 0.88 \\
\hline$\| 1-6(\mathrm{pg} / \mathrm{ml})$ & $-22.21 \pm 15.50$ & $22.42 \pm 18.37$ & 0.76 \\
\hline $\mathbb{I L}-1 \beta(\mathrm{pg} / \mathrm{ml})$ & $45.99 \pm 33.68$ & $24.10 \pm 34.09$ & 0.65 \\
\hline $11-10(\mathrm{pg} / \mathrm{ml})$ & $5.56 \pm 11.18$ & $4.87 \pm 16.17$ & 0.97 \\
\hline IFN $(\mathrm{pg} / \mathrm{ml})$ & $32.01 \pm 23.99$ & $34.58 \pm 79.90$ & 0.98 \\
\hline IFN/IL-10 ratio & $0.04 \pm 0.05$ & $0.24 \pm 0.26$ & 0.65 \\
\hline
\end{tabular}

- values are expressed as mean \pm standard deviation; ${ }^{b}$ changes in levels are: levels at three months - levels at baseline, negative values indicate that levels at three months were lower than levels at baseline. 


\section{Discussion}

This is the first study to relate cytokine production by mononuclear cells stimulated ex-vivo with $C$ pneumoniae, of ischaemic stroke patients, after treatment with azithromycin or placebo. When we compared cytokine levels and the IFN $\gamma / L$ L-10 ratio after three months in both treatment groups, we found no differences. Because of the small population size, we also compared cytokine levels between the two groups over time, i.e. before and after treatment, and found no differences. We conclude that azithromycin does not influence cytokine production in mononuclear cells stimulated with $C$ pneumoniae antigen.

Linear regression analysis, when adjusted for vascular risk factors, age, treatment and $C$ pneumoniae serology, only showed that the difference in change in TNF $\alpha$ levels over time, was related to $C$ pneumoniae serology. The difference between TNF $\alpha$ levels at three months and baseline was greater in patients without $C$ pneumoniae antibodies. A possible explanation for this might be the fact that the distribution of $C$ pneumoniae antibodies between the two groups was disproportionate, with $100 \%$ seropositivity in group A versus $78 \%$ seropositivity in group B. Several studies have shown that TNF $\alpha$ levels are higher in patients with $C$ pneumoniae antibodies, than in patients without $C$ pneumoniae antibodies ${ }^{23-25}$. In our population, however, baseline TNF $\alpha$ levels between seropositive and seronegative patients were not different, nor were TNF $\alpha$ levels after treatment. The relation of TNF $\alpha$ levels with $C$ pneumoniae serology might therefore be purely coincidental.

If $C$ pneumoniae infection plays a specific role in cytokine production, mononuclear cells of patients with $C$ pneumoniae antibodies might be more triggered to produce cytokines when stimulated with $C$ pneumoniae. Treatment of $C$ pneumoniae infection with azithromycin, might subsequently reduce the trigger to cytokine production, leading to lower levels of these cytokines. In our study population, $89 \%$ of the patients were seropositive, and no differences in cytokine levels after three months between the two treatment groups were found. A limitation in this fact is that our sample size is small. However, cytokine levels between the two treatment groups were almost identical after three months, thereby making an association unlikely, even though it was tested in a small population. The effect of azithromycin on levels of inflammation in ischaemic stroke patients has never been tested before. In three small studies, with sample sizes smaller than in our study, the effect of azithromycin on endothelial function and activation was tested. One of these studies found a positive effect of azithromycin on endothelial function ${ }^{26}$, whereas the other two did not ${ }^{27.28}$. All in all, our results do not plead for a specific role of $C$ pneumoniae infection on cytokine production of mononuclear cells. Cytokine production of mononuclear cells might be triggered as the result 
of a more aspecific effect of inflammation in general as opposed to a specific effect of $c$ pneumoniae. The role of inflammation in atherosclerosis is underlined by the fact that T-lymphocytes present in the atherosclerotic plaque are mostly the inflammatory Th1 type, with only a small number of antiinflammatory $T h 2$ cells ${ }^{29}$. Azithromycin has anti-inflammatory effects as well as antimicrobial effects ${ }^{21}$, and attenuation of the inflammatory response in general might therefore affect cytokine production, and the Thy/Th2 balance, which is reflected in the IFN $\gamma /$ LL-10 ratio. However, the IFN $\gamma /$ LL-10 ratio did not differ between patients treated with azithromycin or placebo, nor was there a difference in change of the ratio after treatment, suggesting that azithromycin does not influence the inflammatory response, after three months. In the ACADEMIC study, treatment of patients with cardiovascular disease with azithromycin in a dose similar to our study, did not reduce levels of IL-6 and $\mathrm{IL}-1 \beta$ after three months, but reduced levels were seen affer six months suggesting a more delayed effect of azithromycin in levels of inflammation ${ }^{30}$.

In summary: stimulation of mononuclear cells with $C$ pneumoniae leads to cytokine production of these cells. A three-month course of azithromycin does not influence cytokine production in mononuclear cells of ischaemic stroke patients, stimulated with $C$ pneumoniae, nor does it influence the IFNy/IL-10 ratio, after three months. Therefore, we conclude that induction of cytokine production is not affected by treatment with azithromycin. 


\section{References}

1. Ross $R$. The pathogenesis of atherosclerosis: a perspective for the 1990s. Nature. $1993,362: 801-9$.

2. Daugherty $A_{1}$ Rateri $D L$. T Iymphocytes in atherosclerosis: the yin-yang of Th1 and Th2 influence on lesion formation. Ciro Res. 2002;90:1039-40.

3. Laurat $E$, Poirier $B$, Tupin $E$, Caligiuri $G$, Hansson GK, Bariety J, Nicoletti $A$. ln vivo downregulation of $T$ helper cell 1 immune responses reduces atherogenesis in apolipoprotein E-knockout mice. Circulation. 2001;104:197-202.

4. Liuzzo G, Goronzy JJ, Yang H, Kopecky SL, Holmes DR, Frye RL, Weyand CM. Monoclonal Tweell proliferation and plaque instability in acute coronary syndromes. Circulation. $2000 ; 101 ; 2883-8$.

5. Saikku P, Leinonen M. Mattila K, Ekman MR, Nieminen MS, Makela PH, Huttunen JK, Valtomen $V$. Senologicall evidence of an association of a nowel Chlamydia, TWAR with chronic coronary heart disease and acute myocardial infarction. Lancet. 1988;2:98,3-6.

6. Cook PJ, Honeybourne D, Lip GYH, Beevers DG, Wise $R_{n}$ Davies AH. Chlamydia pneumoniae antibody titers are significantly associated with acute stroke and transient cerebral ischemia: the West Birmingham Stroke Project. Stroke. 1998;29:404-10.

7. Elkind MS, Lin IF, Grayston JT, Sacco RL. Chlamydia pneumoniae and the risk of first ischemic stroke: The Northern Manhattan Stroke Study. Stroke. 2000;31:1521-5.

8. Fagerberg B, Gnarpe J, Gnarpe H, Agewall $S$, Wikstrand J. Chlamydia pneumoniae but not cytomegalovirus antibodies are associated with future risk of stroke and cardiovascular disease: a prospective study in middle-aged to elderly men with treated hypertension. Stroke. 1999;30:299-305.

9. Voorend $M_{*}$ Faber $C$, van der Ven $A$, Kessels $F$, Bruggeman $C A$, Lodder J. Chlamydia pneumoniae is a likely risk factor for ischemic stroke in young patients. Joumal of stroke and cerebrovascular diseases. 2004;13:85-91.

10. Wimmer ML, Sandmann Strupp R, Saikku P, Haberl RL. Association of chlamydial infection with cerebrovascular disease. Stroke. 1996;27:2207-10.

11. Coombes BK, Mahony JB. Chlamydia pneumoniae infection of human endothelial cells induces proliferation of smooth muscle cells via an endothelial cell-derived soluble factor(s). Infect Immun. 1999;67:2909-15.

12. Fryer RH, Schwobe EP: Woods ML, Rodgers GM. Chlamydia species infect human vascular endothelial cells and induce procoagulant activity. . Investig Med. 1997;45:168-74.

13. Gaydos CA, Summersgill JT, Sahney NN, Ramirez JA, Quinn TC. Replication of Chlamydia pneumoniae in vitro im human macrophages, endothelial cells, and aortic artery smooth muscle cells. Infect limmun. 1996,64:1614-20.

14. Kaukoranta Tolvanen SS, Laitinen $K$ Saikku $P_{n}$ Leinonen M. Chlamydia pneumoniae multiplies in human endothelial cells in vitro. Microb Pathog. 1994;16:313-9.

15. Kaukoranta Tolvanen SS, Ronni T, Leinonen M, Saikku P, Laitinen K. Expression of adhesion molecules on endothelial cells stimulated by Chilmydia pneumoniae. Micrab Pathog. $1996: 21: 407-11$.

16. Rodel J, Woylas $M$, Groh $A$, Schmidt $K H$, Hartmann M, Lehmann $M$, Straube E. Production of basic fibroblast growth factor and interleukin 6 by human smooth muscle cells following infection with Chlamydia pneumoniae. Infect Immun. 2000;68:3635-41.

47. Gaydos CA. Growth in vascullar cells and cytokine production by Chlamydia pneumoniae. $J$ Infect Dis. 2000;181 Suppl 3:\$473-8.

18. Caspar-Bauguil $S$, Puissant $B$, Nazzal D, Lefevre $J C$, Thomsen $M$, Salvayre $R$, Benoist $H$. Chlamydia pneumoniae induces interleukin-10 production that down-regulates major histocompatibility complex class I expression. J Infect Dis. 2000;182:1394-401.

19. Netea MG, Selzman $C H$, Kullberg BJ, Galama JM, Weinberg A, Stalenhoef AF, Van der Meer JW. Dinarello CA. Acellular components of Chlamydia pneumoniae stimulate cytokine production in thuman blood mononuclear cells. Eur J Immunol. 2000;30:541-9. 
20. Geng $Y$, Shane RB, Berencsi $K$, Gonczal E, Zaki MH, Margolis DJ, Trinchieri G, Rook AH. Chlamydia pneumoniae inibibits apoptosis in human peripheral blood mononuclear cells through induction of IL-10. J Immunol. 2000;164:5522-9.

21. Amsden GW. Anti-inflammatory effects of macrolideswan underappraciated benefit in the treatment of community-acquired respiratory tract infections and chronic inflammatory pulmonary conditions? I Antimicrob Chemother. 2005;55; $10-21$.

22. Vainas $T$, De Graaf $\mathbb{R}_{n}$ Stassen $F R$, Kurvers $H A$, Grauls $G E$, Kitslaat PJ, Bruggeman $C A$. Chlamydia pneumoniae serology: comparing a commercial enzyme immunoasiay and microimmunofluorescence test in patients with cardiovascular disease. Apmis. 2003;11: 363-9.

23. Bruunsgaard $H$, Ostergaard $L$, Andersen-Ranberg $K$, Jeune $B$, Pedersen $B K$. Proinflammatory cytokines, antibodies to Chlamydia pneumoniae and age-associated diseases in Danish centenarians: is there a link? Scand J Infect Dis. 2002,34:493-9.

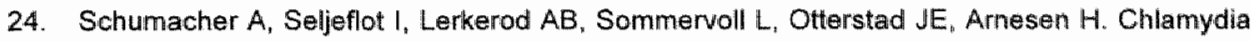
LPS and MOMP seropositivity are associated with different cytokine profilles in patients with coronary heart disease. Eur J Clin Invest. 2005;35:431-7.

25. Blanc $P_{\text {, Corsi }} \mathrm{AM}_{n}$ Gabbuti $A_{4}$ Peduzzi $C$, Meacci $F$, Olivieri $F$, Lauretani $F_{t}$ Francesco $M$, Ferrucci L. Chlamydia pneumoniae seropositivity and cardiovascular risk factors: The InCHIANTI Study. I Am Geriatr Soc 2004;52:1626-31.

26. Parchure N, Zouridakis EG, Kaski JC. Effect of Azithromycin treatment on endothelial function in patients with coronary artery disease and evidence of Chlamydia pneumoniae infection. Circulation. 2002:105:1298-303.

27. Kuvin JT, Gokce N, Holbirook M. Hunter LM, Patel AR, Sliney KA, Craven DE, Grayston JT, Keaney JF, Jr, Karas RH, Vita JA. Effect of short-term antibiotic treatment on Chlamydia pneumoniae and peripheral endothelial function. Am J Cardiol. 2003;91:732-5.

28. Semaan HB, Gurbel PA, Anderson JL, Muhtestein JB, Carlquist JF, Horne BD, Serebruary $V L$. The effect of chronic azithromycin therapy on soluble endothelium-derived adhesion molecules in patients with coronary artery disease. J Cardiovasc Pharmacol. 2000,36:533-7.

29. Benagiano M, Azzurri A, Ciervo $A_{*}$ Amedei $A_{\text {, Tamburini }} C_{n}$ Ferrari $M$, Telford JL, Baldari $C T$, Romagnani S, Cassone A, D'Elios MM, Del Prete $G$. T helper type 1 lymphocytes drive inflammattion in human atherosclerotic lesions. Proc Natl Acad Sci U S A. 2003:100:6658-63.

30. Anderson JL, Muhlestein JB, Carlquist J, Allen A, Trehan $S$, Nielson $C_{n}$ Hall S, Brady J, Egger M. Horne B, Lim T. Randomized secondary prevention trial of azithromycin in patients with coronary artery disease and serolagical evidence for Chlamydia pneumoniae infection: The Azithromycin in Coronary Artery Disease: Elimination of Myocardial Infection with Chlamydia (ACADEMIC) situdy. Circulation. 1999;99:1540-7. 
100 


\section{Chapter 8}

General discussion 
102 Chapter 


\section{General discussion}

Although the role of $\mathrm{C}$ pneumoniae infection in atherosclerosis and clinical vascular events has been extensively investigated, final judgement has not passed yet. It is still unknown whether the presence of $C$ pneumoniae is coincidental, or if there is a causal relationship.

This thesis addresses the question whether there is a role for $C$ pneumoniae infection in ischaemic stroke, by means of an animal experiment, neuropathologilcal examinations of post mortem brain tissue and four clinical studies on the association between $C$ pneumoniae antibody titres, inflammatory parameters, common carotid artery intima-media thickness and ischaemic cerebral lesions.

In 1886, Koch postulated his criteria to prove the involvement of a micraorganism in a specific disease, which were: 1) the pathogen must be present in (nearly) all cases of the disease, 2) the pathogen must be isolated from the host with the disease, and grown in pure culture, 3) the specific disease must be produced when a pure culture of the pathogen is inoculated in a healthy susceptible host, 4) the bacteria must be recoverable from the experimentally infected host. Koch's postulates have some limitations, for instance the effect of therapy is not taken into account, but they can still be used as a footing to discuss the role of $C$ pneumoniae in ischaemic stroke.

Initial evidence of infection with $C$ pneumoniae in individuals with ischaemic stroke comes from serological studies. The presence of Immunoglobulin (lg) $\mathrm{G}$ and $\lg A$ was assessed in a stroke population and compared to healthy controls $^{1.7}$. In a small population of young people with ischaemic stroke, we found anti- $C$ pneumoniae $\lg A$ antibodies more often in stroke patients than in healthy controls. In the past, the presence of $\lg A$ antibodies was believed to reflect chronic persistent $C$ pneumoniae infection, but it has not been validated as such yet ${ }^{8}$. Criteria have been posted only for acute infection (IgM>1:16, or a four fold increase in $\lg G$ ) and presumed past infection (lgG>1:16), using the microimmunofluorescence (MIF) test. Using these criteria, seroprevalence is very high, and it rises with age ${ }^{9}$. In the population of young people with stroke (mean age 44 years), seroprevalence for IgG was $69 \%$, compared to $81 \%$ in the population of the ACSI trial (mean age 64 years). As the presence of antibodies only reflects past infection, proving the role of $C$ pneumoniae in clinical ischaemic stroke also requires detection of the presence of the microorganism in the vascular wall of the cerebropetal or cerebral vessels. Positive antibody titres do "not reflect vascular infection, as the presence of $C$ pneumoniae is not always demonstrated in the vascular wall of patients with a positive antibody titre ${ }^{10}$. Collection of atherosclerotic material during life is nearly impossible, and is only available from the internal carotid artery fragments obtained during carotid endarterectomy, this reflects only a small 
selected group of stroke patients, as approximately $10 \%$ of the ischaemic stroke population requires carotid endarterectomy. The presence of C pneumoniae in the larger intracerebral vessels can only be investigated postmortem as described in chapter 4 . We failed to establish the presence of C pneumoniae in large intracerebral vessel samples, although all the vessels had signs of atherosclerosis varying from intima fibrosis to fully developed atherosclerotic plaques with calcifications. C pneumoniae was only found in one sample of the basal ganglia. A limitation to these results might be that the cases were not stroke patients. However, another study on the presence of $C$ pneumoniae in cerebral arteries found no differences between stroke patients and controls ${ }^{11}$. Further reports on the presence of $C$ pneumoniae in intracerebral vessels have been scarce, in the mere three reports prevalence rates varied from $0-66 \%{ }^{12-14}$. The presence of $C$ pneumoniae within the vessel wall was reported to be very patchy, and consequently "false negative results could emerge ${ }^{15}$. Differences in methodology between these studies account in part for the variable results. However, even taken that into account, the results of the serological and pathological studies do not meet Koch's first postulate of infection. Proving the second postulate is difficult in the case of $C$ pneumoniae, as the micro-organism is very hard to culture. However, in one study C pneumoniae was isolated from a atherosclerotic coronary artery and successfully cultured ${ }^{16}$, in a later study, $C$ pneumoniae was isolated from $16 \%$ of coronary artery specimens ${ }^{17}$.

For obvious reasons, Koch's third and fourth postulate (the specific disease must be produced when a pure culture of the pathogen is inoculated in a healthy susceptible host, and the bacteria must be recoverable from the experimentally infected host) can only be investigated in animal studies. Cpnewmoniae infection accelerates atherosclerosis progression in Apolipoprotein $E$ deficient mice ${ }^{18}$, and early atherosclerotic lesions are seen in the aorta of rabbits infected with $C$ pneumoniae ${ }^{19}$. In the infected animals the presence of $C$ pneumoniae could be established in the vascular wall by polymerase chain reaction and immunohistochemistry. In our study we proved that intraperitoneal injection of $C$ pneumoniae leads to cerebral infection, thereby proving haematogenic dissemination of $C$ pneumoniae into the brain. In the mouse type with extensive atherosclerosis, cerebral C pneumoniae infection leads to enhanced microglial activation. Microglial activation has been indicated as a key factor in neurodegenerative and neuroinflammatory disorders such as Alzheimer's disease and Multiple Sclerosis ${ }^{20}$ and is associated with chronic cerebral ischaemia. Therefore, it can be hypothesized that $C$ pneumoniae infection might play a role in these conditions. These observations indicate a role for $C$ pneumoniae infection in the initiation and acceleration of the atherosclerotic process and (ischaemic) cerebral damage in an animal model. Extrapolation to the human situation, 
however, is difficult. Furthermore, although extensive atherosclerosis is found in these animals, a trombo-embolic event such as myocardial infarction or cerebral infarction has not been investigated in these animal models. With animal models, therefore the third and fourth of Koch's postulates may be proved, but as said before, extrapolation to the human situation is virtually impossible. Therefore it is difficult to assess causal relationship of $C$ pneumoniae infection and stroke, using Koch's postulates. Furthermore, the role of $C$ pneumoniae in stroke may not be a specific quality of $C$ pneumoniae, as the risk of ischaemic stroke is associated with infection in general, especially infections occurring several weeks before the stroke ${ }^{21}$. However, as opposed to other micro-organisms, $C$ pneumoniae has the ability to remain inside the host in a chronic state, thereby causing a continuous state of low grade inflammation. This leads to increased levels of inflammatory agents such as $\mathrm{C}$ reactive protein (CRP) and inflammatory cytokines such as Interleukin-6 (IL-6), TNF $\alpha$, or IL-1 $\beta$. Increased levels of CRP and IL-6 are associated with increased stroke risk in apparently healthy people ${ }^{22.23}$, and CRP levels are higher in stroke patients compared to healthy controls ${ }^{24}$. However, different types of stroke can be identified, with different types of vascular pathology and different risk of recurrent stroke ${ }^{25}$. If levels of inflammatory agents differ between the different types of stroke this might have implications for eventual secondary prevention. Our study of CRP and different cytokines in a stroke population revealed no differences in inflammatory parameters between cortical infarcts and lacunar infarcts. Furthermore, levels of inflammation were not associated with the presence of silent ischaemic brain lesions. So, even though CRP and IL-6 levels might identify patients at risk of stroke, they cannot differentiate between types of stroke, and might not be able to identify patients with a higher risk of recurrent stroke. So there seems to be no specific role of C pneumoniae in cerebral atherosclerosis. In large cohort trials, CRP levels have been associated with carotid intima-media thickness (IMT) ${ }^{26,27}$. Other studies report an association between the presence of anti Chlamydia antibodies and IMT. The IMT is regarded as an early sign of carotid atherosclerosis, and $C$ pneumoniae could also contribute to stroke risk through this mechanism. The relation between IMT and risk of stroke however has been investigated in large cohort studies and the usefulness of IMT levels in the individual patient has not been established yet "nor is it evident whether IMT is a useful predictive parameter in stroke patients. In our stroke population we could not relate IMT to CRP or any of the tested cytokines, nor to $C$ pneumoniae serológy. Furthermore IMT values did not differ between stroke types. So, again using a marker of generalized atherosclerosis, we were unable to detect any specific role of $C$ pneumoniae.

However, if a role for $C$ pneumoniae infection in stroke is still assumed, treatment with antibiotics against $C$ pneumoniae should be effective in the 
secondary prevention of stroke. This has been tested for cardiovascular disease and peripheral arterial occlusive disease. The available evidence points in different directions, with some studies finding a reduction in clinical cardiovascular events in patients treated with antibiotics ${ }^{28.29}$, whereas others found no differences between treatment or placebo ${ }^{30-32}$. Studies that reported a reduction in vascular events were small with a limited duration of follow up. Two larger studies, including over 10000 patients, reported no significant reduction in clinical vascular events in patients treated for either three months $^{30}$ or one year ${ }^{31}$. The effect of antibiotic treatment can also be tested using non-clinical endpoints, i.e. surrogate endpoints. These trials require a smaller sample size and are therefore easier to perform. Most of these studies found no effect of antibiotic treatment in endothelial markers such as adhesion molecules $^{33.34}$; one study found a reduction in E-selectin accompanied by improved endothelial function ${ }^{35}$. Carotid IMT is often used as a surrogate endpoint in clinical trials. The antibiotic roxithromycin has been proven to reduce progression of carotid IMT at two years of follow up, and therefore might lower future risk of stroke and cardiovascular events in stroke patients seropositive for $C$ pneumoniae ${ }^{36}$. This effect, however, proved to be temporarily, at three and four years of follow up increase in carotid IMT was equal to the situation before therapy ${ }^{37}$. Inflammatory parameters such as CRP and IL-6 have were used as a secondary endpoint in the ACADEMIC trial, which only found a decrease in inflammatory parameters three months after the end of the study medication ${ }^{38}$. In our stroke population we investigated whether treatment with azithromycin influences the ability of mononuclear cells to produce cytokines after stimulation with $C$ pneumoniae. Azithromycin did not change cytokine levels after a three-month treatment course. Several considerations have to be made in assessing the effect of antibiotics on clinical vascular events such as stroke. C pneumoniae has proven to be very resistant to antibiotic treatment in vitro ${ }^{39}$, and long term treatment with antibiotics do not fully eliminate $C$ pneumoniae from circulating human monocytes ${ }^{40}$. So even long term treatment with antibiotics such as in the ACES study ${ }^{31}$ (one year) might not be sufficient to fully eradicate $C$ pneumoniae. In fact, the addition in secondary prevention from antibiotics might only come when they are used life long, such as platelet aggregation inhibitors and statins, raising the problem of antibiotic resistance. Furthermore, in animal studies the effect of azithromycin is only seen when the antibiotic is administered just after infection, something that is not possible in the human situation.

This thesis addresses the question whether there is a role for $C$ pneumoniae infection in ischaemic stroke in almost any aspect. Our animal study showed that $C$ pneumoniae has the ability to enter the brain via haematogenic dissemination and that, in susceptible animals, this leads to microglial 
activation, which is seen in area's of chronic cerebral ischaemia ${ }^{4}$. However, post mortem examination of 20 human brains showed $C$ pneumoniae in only one sample of the basal ganglia and in none of the large cerebral vessels. In the four clinical studies, we found IgA antibodies against $C$ pneumoniae more often in stroke patients than in healthy controls. No differences were found in $\lg G$ antibodies and the overall prevalence of $\lg G$ antibodies was high. An even higher seroprevalence was found in the older stroke population "and in this stroke population, we could not find a relationship between $C$ pneumoniae serology, inflammatory parameters and stroke subtype. Furthermore, within our stroke population we found no correlation between inflammatory levels, $C$ pneumoniae serology and carotid IMT, which is considered an early sign of carotid atherosclerosis. A three-month course of azithromycin does not influence cytokine production of mononuclear cells incubated with $C$ pneumoniae. Taken the results of these studies into account, the role for C pneumoniae infection in clinical stroke seems not to be very important, although we cannot be $100 \%$ sure of this given the above mentioned considerations. Therefore, there might be a more aspecific effect of infections in general as opposed to a specific effect of $C$ pneumoniae. As of yet, there seems to be no rationale for a large secondary prevention trial on the effect of antibiotics against $C$ pneumoniae. The outcome of a small trial using surrogate endpoints may definitely forestall such a trial, or could surprisingly argue in its favour. The results of the ACSI trial (Azithromycin for the prevention of the progression of Cerebral ischaemic lesions in patients Surviving a noncardioembolic cerebral Infarct), are therefore eagerly awaited. 


\section{References}

1. Johnsen SP, Overvad $K$, Ostergaard $L$, Tjonneland $A_{4}$ Husted $S E_{n}$ Sorensen HT. Chlamydia pneumoniae seropositivity and risk of ischemic stroke: a nested case-control study. Eur of Epyidemiol. 2005,20;59-65:

2. Ngeh $J$ Gupta $S$, Goodbourn $C$, Panayiotou $B$, McElligott $G$. Chlamydia pneumoniae in elderly patients with stroke (C-PEPS): a case-control study on the seroprevalence of Chlamydia pneumonilae in elderly patients with acute cerebrovascular disease. Cerebrovasc Dis. $2003 ; 15: 11-6$.

3. Heuschmann $P U$, Neureiter $D$, Gesslein $M$, Craiovan $B$, Maass $M$, Faller $G$, Beck $G$, Neundoerfer B, Kolominsky Rabas PL. Association between infection with Helicobacter pylori and Chlamydia pneumoniae and risik of ischemic stroke subtypes: Results from a papulationbaised case-control study. Stroke. 2001;32:2253-8.

4. Cook PJ. Honeybourne $D$, Lip GYH. Beevers DG, Wise $R$, Davies AH. Chlamydia pneumoniae antibody titers are significantly associated with acute stroke and transient cerebral ischemia: the West Birmingham Stroke Project. Stroke. 1998;29:404-10.

5. Elkind MS, Lin IF, Grayston JT, Sacco RL. Chlamydia pneumoniae and the risk of first ischemic stroke: The Northern Manhattan Stroke Study. Stroke. 2000;31:1521-5.

6. Fagerberg $B$, Gnarpe $ل_{1}$ Gnarpe $H$, Agewall $S$, Wikstrand $J$ Chlamydia pneumoniae but not cylomegalowirus antibodies are associated with future risk of stroke and cardiovascular disease: a prospective study in middle-aged to elderly men with treated hypertension. Stroke. $1999 ; 30: 299-305$.

7. Wimmer ML, Sandmann Strupp R, Saikku P, Haberl RL. Association of chlamydial infection with cerebrovascular disease. Stroke. 1996;27:2207-10.

8. Dowell SF, Peeling RW, Boman J, Cartone GM, Fields BS, Guarner J, Hammerschlag MR, Jackson LA, Kuo CC, Maass M, Messmer TO, Talkington DF, Tondella ML. Zaki SR. Standardizing Chlamydia pneumoniae Assays: Recommendations from the Centers for Disease Control and Prevention (USA) and the Laboratory Centre for Disease Control (Canada). Clin Infect Dis. 2001;33:492-503.

9. Einarsson S, Sigurdsson HK, Magnusdottir SD, Erlendsdottir H, Briem H, Gudmundsson S. Age specific prevalence of antibodies against Chlamydia pneumoniae in lceland. Scand $J$ Infect Dis. 1994;26:393-7.

10. Maass M, Gieffers J, Krause E, Engel PM, Bartels $C_{n}$ Solbach W. Poor correlation between microimmunofluorescence serology and polymerase chain reaction for detection of vascular Chlamydia pneumoniae infection in coronary artery disease patients. Med Microbiol Immunof Bert. 1998;187:103-6.

11. Wohlschlaeger J, Wimmer ML, Nagler DK, Haberl R, Weis S. Identification of Chlamydia pneumoniae in intracranial and extracranial arteries in patients with stroke and in controls: combined immunohistochemical and polymerase chain reaction analyses. Hum Pathol. $2005 ; 36: 395-402$.

12. Vink $A$, Poppen $M$, Schoneveld $A H$, Roholl PJ, de Kleijn DP, Borst $C$, Pasterkamp $G$. Distribution of Chlamydia pneumoniae in the human arterial system and its relation to the local amount of atherosclerosis within the individual. Circulation. 2001:103:1613-7.

13. Virok D, Kis Z, Karai L, Intzedy L, Burian K, Szabo A, Ivanyi B, Gonczol E. Chlamydia pneumoniae in atherosclerotic middle cerebral artery. Stroke. 2001:32:1973-6.

14. Rassu M, Cazzavillan $S$, Scagnelli M, Peron $A$, Bevilacqua PA, Facco M, Bertoloni G, Lauro $F M$, Zambello $R$, Bonoldi $E$. Demonstration of Chlamydia pneumoniae in atherosclerotic arteries from various vascular regions. Atherosclerosis. 2001:158:73-9.

15. Cochrane $M_{i}$ Pospischil $A$, Walker $P$, Gibbs $H_{*}$ Timms $P$. Distribution of Chlamyclia pneumoniae DNA in atherosclerotic carotid arteries: significance for sampling procedures. $J$ Clin Microbiol. 2003:41:1454-7.

16. Ramirez JA. Isolation of Chlamydia pneumoniae from the coronary artery of a patient with coronary atherosclerosis. The Chlamydia pneumonilae/Atherosclerosis Study Group. Ann Intem Med. 1996;125:979-82. 
17. Maass $M$. Bartels $C$, Engel PM, Mamat U, Sievers HH. Endovascular presence of viable Chlamydia pneumoniae is a common phenomenon in coronary artery disease. $\mathrm{J}$ Am Coll Cardiol. 1998; $31: 827-32$.

18. Moazed TC, Campbell LA, Rosenfeld ME, Grayston JT, Kuo CC. Chlamydia pneumoniae infection accelerates the progression of atherosclerosis in apolipoprotein E-deficient mice. $J$ Infect Dis. 1999;180:238-41.

19. Fong IW, Chiu B, Viura $E$, Jang D, Mahony JB. De Novo induction of atherosclerosis by Chlamydia pneumoniae in a rabbit model. Infect Immun. 1999;67:6048-55.

20. Gonzales-Scarano $F$, Baltuch $G$. Microglia as mediators of inflammatory and dogenerative diseases. Annu. Rev. Neurosci. 1999:219-240.

21. Bowa $\mathrm{Y}$, Bornstein NM, Korczyn AD. Acute infection as a risk factor for ischemic stroke. Stroke. 1996;27:2204-6.

22. Ridker PM, Ciusthman M, Stampfer MJ, Tracy RP. Hennekens CH. Inflammation, aspirin, and the risk of cardiovascular disease in apparently healthy men. $N$ Engl J Med. 1997,336:973-9.

23. Ridker PM. Buring JE, Shih J, Matias M. Hennekens CH. Prospective study of C-reactive protein and the risk of future cardiovascular events among apparently healthy women. Circulation. 1998;98:731-3.

24. Ford ES, Gilles WH. Serum C-reactive protein and self-reported stroke: findings from the Third National Health and Nutrition Examination Survey. Arterioscler Thromb Vasc Biol. 2000;20:1052-6.

25. de Jong $G$, van Raak $L$, Kessels $F$, Lodder J. Stroke subtype and mortality, follow-up study in 998 patients with a first cerebral infarct. $J$ Clin Epidemiol. 2003:56:262-8.

26. Folsom AR, Pankow JS, Tracy RP, Arnett DK, Peacock JM, Hong Y, Djousse L., Eckfeldt JH. Association of C-reactive protein with markers of prevalent atherosclerotic disease. Am J Cardiol. 2001;88:112-7

27. Sitzer M. Markus HS, Mendall MA, Liehr R, Knorr U, Steinmetz H. C-reactive protein and carotid intimal medial thickness in a community population. J Cardiovasc Risk. 2002;9: 97-103.

28. Gurfinkel E. Inflammation, infection, or both in atherosclerosis: the ROXIS trial in perspective. I Infect Dis. 2000;181 Supp\| 3:S566-8.

29. Gupta S. Chlamydia pneumoniae, monocyte activation, and azithromycin in coronary heart disease. Am Heart J. 1999;138:5539-41.

30. O'Connor CM, Dunne MW, Pfeffer MA, Muhlestein JB, Yao L, Gupta S, Benner Ru, Filsher MR, Cook TD. Azithromycin for the secondary prevention of coronary heiant disease events: the WIZARD study: a randomized controlled trial. Jama. 2003:290:1459-66.

31. Grayston JT, Krommal RA, Jackson LA, Parisi AF, Muhlestein JB, Cohen JD, Rogers MJ, Crouse JR, Borrowdale $S L$, Schron $E_{*}$ Knirsch C. Azithromycin for the secondiary prevention of coronary events. N Engl J Med. 2005;352:1637-45.

32. Vainas T, Stassen FR, Schurink GW, Tordoir JH, Welten RJ. van den Akker LH, Kurvers HA, Bruggeman CA, Kitslaar PJ. Secondary prevention of atherosclerosis through chlamydia pneumoniae eradication (SPACE Trial): a randomised clinical trial in patients with peripheral arterial disease. Eur J Vasc Endovasc Surg 2005:29:403-11.

33. Gabtiel AS, Ahnve S, Gnarpe H, Gnarpe J, Martinsson A. Azithromycin therapy in patients with chronic Chlamydia pneumoniae infection and coronary heart disease: immediatte and long-term effects on inflammation, coagulation, and lipid status in a double-blind, placebocontrolled study. Eur J interm Med. 2003:14:470-8.

34. Semaan HB, Gurbel PA, Anderson JL, Muhlestein JB, Carlquist JF, Horne BD, Serebruany VL. The effect of chronic azithromycin therapy on soluble endothelium-derived adhesion molecules in patients with coronary artery disease. J Cardiowasc Pharmacol 2000;36:533-7.

35. Parchure $N$, Zouridakis $E G$, Kaski JC. Effect of Azithromycin treatment on endothelial function in patients with comonary artery disease and evidence of Chlamydia pneumoniae infection. Circulation 2002;105:1298-303.

36. Sander $D_{\|}$Winbeck $K$. Klingelhofer $J$, Etgen $T$. Canrad B. Reduced progression of early carotid atherosclerosis after antibiotic treatment and Chlamydia pneumoniae seropositivity. Circulation. 2002;106:2428-33. 
37. Sander D, Winbeck $K$, Klingelhofer $J$, Etgen $T$, Conrad $B$. Progression of early carotid atherosclerosis is only temporarily reduced after antibiotic treatment of Chlanydia pneumoniae seropositivity. Circulation. 2004:109:1010-5.

38. Anderson JL, Muhlestein JB, Carlquist J, Allen A, Trehan $S_{*}$ Nielson $C_{\text {, Hall }} \mathrm{S}_{\text {, Brady J }}$ Egger M, Home $B$; Lim T. Randomized secondary prevention trial of azithromycin in patients with coronary artery disease and serological evidence for Chlamydia pneumoniae infection: The Azithromycin in Coronary Aitery Disease: Elimination of Myocardial Infection with Chlamydia (ACADEMIC) study. Circulation. 1999;99:1540-7.

39. Kutin $A$, Roblin PM, Hammerschlag MR. Effect of prolonged treatmenit with azithromycin, clarithromycin, or levofloxacin on Chlamydia pneumoniae in a continuous-infection Model. Antimicrob Agonts Chemother: 2002;46,409-12.

40. Gieffers $J$, Fullgraf $H$, Jahn $J$, Klinger $M$, Dalhoff $K$, Katus $H A_{\text {, solbach }} W_{3}$ Maass $M$. Chlamydia pneumoniae infection in circulating human monocytes is refractory to antibiotic treatment. Circulation 2001:103:351-6.

41. Tomimoto $H$, Akiguchi 1. The role of immunologic reactions in the pathogenesis in Binswanger's disease; a clue to therapeutic approach. Rinsho Shinkeigaku. 1999*39:56-8 
Summary 
14 


\section{Summary}

Atherosclerosis is defined as an inflammatory, immune-mediated disorder: which develops following endothelial injury. Causes of endothelial injury include hypertension, smoking and elevated homocysteine. One of the factors implicated in the pathogenesis of atherosclerosis is infection, more specifically infection with $C$ pneumoniae. Extensive research has been done in the area of infections and atherosclerosis of the coronary arteries; atherosclerosis of the (pre-) cerebral vessels has received less attention in this respect. In both areas results and opinions about the role of $C$ pneumoniae in vascular events have been controversial. In this thesis we aim to answer questions on the association between $C$ pneumoniae infection and (pre-) cerebral vascular disease.

In chapter 2 we describe the presence of anti-Chlamydia antibodies in patients with an ischaemic stroke under the age of fifty. Immunoglobulin $G$ (IgG) and $\lg A$ antibodies are produced after each infection, and the presence antiChlamydia $\operatorname{lgG}$ and $\lg A$ antibodies therefore is proof of a prior infection. This study included 41 patients, with atherosclerosis as the probable cause of the stroke, and 55 healthy controls. The presence of $\lg G$ and $\lg A$ antibodies was determined in the serum of these patients. We found that $\lg A$ antibodies against $C$ pneumoniae were more prevalent in patients with ischaemic stroke than in the healthy controls (crude OR: $2.1 ; 90 \% \mathrm{Cl} 1.1-9.5, \mathrm{p}=0.04$ ). After adjusting for hypertension, smoking and hypercholesterolaemia, positive Chlamydia antibodies remained associated with stroke (adjusted OR: $2.8,90 \%$ Cl 1.1-7.1, $p=0.04$ ).

In chapter 3 we describe a mouse experiment, issued to address the question whether $C$ pneumoniae could enter the brain after an intraperitoneal injection. and whether the presence of $C$ pneumoniae caused microglial activation. Microglial cells are the immune effector cells of the brain, and they respond to infection. trauma and ischaemia. Activation of microglial cells leads to the production of potentially neurotoxic agents such as tumour necrosis factor alpha (TNF $\alpha$ ) and interleukin ( $\mid L)-1$ beta $(I L-1 \beta)$. The presence of activated microglial cells has been described in conditions such as Alzheimer's disease, and in areas of chronic cerebral ischaemia. Furthermore, we investigated whether $C$ pneumoniae infection leads to a higher permeability of the blood brain barrier, the natural protection wall of the brain against micro-organisms and toxic agents. For this purpose we used three types of mice: mice with atherosclerosis, i.e. Apolipoprotein $E$ (ApoE) knockout (KO) and ApoE/Low Density Lipoprotein receptor (ApoE/LDLr) KO mice both on a C57BL/6J background, and mice without atherosclerosis, i.e. wild type C57BL/6J mice. 
Using a highly sensitive pollymerase chain reaction, we could detect C preumoniae DNA in the brain tissue of $30 \%$ of the infected mice. The number of infected mice was the highest shortly after infection ( 3 days) and declined in the three weeks after infection. The permeability of the blood brain barrier was not altered in the infected mice. Activated microglial cells were visualized using immunahistochemistry. We found a significant increase in the number of activated microglial cells in the brains of $C$ pneumoniae $P C R$ positive ApoE/LDLr KO mice, compared to mock-infected mice. There were no differences in microglial activation between the $C$ pneumoniae infected $C$ pneumoniae PCR negative mice and to the mock-infected mice. Furthermore we observed a higher number of activated microglia in atherosclerotic mice compared to non-atherosclerotic mice. We concluded that intraperitoneal injection of $\mathrm{C}$ pheumoniae leads to cerebral infection, and in the susceptible mouse, this leads to microglial activation.

Ischaemic cerebrovascular disease can be divided in two entities. Large vessel disease, which is due to atherosclerosis of the larger cerebral vessels, causes mainly larger, usually called territorial infarcts, which often involve the cortex. Small vessel disease causes small infarcts, less than $15 \mathrm{~mm}$ in diameter on cerebral imaging, which are located in the deep brain structures (basal ganglia and internal capsule) or the pons; these are often referred to as lacunar infarcts. Small vessel disease is also the cause of more diffuse damage to the white matter of the brain: leukoaraiosis. C pneumoniae, Cytomegalovirus (CMV) and Herpes Simplex virus type 1 (HSV-1) have been linked to large vessel atherosclerosis, and have been detected in brain tissue. The role of these micro-organisms in cerebral small vessel disease however, is still unknown. In chapter 4 we describe the post-mortem presence of C pneumoniae, CMV and HSV-1 in the cerebral large vessels, small vessels and brain tissue of patients who died from various causes. In the majority of these cases, signs of large vessel disease and small vessel disease were present; in most cases this was asymptomatic. A PCR was performed on paraffin embedded tissue, to establish the presence of DNA of the above mentioned micro-organisms. Subsequently immunohistochemistry was used on adjacent paraffin slides to locate the micro-organisms within the brain tissue. Using the PCR method, we found no evidence of the presence of C pneumoniae, CMV, or HSV-1 in any of the cerebral large vessels. We found $C$ pneumoniae in the brain tissue (periventricular white matter) of one case and CMV in the brain tissue (basal ganglia) of another case. By immunohistochemistry, the presence of CMV in the PCR positive sample could not be confirmed. $C$ pneumoniae was present in ganglion cells and underneath the basal membrane of an arteriole. We concluded that, even though signs of large and small vessel disease were present in most cases, the presence of 


\section{Summary $\mid+15$}

the above mentioned micro-organisms was minimal. $C$ pneumoniae, CMV and HSV-1, therefore do not seem to play an important rolle in (asymptomatic) cerebral large vessel and small vessel disease.

The chapters 5, 6 and 7 are clinicall studies, using a patient population derived from the ACSI study (Azithromycin for the prevention of the progression of Cerebral ischaemic lesions in patients Surviving a non-cardio embolic cerebral Infarct), which investigates the effect of a three-month treatment schedule of azithromycin on ischaemic cerebral damage progression measured at two years.

In chapter 5, 149 patients are divided into two groups, patients with a cortical infarct or a single symptomatic lacunar infarct were assigned to the large vessel disease group, and patients with asymptomatic lacunar infarcts and leukoaraiosis were assigned to the small vessel disease group. C pneumoniae and inflammatory parameters such as high sensitive $\mathrm{C}$-reactive protein (hsCRP) and cytokines such as IL-6 have been linked to cerebral large vessel disease, but it is unclear whether $C$ pneumoniae infection and inflammation are related to small vessel disease, especially to the chronic, progressive type which results in silent lacunar infarcts and leukoaraiosis (silent brain lesions: $\mathrm{SBL}$ ). For this purpose, we investigated the relation between the presence of $C$ pneumoniae lgG antibodies, and inflammatory parameters (tumour necrosis factor alpha (TNF $\alpha$ ), interleukin (IL) $6, I L-1 \beta, I L-10$ and IFN $\gamma$ ) and the presence of SBL on magnetic resonance imaging of the brain. Inflammatory markers did not differ between patients with and without silent brain lesions, nor did the presence of $C$ pneumoniae antibodies. Furthermore, inflammatory markers were not different in patients with and without $C$ pneumoniae antibodies. Therefore, we concluded that $C$ preumoniae infection is not related to cerebral small vessel disease.

Common carotid intima-media thickness (CCA-IMT) can be assessed noninvasively by B-mode ultrasonography. Increases in IMT are associated with an increased risk of myocardial infarction and stroke, but this has onlly been investigated in large population based studies in healthy individuals. The same thing is true for the relation between $C$ pneumoniae infection and inflammatory markers and CCA-IMT. It is unknown whether CCA-IMT is a predictive factor in a selected population of stroke patients, and how CCA-IMT is related to stroke subtype. In chapter 6, we sought to find out whether CCA-IMT is related to stroke subtype, and the presence of ipsilateral SBL on MRI. Furthermore, we investigated the relation between serum inflammatory parameters, $C$ pneumoniae serology, and CCA-IMT. In our patient population ( $N=75)$, there were no differences in mean CCA-IMT with regard to the presence of ipsilateral 
SBL. Furthermore, we found that, in a selected population of stroke patients, CCA-IMT was not related to $C$ pneumoniae serology and inflammatory parameters. We concluded that CCA-IMT values are not different in the different stroke subtypes and are not related to the presence of SBL, in a population of patients with a symptomatic stroke. Furthermore, CCA-IMT is not related to $C$ pneumoniae serology, or inflammatory parameters.

In chapter 7, we investigated whether treatment with azithromycin, an antimicrobial and anti-inflammatory agent, reduced $C$ pneumoniae induced cytokine production by blood mononuclear cells. For this purpose levels of the cytokines TNF $\alpha, \mathrm{IL}-6, \mathrm{IL}-1 \beta, \mathrm{IL}-10$ and IFN $\gamma$ were assessed in mononuclear cells. These cells were stimulated with $C$ pneumoniae antigen, and subsequently, cytokine levels were assessed in the supernatant. The cytokine levels of 75 patients, which had been randomised in the ACSI trial, were assessed, before and after treatment. The patients were randomised to receive either azithromycin $500 \mathrm{mg}$ or a matching placebo once daily for 3 days, then once weekly for twelve weeks. Blood was drawn at randomisation and at three months, after finishing the course of study medication. After three months of treatment, there were no significant differences in cytokine levels in the supernatant of $C$ pneumoniae stimulated cells between the two treatment groups. Furthermore, when we measured the changes in the cytokine levels before and after treatment, we found no significant differences in changes in the cytokine levels, between the two patient groups. We concluded that azithromycin does not influence $C$ pneumoniae induced cytokine production of mononuclear cells.

In this thesis the relation between $C$ pneumoniae infection and ischaemic stroke is addressed form different directions. The animal experiment showed that $C$ pneumoniae can infect the brain through haematogenic spread and, that cerebral infection with $C$ pneumoniae causes microglial activation in susceptible animals. Furthermore, we found anti-Chlamydia IgA antibodies more often in young patients with ischaemic stroke than in controls. In spite of the above mentioned results, we conclude that there is no significant role for $C$ pneumoniae infection in ischaemic stroke. The presence of $C$ pneumoniae in cerebral vessels and brain tissue is scarce, and in several clinical studies we found no relation between $C$ pneumoniae infection and $S B L$, nor was $C$ pneumoniae infection or inflammation related to CCA-IMT. Furthermore, there was no effect of azithromycin on $C$ pneumoniae induced cytokine production of mononuclear cells. 
Samenvatting 


\section{Samenvatting}

Atherosclerose is een chronisch progressief inflammatoir proces, waarbij algemeen aangenomen wordt dat endotheelschade aan de basis van dit proces ligt. Verschillende oorzaken voor deze endotheelschade zijn al bekend, zoals hypertensie, roken en een verhoogd homocysteine gehalte. Infecties, vooral infecties met $C$ pneumoniae, worden ook genoemd als mogelijke bijdragers aan het proces van atherosclerose. In het verleden is uitgebreid onderzoek verricht naar de relatie tussen $C$ pheumoniae infectie en atherosclerose van de coronair vaten; de cerebropetale vaten zijn hierin onderbelicht gebleven. De resultaten van studies op dit terrein die werden beschreven door diverse onderzoekers waren zeer tegenstrijdig; sommigen vonden een duidelijke relatie tussen $C$ pneumoniae infectie en atherosclerose, anderen vonden deze relatie juist niet. Dit proefschrift probeert de vraag of er een relatie is tussen $C$ pneumoniae infectie en cerebrovasculaire ischemie te beantwoorden.

In hoofdstuk 2 beschrijven we de relatie tussen de aanwezigheid van imuunglobuline $(\mathrm{lg}) \mathrm{G}$ en $\mathrm{IgA}$ antilichamen tegen $\mathrm{C}$ pheumoniae in patiënten met een herseninfarct op jonge leeftijd, in vergeliiking met gezonde controles. IgG en IgA antilichamen worden geproduceerd na iedere infectie en de aanwezigheid van anti-Chlamydia $\lg G$ en IgA antilichamen wijst derhalve op een doorgemaakte $C$ pneumoniae infectie. In deze studie werden 41 patiënten geincludeerd die jonger waren dan 50 jaar en een herseninfarct hadden doorgemaakt, waarvan de meest waarschijnlijke oorzaak atherosclerose was. De aanwezigheid van $\lg G$ en $\lg A$ antistoffen werden bepaald in het serum van deze patiënten en dit werd vergeleken met het serum van 55 gezonde controles. We vonden dat igA antistoffen tegen $C$ pneumoniae vaker in de patiëntengroep voorkwamen dan in de controle groep (OR 2.1; 90\% $\mathrm{Cl} 1.1-9.5$, $p=0.04)$. Ook na corrigeren voor factoren als hypertensie, roken, hypercholesterolemie en diabetes mellitus, was er nog een significante relatie tussen de aanwezigheid van $\lg A$ antistoffen tegen $C$ pneumoniae en een herseninfarct op jonge leeftijd (gecorrigeerde OR: $2.8,90 \%$ Cl 1.1-7.1, $p=0.04$ ).

In hoofdstuk 3 wordt een muisexperiment beschreven. In dit experiment werd onderzocht of $C$ pneumoniae de hersenen kan infecteren na intraperitoneale toediening en of deze infectie leidt tot een reactie, namelijk tot activatie van microglia cellen. Microgllia cellen zijn de immuuncellen van de hersenen en deze cellen reageren op infectie, trauma of ischemie van de hersenen. De activatie van microglia cellen leidt tot de productie van verschillende cytokines

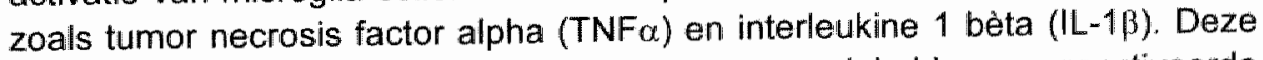
stoffen zijn potentieel, neurotoxisch. De aanwezigheid van geactiveerde 
microglia cellen is reeds beschreven bij de ziekte van Alzheimer en in gebieden van de hersenen die zijn blootgesteld aan chronische ischemie. Daarnaast werd gekeken of $C$ pneumoniae infectie werd veroorzaakt door, of leidde tot een verhoogde doorlaatbaarheid van de bloed-hersen barrière. De bloedhersen barrière is de natuurlijke beschermer van de hersenen tegen schadelijke stoffen in de circulatie. Een verhoogde doorlaatbaarheid van deze bloed-hersen barrière kan ertoe leiden dat de hersenen worden bloot gesteld aan deze schadelijke stoffen. Om deze vragen te beantwoorden werden drie typen muizen geïnfecteerd, namelijk muizen met atherosclerose: de Apolipoproteine $E$ (ApoE) knockout (KO) en ApoE/Low Density Lipoprotein receptor (ApoE/LDLr) KO muizen en controle muizen, de C57BL/6J muizen. Met een zeer gevoelige polymerase ketting reactie test werd het DNA van $C$ pneumoniae gevonden in $30 \%$ van de geïnfecteerde muizen. Het aantal geïnfecteerde muizen was het hoogst drie dagen na de intraperitoneale injectie. Uit het onderzoek bleek ook dat de bloed-hersen barrière niet was aangetast na infectie. De activatie van microglia cellen werd in beeld gebracht door een immunohistochemische kleuring. Hierbij vonden we in de hersenen van de geïnfecteerde ApoE $/ L D L r$ KO muizen significant meer geactiveerde microglia cellen dan in de niet geïnfecteerde ApoE/LDLr KO muizen. Daarnaast bleken de ApoE/LDLr KO muizen meer geactiveerde microglia cellen te hebben dan de $C 57 \mathrm{BL} / 6 \mathrm{~J}$ muizen. We concludeerden dat intraperitoneale injectie van $C$ pneumoniae leidt tot een cerebrale infectie, die in de muizen met atherosclerose leidde tot een verhoogd aantal geactiveerde microglia cellen.

Het herseninfarct kan worden ingedeeld in twee groepen: large vessel disease en small vessel disease. Large vessel disease staat voor de atherosclerose van de grotere hersenvaten; waardoor de grotere zogenaamde corticale herseninfarcten worden veroorzaakt. Small vessel disease staat voor vaatwandveranderingen in de kleinere hersenvaten, het type infarct wat hierbij wordt gezien is de zogenaamde lacunaire infarct. Lacunaire infarcten zijn niet groter dan $15 \mathrm{~mm}$ in doorsnede en worden vooral gezien in de diepere hersenstructuren zoals de capsula interna en de basale ganglia. Daarnaast wordt small vessel disease geassocieerd met chronische progressieve afwijkingen zoals stille lacunaire infarcten en leukoaraiosis ("silent brain lesions" = SBL). C pneumoniae, Cytomegalovirus (CMV) en Herpes Simplex virus type 1 (HSV-1), zijn allen in verband gebracht met atherosclerose en zijn allen eerder aangetoond in hersenweefsel. Echter, de rol van deze microorganismen in de vaatwandveranderingen van de kleine hersenvaten is nog nooit eerder beschreven. In hoofdstuk 4 beschrijven we de onderzoek naar aanwezigheid van C pneumoniae, CMV en HSV-1 in de grote hersenarteriën, 
de kleine hersenvaten en hersenweefsel, dat is verkregen bij obductie van mensen die waren overleden aan diverse oorzaken.

De polymerase ketting reactie werd hier uitgevoerd op weefsel wat gefixeerd was in formaline en daarna ingebed in paraffine. Daarnaast werd op weefsel waar een van de micro-organismen werd gevonden een immunohistochemische kleuring toegepast om de locatie van het micro-organisme aan te tonen. Met de polymerase ketting reactie werd in slechts twee casus. DNA gevonden van $C$ pheumoniae (in de periventriculaire witte stof) en CMV (in de basale kernen) Geen van de microworganismen werd aangetoond in de grote hersenarteriën, hoewel in bijna alle hersenarteriën tekenen van atherosclerose werden gezien. Met immunohistochemie konden alleen $\mathrm{C}$ pneumoniae antigenen worden aangetoond; deze bevonden zich in de ganglion cellen van de hersenen en onder de basale membraan van een hersenarteriole. Hieruit concludeerden we dat ondanks dat er in het merendeel van de weefsels aanwijzingen werden gevonden voor atherosclerose, arteriolosclerose en ischemische hersenschade, de aanwezigheid van de bovengenoemde microorganismen minimaal was. Deze micro-organismen lijken dus geen rol te spelen in asymptomatische ischemische hersenschade en vaatwandveranderingen.

In hoofdstuk 5 werden 149 patiënten verdeeld in twee groepen: patiënten met corticale infarcten en éen enkel symptomatisch lacunair infarct werden ingedeeld in de groep large vessel disease en patiënten met stille lacunaire infarcten en leukoaraiosis werden ingedeeld in de small vessel disease groep. $C$ pneumoniae antistoftiters en inflammatoire parameters zoals high sensitive C-reactief proteinne (hsCRP) en cytokines als IL-6, worden in het algemeen geassocieerd met atherosclerose van de grote cerebrale vaten. Het is onduidelijk of $C$ pneumoniae infectie en inflammatie ook een rol spelen in het ontstaan van small vessel disease en de of C pneumoniae infectie gerelateerd is aan de aanwezigheid van asymptomatische ischemische laesies zoals stille lacunaire infarcten en leukoarariosis (SBL). Hiertoe onderzochten we de relatie tussen de aanwezigheid van $C$ pneumoniae $\lg G$ antilichamen en inflammatoire parameters in het serum (hsCRP, IL-6, TNF $\alpha, I L-1 \beta, I L-10$, en $\mathbb{F} F N_{\gamma}$ ) en de aanwezigheid van SBL op de magnetische resonantie scan (MRI) van de hersenen. Het resultaat van dit onderzoek was dat er geen verschil gevonden werd in inflammatoire parameters tussen de groep patiënten met en zonder $\mathrm{SBL}$, ook de aanwezigheid van $C$ pneumoniae IgG antilichamen verschilde niet tussen beide patientengroepen. $C$ pneumoniae infectie is dus niet gerelateerd aan cerebrale small vessel disease.

Het meten van de intima-media dikte van de arteria carotis communis (CCA(MT) is een veilig en non-invasief onderzoek. Het is alom bekend dat de dikte 
van de CCA-IMT gerelateerd is aan het risico op het krijgen van een vasculair event. Dit is echter alleen beschreven in grote studies in gezonde patiënten populaties. Hetzelfde geldt voor de relatie tussen inflammatoire parameters en de dikte van de CCA-IMT. Het is niet bekend of de CCA-IMT in een selecteerde patiëntenpopulatie ook een voorspellende factor is. Tevens zijn data over de relatie tussen CCA-IMT en de verschillende subtypen van het herseninfarct spaarzaam. Zoals beschreven is in hoofdstuk 6 onderzochten we of de CCA-IMT gerelateerd is aan de aanwezigheid van ipsilaterale SBL. Dit werd vervolgens gerelateerd aan de aanwezigheid van $C$ pneumoniae $\| g G$ antistoffen en inflammatoire parameters in het bloed. In onze patiëntenpopulatie $(N=75)$ vonden we geen verschillen in de gemiddelde CCA-IMT waarden in de aan- en afwezigheid van ipsilaterale SBL. Verder vonden we in een populatie die exclusief bestond uit patiënten met een herseninfarct geen relatie tussen de dikte van de CCA-IMT, inflammatoire parameters en C pneumoniae serologie.

In hoofdstuk 7 beschrijven we het effect van een drie maanden durende antibiotica kuur met azithromycine op de cytokine productie van mononucleaire cellen in het bloed. In dit experiment werden de mononucleaire cellen gestimuleerd met $C$ pneumoniae antigeen, waarna de productie van de cytokines TNF $\alpha, I L-1 \beta, I L-6, I L-10$ en IFN $\gamma$ werd gemeten in het supernatant. Van 75 patiënten die deelnamen aan het ACSI onderzoek werd bloed afgenomen voor en na de azithromycine inname. De patiënten waren bij loting in twee groepen verdeeld en kregen azithromycine of een placebo: $500 \mathrm{mg}$ per dag gedurende de eerste drie dagen, en $500 \mathrm{mg}$ per week voor een periode van twaalf weken. Na drie maanden was er geen verschil in de bloedspiegel

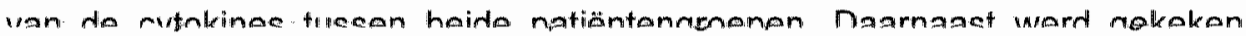
naar het verschil in bloedspiegels van de cytokines voor en na de behandeling. ook hiler werd geen verschil gevonden. Uit dit onderzoek kan worden geconcludeerd dat azithromycine heeft geen effect op de cytokine productie van mononucleaire cellen die worden gestimuleerd met $C$ pneumoniae antigeen.

In dit proefschrift werd op verschillende manieren gekeken naar een eventuele relatie tussen een infectie met $C$ pneumoniae en herseninfarcten. Het diermodel liet zien dat $C$ pneumoniae het brein kan infecteren en microglia activatie veroorzaakt, zoals ook wordt gezien bij chronische ischemie van de hersenen. Jonge patiënten met een herseninfarct hadden vaker anti-Chlamydia IgA antistoffen dan gezonde controles. Ondanks bovengenoemde resultaten lijkt er geen (grote) rol weggelegd voor $C$ pneumoniae infectie in het ontstaan van cerebrale ischemie. De aanwezigheid van $C$ pneumoniae in de hersenvaten en hersenweefsel bleek zeer minimaal te zijn en in de klinische 
studies werd geen relatie gevonden tussen $C$ pneumoniae serologie en de aanwezigheid van SBL op MRI en de dikte van de CCA-IMT. Daarnaast werd geen effect gevonden van behandeling met azithromycine op de cytokine productie van mononucleaire cellen. 
Dankwoord 
126 


\section{Dankwoord}

Hoewel het schrijven van een proefschrift met name in het laatste stadium vaak een eenzame ervaring is van het doorwerken tot in de kleine uurtjes van de nacht, kan niemand een dergelijk project alleen doen en dat geldt zeker ook voor mij. Dit proefschrift was er niet gekomen als ik niet de hulp had gehad van een aantal mensen, die ik dan ook will bedanken:

Mijn beide promotoren: Prof. dr. C. A. Bruggeman en Prof. dr. M. Limburg. Cathrien, door onderzoek te doen op de Medische Microbiologie heb ik mijn kennis kunnen verrijken, zowel op wetenschappelijk gebied als op het gebied van de microbiologie. Daar ben ik je erg dankbaar voor. Verder wil ik je bedanken voor de je begeleiding de afgelopen jaren en je snelle beoordeling van de manuscripten, waardoor het toch nog lukt om in 2005 te promoveren.

Martien, als neuroloog in opleiding die wetenschappelijk onderzoek doet, is voor mij de brug tussen wetenschap en kliniek belangrijk. Door het maken van CAT's en PICO's is voor mij deze brug ontstaan en heb ik kritisch leren kijken naar alledaagse problemen in de kliniek. Daarvoor wil ik je dan ook bedanken.

Mijn beide copromotoren: Dr. A. J. A. M. van der Ven en Dr. J. Lodder.

Beste André, vooral in het begin van het onderzoek was jij de drijvende kracht. Jouw onuitputtelijke ideeën werden soms in de kop gedrukt, maar hebben er toch toe geleidt dat het antwoord op de vraag in dit proefschrift van verschillende kanten wordt belicht. Zonder jou zou dit proefschrift minder compleet zijn geweest dan dat het nu is, waarvoor mijn dank.

Beste Jan, voor milj was je de drijvende kracht in de laatste fase. De combinatie van wetenschappelijke kennis en gedrevenheid heeft er al toe geleidt dat velen onder jouw begeleiding gepromoveerd zijn en nu kan ik ook worden toegevoegd aan deze lijst. Dit proefschrift was er waarschijnlijk niet (nu) gekomen als jij me niet de spreekwoordelijke stok achter de deur had gegeven die ik zo nodig had om dit project af te ronden. Je bent een ware copromotor!

Ir. F. Kessels. Beste Fons, je bent er weer in geslaagd om een statistische "nitwit" de basis beginselen van de statistiek bij te brengen. Bedankt dat je altijd tijd voor me vrij wilde maken (ook als dat eigenlijk niet kon.)

Prof. dr. Jaap Troost. Zonder opleiding neurologie was dit boekje er nooit gekomen, bedankt dat u me deze kans hebt willen geven.

Gert, jiij hebt de gave om mensen die een laboratorium inkomen met twee linkerhanden (of in mijn geval met twee rechterhanden) om te toveren in ware lab professionals. In de drie jaar dat ik op het lab was heb ik ontzettend veel 
van je geleerd en heb ik genoten van je vriendschap. Ik hoop dat we in de toekomst beide in goede gezondheid deze vriendschap kunnen voortzetten.

Sabine en Selma, als doorwinterde analisten hebben jullie beide mij bijgestaan in het doen van mijn experimenten, waarvoor mijn hartelijke dank.

De afdeling Medische Microbiologie is rijkelijk voorzien van aio's en andere onderzoekers die allen op hun eigen manier hun bijdrage hebben geleverd aan de totstandkoming van dit boekje. Daarom glaat mijn dank uit naar Frank, Geoffrey, Rick, Jeroen, Joanne, Ellen, Martijn, Patrick, Yvonne, Suzanne, Koen, Sita, Maartje en Tanja.

Inge, Rajaa en Tryfon, niet alleen de dagen op het lab hebben een onvergetelijke indruk achtergelaten, maar ook het wandelen in New York en New Orleans en het zwemmen in de middellandse zee. Ik hoop nog lang van jullie vriendschap te kunnen genieten.

De neurologen en arts-assistenten neurologie wil ik allen graag bedanken voor hun steun, en vriendschap de afgelopen jaren. Mijn speciale dank gaat uit naar Anita, Annemarie en Marjanke, die met name in de laatste fase een grote steun zijn geweest, soms alleen door er te zijn, maar vaak door mijn aandacht even af te leiden en er voor te zorgen dat $i k$ vol energie weer verder kon. Ik hoop straks hetzelfde terug te kunnen doen.

Tiny, door de lay-out voor mij te doen heb je me ongetwijfeld gered van talloze avonden vol frustratie. Het resultaat is mooier geworden dan ik ooit zelf had kunnen doen! (en Elske: bedankt voor de tip!)

De mensen van de afdeling KNF bedank ilk niet alleen voor het verrichten van de intima-media dikte metingen van mijn onderzoekspatiënten. Het jaar dat ik met jullie heb mogen samenwerken is een onvergetelijke ervaring gebleken, ik kom graag nog eens terug.

Voor hun bijdrage aan enkele hoofdstukken in mijn proefschrift gaat mijn dank uit naar Dr. Bela Kubat, Prof. dr. Harry Steinbusch, Dr. Monique Mulder en Prof. dr. Marja van Dieijen-Visser.

De medewerkers van de MRI van de afdeling radiologie, bedankt voor het verrichten van de MRl's voor mijn onderzoekspatiënten. Mijn speciale dank gaat uit naar Henk Schoenmakers, die er voor heeft gezorgd dat alle MRI's beschilkbaar waren voor beoordeling. 
Alle patiënten dank voor hun medewerking.

Mijn beide paranimfen Marcel (Job) Roelofs en Nicole Dekeling.

Job, als echtgenoot van mijn zus werd jij toegevoegd aan onze familie. Voor mij ben je niell alleen mijn zwager, maar ook een vriend. Al lang geleden heb ik je gevraagd om mijn paranimf te zijn en eindelijk is het nu zover! Bedankt dat je straks naast me staat.

Nicole, onze vriendschap begon toen ik als extra inwoner werd toegevoegd aan de flat in de Bijlmer in Amsterdam. Na jarenlang ontbijt met de volkskrant op zondagmorgen en het kijken naar Ajax op zondagavond (en soms op andere dagen), gingen we leder onze eigen weg, maar gelukkig bleef de vriendschap bestaan. Bedankt dat je straks naast me staat.

Mijn familie.

Monica, voor jou geldt hetzelfde als voor Job, je bent niet alleen mijn zus maar ook een vriendin. Als goede zussen en vriendinnen zijn we het niet altijd met elkaar eens, maar ik weet dat ik altijd op je kan rekenen en dat is voldoende. En bedankt dat ik altijd als ik bij jou en Job ben weer kan genieten van "mijn mannetjes", Bram en Pim.

Tot slot mijn ouders. Lieve mam en pap, zonder jullie eindeloze steun en liefde was ik nooit zover gekomen. Juillie zijn nog steeds mijn grote voorbeeld. Dit boekje is voor jullie. 
Curriculum vitae 


\section{Curriculum vitae}

Johanna Maria Voorend (roepnaam Manuela) werd geboren op 12 september 1971 te Breukelen. In 1989 deed ze eindexamen WWO aan de RSG Broklede te Breukelen, waarna ze geneeskunde ging studeren aan de Universiteit van Amsterdam. In 1996 behaalde ze het artsendiploma en werkte vervolgens een jaar als AGNIO neurochirurgie in het Slotervaart ziekenhuis in Amsterdam. Na twee jaar AGNIO neurologie werd in 2000 gestart met een AGIKO constructie neurologie, waarin werd gestart met het onderzoek naar de relatie tussen Chlamydia pneumoniae en herseninfarcten, waarvan dit proefschrift het resultaat is. In februari 2003 startte zij met de opleiding tot neuroloog, die ze in augustus 2008 hoopt af te ronden. 